\title{
Die Funktion des Wnt Antagonisten XsFRP5 während der frühembryonalen Musterbildung des Entoderms in Xenopus laevis
}

\author{
Dissertation \\ zur Erlangung des Doktorgrades \\ der Mathematisch-Naturwissenschaftlichen Fakultäten \\ der Georg-August-Universität zu Göttingen \\ vorgelegt von \\ Katharina Damianitsch \\ aus Wien, Österreich
}

Göttingen 2008 
Referent: Prof. Tomas Pieler

Korreferent: Prof. Ernst Wimmer

Tag der mündlichen Prüfung: 
Meiner Familie 


\section{Inhaltsverzeichnis}

Inhaltsverzeichnis

Abbildungsverzeichnis

VIII

Tabellenverzeichnis

$x$

Abkürzungsverzeichnis

XI

\section{Einleitung}

1.1 Die Entwicklung des Gastrointestinaltrakts in Xenopus laevis

1.1.1 Entoderm-Entwicklung in Xenopus Embryonen

1.1.2 Leberentwicklung

1.1.3 Pankreasentwicklung

\subsection{Wnt Signaltransduktion}

1.2.1 Der kanonische Zweig der Wnt Signaltransduktion

1.2.2 Der nicht-kanonische Zweig der Wnt Signaltransduktion

1.2.3 Möglichkeit einer Synergie zwischen $\Delta$ Np63 $\alpha$ und kanonischer Wnt Signaltransduktion

1.2.4 Extrazelluläre Antagonisten der Wnt Signaltransduktion

1.2.4.1 Die Dickkopf Klasse

1.2.4.2 Die sFRP Klasse

1.2.4.3 sFRP5 Orthologe

1.3 Die Rolle der Wnt Signaltransduktion bei der entodermalen Musterbildung in Vertebraten

1.3.1 Dorso-ventrale Achsenspezifikation in Xenopus Embryonen 
1.3.2 Die Bedeutung der Wnt Signaltransduktion bei der Differenzierung des Gastrointestinaltrakts

1.4 Zielsetzung der Arbeit

2 Material

\subsection{Organismen}

2.1.1 Xenopus laevis

\subsubsection{Escherichia coli}

2.2 Chemikalien

2.3 Gebrauchswaren und Geräte

2.4 Computer-Software

2.5 Enzyme

2.6 Molekulargewichtsstandards

2.6.1 DNA Marker

2.6.2 Protein Marker

2.7 Reaktionssysteme (Kits)

\subsection{Vektoren und Konstrukte}

2.8.1 pGEM-T und Derivate

2.8.2 pCS2+ und Derivate

2.8.3 Überexpressionskonstrukte und Konstrukte für whole-mount in situ Hybridisierungssonden 
2.8.3.1 Konstrukte, die im Rahmen dieser Arbeit erhalten oder generiert wurden

2.8.3.2 Konstrukte zur Herstellung von CapRNA oder markierter „antisense" Sonden aus dem Laborbestand

\subsection{Oligonukleotide}

2.9.1 RT-PCR Oligonukleotide

2.9.2 Sequenzierungsoligonukleotide

2.9.3 Morpholino Oligonukleotide

2.10 Antikörper

2.10.1 Primäre Antikörper

2.10.2 Sekundäre Antikörper

2.11 Medien und Stammlösungen

3.1 Arbeiten mit Bakterien

3.1.1 Anzuchtbedingungen 36

3.1.2 Herstellung chemisch-kompetenter E. coli Zellen 36

3.1.3 Chemische Transformation von Bakterienzellen 36

3.1.4 Anlegen von Glyzerol-Stammkulturen 36

$\begin{array}{lll}3.2 & \text { Arbeiten mit DNA } & 37\end{array}$

3.2.1 Präparation von Plasmid-DNA im analytischen und präparativen Maßstab 
$\begin{array}{lll}\text { 3.2.1.3 Midi-Präparation } & 37\end{array}$

3.2.1.4 Konzentrationsbestimmung von Nukleinsäuren 38

3.2.2 Nicht-denaturierende Agarose-Gelelektrophorese 38

3.2.3 Isolierung von DNA-Fragmenten aus Agarosegelen 38

3.2.4 Aufreinigung von PCR Fragmenten und Restriktionsansätzen 38

3.2.5 Restriktionsendonukleolytische Spaltung von DNA 39

3.2.5.1 Spaltung von PCR-Termini 39

3.2.5.2 Spaltung von Vektoren und Plasmiden 39

3.2.5.3 Linearisierung von „sense“ und „antisense“ Matrizen für die RNASynthese

3.2.6 Dephosphorylierung von DNA-Fragmenten 39

$\begin{array}{lll}\text { 3.2.7 } & \text { Oligomerisierung kurzer DNA-Fragmente } & 39\end{array}$

$\begin{array}{ll}\text { 3.2.8 Ligation von DNA-Fragmenten } & 40\end{array}$

3.2.9 Polymerasekettenreaktion (PCR) 41

3.2.9.1 Analytischer Maßstab 41

$\begin{array}{ll}\text { 3.2.9.2 Präparativer Maßstab } & 41\end{array}$

3.2.10 Sequenzierung 41

$\begin{array}{lll}3.3 & \text { Arbeiten mit RNA } & 41\end{array}$

3.3.1 in vitro Synthese von RNA $\quad 41$

3.3.1.1 in vitro Transkription von Monomethylguanosin-Cap-RNA zur Mikroinjektion in Xenopus Embryonen 41

3.3.1.2 in vitro Transkription Digoxigenin-markierter RNA-Sonden 42

3.3.2 Aufreinigung von RNA $\quad 42$

3.3.3 Whole-mount in situ Hybridisierung 42 
3.3.3.3 Whole-mount in situ Hybridisierung

3.3.3.4 Reduktion der Hintergrundfärbung sowie Bleichung pigmentierter Embryonen und Explantate

3.3.3.5 Vibratomschnitte

3.3.4 Präparation von DNA-freier Gesamt-RNA

3.3.4.1 aus verschiedenen Embryonalstadien

3.3.4.2 aus adulten Geweben und Organen

3.3.4.3 aus animalen Kappen-Explantaten

3.3.5 Semiquantitative Reverse Transkriptase Polymerase-Kettenreaktion (RT-PCR)

3.4.1 in vitro Transkription und Translation („,TnT“)

3.4.2 Ko-Immunopräzipitation

3.4.3 Western Blot

3.5 Manipulierung von Xenopus Embryonen

3.5.1 Stimulation der Eiablage

3.5.2 Präparation von Xenopus Testes

3.5.3 Mikroinjektion

3.5.3.1 Achsenduplikations-Assay 
3.5.6 Behandlung der Embryonen oder animalen Kappenexplantate mit Chemikalien

3.5.6.1 Retinsäure und Retinsäure-Antagonist BMS453-Behandlung

4.1 Biochemische und funktionale Charakterisierung des sekretierten Wnt Antagonisten Xenopus sFRP5

4.1.1 XsFRP5 zeigt während der Embryonalentwicklung ein sehr dynamisches Expressionsmuster

4.1.2 Biochemische Interaktionsstudien von XsFRP5 mit verschiedenen Xenopus Wnt Proteinen

4.1.2.1 Ko-Injektion von XsFRP5 inhibiert die Wnt-vermittelte dorsale Achsenduplikation

4.1.2.2 Ko-Immunopräzipitation von XsFRP5 und unterschiedlicher Xwnt Proteine

4.1.2.3 Überexpression von XsFRP5 in ganzen Embryonen führt zu Defekten der anterior-posterioren Körperachse

4.1.3 Funktionelle Charakterisierung von XsFRP5 während der Organogenese

4.1.3.1 Der Funktionsverlust von XsFRP5 nach Injektion von „antisense“ Morpholino Oligonukleotiden führt $\mathrm{zu}$ einer Reduktion der ventralen Pankreasanlage und $z u$ einer Vergrößerung des Magens

4.1.3.2 Die intrazelluläre Stimulation kanonischer Wnt Signaltransduktion bewirkt eine Reduktion der ventralen und einen Verlust der dorsalen Pankreasanlage

4.1.3.3 Expressionsanalyse von XsFRP5 und verschiedenen Xwnt Proteinen

4.1.4 Überexpression von XsFRP5 und VegT in animalen Kappenexplantaten induziert pankreatische Genexpression 
4.1.4.1 Die XsFRP5-vermittelte pankreatische Genexpression in VegTinjizierten Kappenexplantaten ist Retinsäure-abhängig

4.1.4.2 Die Überexpression von XsFRP2 und VegT führt nicht zur Induktion pankreatischer Markergen-Expression in animalen Kappenexplantaten

4.1.4.3 Analyse der Expression verschiedener Xwnts in VegT-injizierten Kappenexplantaten

4.2 Analyse des Synergieeffektes von $\Delta \mathrm{Np} 63 \alpha$ auf die Lef1vermittelte Wnt Signaltransduktion

5 Diskussion

5.1 Identifizierung von Wnt Bindungspartnern für XsFRP5

5.2 Funktionale Charakterisierung von XsFRP5 in der entodermalen Organogenese

5.3 Verknüpfung von Wnt Signalen mit anderen Signalwegen

6 Zusammenfassung

Danksagung 


\section{Abbildungsverzeichnis}

Abb. 1.1 Schematische Darstellung der Entwicklung entodermaler Organe in Xenopus laevis.

Abb. 1.2 Entwicklung und temporäres Genexpressionsprofil des Pankreas in Xenopus Embryonen (Pieler und Chen, 2006).

Abb. 1.3 Schematische Darstellung der kanonischen Wnt Signaltransduktion (Fuerer et al., 2008).

Abb. 1.4 Schematische Darstellung der beiden primären nicht-kanonischen Wnt Signalwege [modifiziert nach (Semenov et al., 2007)].

Abb. 1.5 Schematische Darstellung der funktionalen Domänen von p53 und p63 Proteinen (Barbieri und Pietenpol, 2006).

Abb. 1.6 Schematische Darstellung der Funktionsweise von Dkk Proteinen [modifiziert nach (Kawano und Kypta, 2003)]

Abb. 1.7 Vergleich der Domänenstruktur von sFRP und Frizzled-Rezeptor Proteinen.

Abb. 1.8 Schematische Darstellung der Funktionsweise von „secreted Frizzled-related“ Proteinen [modifiziert nach (Kawano und Kypta, 2003)].

Abb. 1.9 Schematische Darstellung der dorso-ventralen Achseninduktion in Xenopus laevis (Tao et al., 2005).

Abb. 4.1 XsFRP5 zeigt ein ausgeprägt dynamisches Expressionsverhalten in Xenopus Embryonen.

Abb. 4.2 Die Expression von XsFRP5 beginnt während der Gastrulation und bleibt in späten Embryonalstadien wie auch in vielen adulten Geweben erhalten.

Abb. 4.3 XsFRP5 ist in der Lage, Xwnt-vermittelte dorsale Achsenduplikation zu unterdrücken.

Abb. 4.4 XsFRP5 ko-präzipitiert mit allen untersuchten Xwnt Proteinen, zeigt jedoch eine unterschiedliche Präferenz einzelner Proteinbanden. 
Abb. 4.5 Frühe Überexpression von XsFRP5 verlangsamt die Gastrulationsbewegungen und induziert Defekte in der konvergenten Extension.

Abb. 4.6 Verschiedene „antisense“ Morpholino Oligonukleotide wurden komplementär zu XsFRP5 und seinem Pseudoallel gewählt.

Abb. 4.7 Mehrere „antisense“ Morpholino-Oligonukleotide komplementär zur XsFRP5 kodierenden Regione (CDS) können die Translation effizient unterdrücken.

Abb. 4.8 Der Funktionsverlust von XsFRP5 im Entoderm führt zu einer Reduktion der ventralen Pankreasanlage sowie zu einer Vergrößerung des Magens unter Verlust duodenaler Stukturen.

Abb. 4.9 Domänenstruktur verschiedener Lef1- bzw. $\beta$-Catenin basierter Hormon-induzierbarer Fusionskonstrukte.

Abb. 4.10 Bei Injektion in frühe Teilungsstadien induzieren konstitutiv aktiv wirkende Konstrukte nach Dexamethason-Behandlung dorsale Achsenduplikation, während dominant-negative Konstrukte zu einer Ventralisierung der Embryonen führen.

Abb. 4.11 Die Aktivierung von Lef1-GR zu unterschiedlichen Zeitpunkten der Entwicklung resultiert in einem Verlust der dorsalen und einer Reduktion der ventralen Pankreasanlage [entnommen aus (Melchert, Diplomarbeit 2007)].

Abb. 4.12 Mehrere Xwnts zeigen komplementäre oder überlappende Expressionsmuster zu XsFRP5 im Stadium 35.

Abb. 4.13 Mehrere Xwnts zeigen komplementäre oder überlappende Expressionsmuster zu XsFRP5 in gastrointestinalen Explantaten des Stadiums 40.

Abb. 4.14 Die Überexpression von XsFRP5 in VegT-injizierten animalen Kappenexplantaten induziert die robuste Expression pankreatischer Markergene.

Abb. 4.15 Durch Behandlung der Kappenexplantate mit dem RetinsäureAntagonisten BMS453 wird die XsFRP5-vermittelte Induktion pankreatischer Markergene unterdrückt. 
Abb. 4.16 Ein Aminosäure-Sequenzvergleich zeigt ähnliche Wnt-bindende Domänen in XsFRP2 und XsFRP5.

Abb. 4.17 XsFRP2 zeigt ein dynamisches, aber deutlich unterschiedliches Expressionsmuster zu XsFRP5.

Abb. 4.18 XsFRP2 induziert keine pankreatische Markergen-Expression in VegT-injizierten Kappenexplantaten.

Abb. 4.19 Eine Vielzahl unterschiedlicher Xwnts wird in VegT-injizierten Kappenexplanataten verschiedener Entwicklungsstadien exprimiert.

Abb. 4.20 $\Delta \mathrm{Np63 \alpha}$ wirkt synergistisch auf die Lef1-GR-vermittelte Achsenduplikation in Xenopus Embryonen.

Abb. 5.1 Schematische Darstellung einer möglichen Korrelation zwischen den Wnt Expressionsmustern und den nach XsFRP5-,„Knockdown" erzielten Effekten auf verschiedene Markergene.

\section{Tabellenverzeichnis}

Tabelle 2.1

Konstruktliste zur in vitro Transkription von CapRNA (sense) und Digoxigenin-markierten Sonden (antisense)

Tabelle 2.2

Liste aller in dieser Arbeit zur Anwendung gekommener Oligonukleotide für die RT-PCR Analyse

Tabelle 2.3

Liste der in dieser Arbeit zur Anwendung gekommenen Sequenzierungsoligonukleotide

Tabelle 2.4 Liste der verwendeten antisense Morpholino Oligonukleotide

Tabelle 2.5 Aufstellung der zur Anwendung gebrachten primären Antikörper

Tabelle 2.6 Aufstellung der zur Anwendung gebrachten sekundären Antikörper

Tabelle 3.1 Inkubationszeiten für den Proteinase K-Verdau Zusammenfassung der erhaltenen Daten aus den

Tabelle 4.1 Interaktionsstudien von XsFRP5 mit verschiedenen Xwnt Proteinen 


\section{Abkürzungsverzeichnis}

A

Abb.

Amp

BCIP

BMB

$\mathrm{Bp}$

bzw.

${ }^{\circ} \mathrm{C}$

CapRNA

Da

DEX

$\mathrm{dH}_{2} \mathrm{O}$

DNA

DNase

DTT

EDTA

EGTA

E. coli

et al.

FA

g

$\mathrm{h}$

HCG

HEPES

$\mathrm{H}_{2} \mathrm{O}$

k

L

LB

$\mathrm{m}$

M

MAB

MEM
Alanin

Abbildung

Ampicillin

5-Brom-4-Chlor-3-Indolyl-Phosphat

„Boehringer Mannheim Blocking“ Reagenz

Basenpaar

beziehungsweise

Grad Celsius

Monomethylguanosin-Cap-RNA

Dalton

Dexamethason

Destilliertes Wasser

Desoxyribonukleinsäure

Desoxyribunuklease

Dithiothreitol

Ethylendiamintetraessigsäure

Ethylenglykol-bis(2-aminoethylether)-N,N`-tetraacetat

Escherichia coli

et altera

Formaldehyd

Gramm

Stunde

humanes Choriongonadotropin

n-(2-Hydroxymethyl)piperazin, N-3-propansulfonsäure

Wasser

Kilo

Liter

Luria-Bertani-Medium

Meter, milli

Molar

Maleinsäurepuffer

MOPS-EGTA-MgSO 4 -Puffer 


\begin{tabular}{|c|c|}
\hline MEMFA & MOPS-EGTA-MgSO 4 -Formaldehyd-Puffer \\
\hline mRNA & Messenger-RNA \\
\hline$\mu$ & Mikro \\
\hline $\mathrm{n}$ & nano \\
\hline NBT & Nitro-Blau-Tetrazolium \\
\hline OD & optische Dichte \\
\hline $\mathrm{p}$ & pico \\
\hline PBS & Phosphat-gepufferte Salinenlösung \\
\hline PCR & Polymerase-Kettenreaktion \\
\hline $\mathrm{pH}$ & negativer dekadischer Logarithmus der Protonen-Konzentration \\
\hline RNA & Ribonukleinsäure \\
\hline RNase & Ribonuklease \\
\hline RT & Raumtemperatur \\
\hline S & Serin \\
\hline SSC & Standard Saline Citrat Puffer \\
\hline TBE & Tris-Borat-EDTA-Elektrophoresepuffer \\
\hline TE & Tris-EDTA \\
\hline Tris & Trishydroxymethylaminomethan \\
\hline$U$ & Einheit „Unit“ der Enzymaktivität \\
\hline Upm & Umdrehungen pro Minute \\
\hline UV & Ultraviolettlicht \\
\hline $\mathrm{v} / \mathrm{v}$ & „volume per volume“ \\
\hline$w / v$ & „weight per volume“ \\
\hline WMISH & whole-mount in situ Hybridisierung \\
\hline X-Gal & 5-Bromo-4-Chloro-3-indolyl-b-D-galactosid \\
\hline z.B. & zum Beispiel \\
\hline
\end{tabular}




\section{Einleitung}

Die Bevölkerung der Industrieländer leidet in steigendem Maß unter sogenannten Zivilisationskrankheiten. Ein Beispiel dafür ist der starke Anstieg von Erkrankungen wie Diabetes Typ I und II (Mellitus). Eine allgemeine Arbeitshypothese der regenerativen Medizin besagt, dass man durch ein genaues Verständnis der molekularen Mechanismen der Embryonalentwicklung Protokolle zur Erzeugung organspezifischer Zellen mit der entsprechenden Stoffwechselleistung terminal differenzierter Zellen aus embryonalen oder adulten Stammzellen ableiten kann. Solche in vitro erzeugten, spezialisierten Zellen könnten dann im Rahmen von zelltherapeutischen Strategien zur Behandlung degenerativer Krankheiten wie Diabetes Mellitus eingesetzt werden. Eine in vitro Differenzierung Insulinproduzierender $\beta$-Zellen aus embryonalen Stammzellen konnte bereits in verschiedenen Laboren erzielt werden (Blyszczuk et al., 2004; Chen et al., 2008). Diese in vitro differenzierten $\beta$-Zellen führten nach Transplantation in hyperglykemische Mäuse jedoch nicht zu einem Absinken der BlutglukoseKonzentration (Chen et al., 2008). Auch Versuche, murine und humane Fibroblasten in vitro zu de-differenzieren und sie einen embryonalen Stammzell-ähnlichen Charakter annehmen zu lassen, konnten bisher nur partielle Erfolge erzielen (Wernig et al., 2007; Yu et al., 2007). Technische Limitationen dieser experimentellen Strategie ergeben sich durch die Verwendung retroviraler Vektoren, um die terminal differenzierten Zellen zu transformieren. Da diese Vektoren unspezifisch ins Genom der Zellen integrieren, kann die Tumor-Induzierende Wirkung dieser in vitro reprogrammierten Zellen nach einer möglichen Re-Implantation nicht ausgeschlossen werden.

Alternativ könnte die Regenerationsfähigkeit adulter Organe genutzt werden. Im Rahmen solcher Prozesse kommt es entweder zur Aktivierung fakultativer Stammzellen, welche bei der Regeneration die organspezifischen Differenzierungsschritte der Embryonalentwicklung zu rekapitulieren scheinen, oder aber zu einem Wiedereintritt terminal differenzierter Zellen in den mitotischen Zellzyklus. An diesen Prozessen kommt unter anderem den FGF („Fibroblast Growth Factor") und Wnt Signalwegen eine Schlüsselrolle zu [zur Übersicht siehe (Stoick- 
Cooper et al., 2007)]. Die Leber ist das Organ mit der höchsten Regenerationskapazität in Säugetieren. Nach partieller Hepatektomie, der Resektion von bis zu $70 \%$ der Lebermasse, treten Hepatozyten wieder in den Zellzyklus ein und bilden durch kompensatorisches Wachstum das ursprüngliche Lebervolumen aus. Darüber hinaus konnten auch fakultative Stammzellen der Leber, die sogenannten „oval cells“, identifiziert werden, die nach einer Intoxikation aktiviert werden [zur Übersicht siehe (Taub, 2004)].

Der Pankreas zeichnet sich demgegenüber durch eine geringere Fähigkeit zur Regeneration aus. Im Fokus der regenerativen Medizin befinden sich insbesondere die Insulin-produzierenden $\beta$-Zellen. Es konnte gezeigt werden, dass adulte $\beta$-Zellen nach partieller Pankreatektomie durch einen Wiedereintritt in den mitotischen Zellzyklus die Zellmasse wiederherstellen können (Dor et al., 2004). Demgegenüber belegt eine neuere Studie, dass in einem Pankreatitis-Mausmodell $\beta$-Zellen aus fakultativen adulten Stammzellen regeneriert werden (Xu et al., 2008). Zusammenfassend kann gesagt werden, dass in Leber und Pankreas Zellregeneration sowohl durch kompensatorisches Wachstum als auch durch die Aktivierung fakultativer Stammzellen stattfinden kann.

Vor diesem Hintergrund soll in der hier vorgelegten Arbeit die Funktion der Wntabhängigen Signalkaskaden im Zusammenhang mit Leber- und Pankreasentwicklung in Xenopus laevis untersucht werden. Xenopus laevis bietet als Modellorganismus im Vergleich zur Maus verschiedene Vorteile, welche die Untersuchung der eben genannten Aspekte erleichtern. Neben der mit 1 bis $2 \mathrm{~mm}$ vorteilhaften Größe der frühen Embryonen, sowie der raschen extraembryonalen Entwicklung bis zur freischwimmenden Kaulquappe in nur vier Tagen, haben Explantations- und Transplantationsexperimente in Xenopus eine lange Tradition (Spemann, 1938). Anhand isolierter, multipotenter Vorläuferzellpopulationen können zur Induktion einzelner Zelltypen benötigte Stimuli und Wachstumsfaktoren gezielt analysiert werden. 


\subsection{Die Entwicklung des Gastrointestinaltrakts in Xenopus laevis}

\subsubsection{Entoderm-Entwicklung in Xenopus Embryonen}

Die Bildung der drei Keimblätter beruht in Xenopus Embryonen auf der asymmetrischen Verteilung maternaler Komponenten entlang der animal-vegetalen Achse der Oocyte. Die mRNAs von VegT und Vg1 sind am vegetalen Kortex der Oocyte verankert und werden im Zuge der Furchungsteilungen in den vegetalen Zellen angereichert, welche das Entoderm bilden. Das Ektoderm bildet sich aus den animalen Zellen und das Mesoderm entsteht im äquatorialen Bereich des Embryos. Embryonen ohne maternales VegT zeichnen sich durch den Verlust des entodermalen Keimblattes aus (Zhang et al., 1998), der Verlust von Vg1 resultiert im Fehlen von Entoderm und dorsalem Mesoderm (Joseph und Melton, 1998). Im Zuge der Gastrulationsbewegungen gelangen die entodermalen Zellen in das Innere des Embryos, wo sie das Archenteron, den Urdarm, bilden.

Aus dem Archenteron, einer Röhrenförmigen, von entodermalen Epithelzellen ausgekleideten Struktur entwickelt sich in Xenopus laevis, ähnlich wie in anderen Vertebraten, der intestinale Trakt. Im Laufe der Entwicklung differenzieren sich von anterior nach posterior das ösophagial-trachiale System, der Magen, das Duodenum mit den anliegenden Organen Leber, Pankreas und Gallenblase, sowie der Dünnund der Dickdarm. Erste Differenzierungsschritte lassen sich in Xenopus laevis bereits am zweiten Entwicklungstag durch die Analyse von Markergenen veranschaulichen. Wie in Abb. $1.1 \mathrm{~A}$ schematisch dargestellt, können schon während der Gastrulation einzelne Vorläuferzellpopulationen im Entoderm lokalisiert werden. In Stadium 40/41 (Abb. 1.1 B) haben sich bereits einzelne Organe, wie die Leber (rot dargestellt) und der Pankreas (grün dargestellt) differenziert, während das Darmrohr erst in späteren Stadien (Abb. $1.1 \mathrm{C}$ ) die charakteristischen Schlingen ausbildet. 


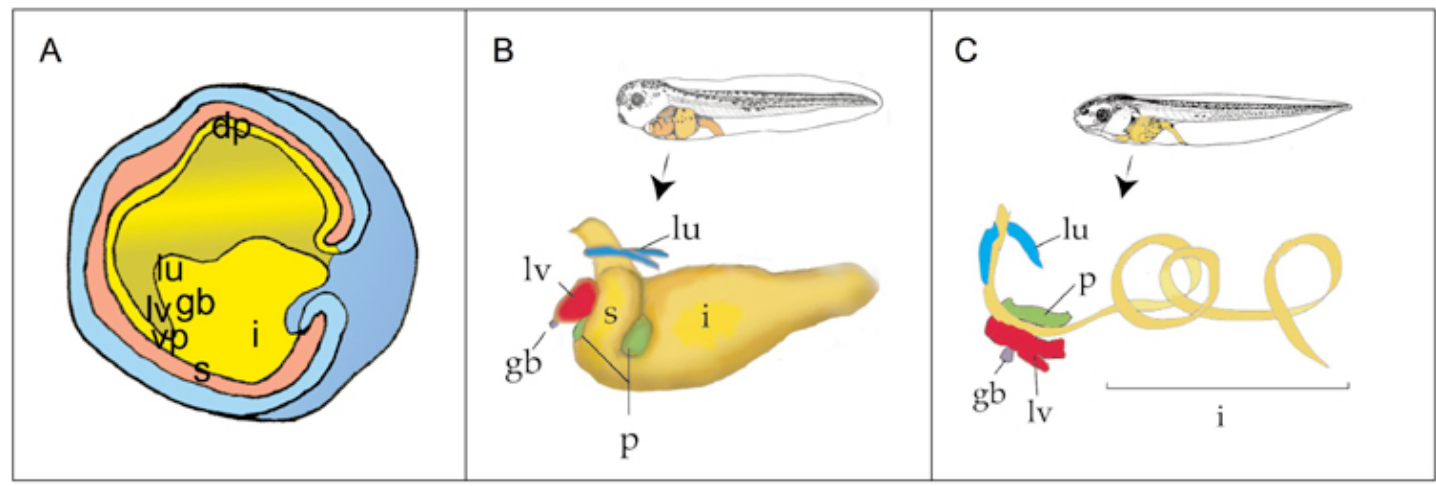

Abb. 1.1: Schematische Darstellung der Entwicklung entodermaler Organe in Xenopus laevis. (A) Sagittaler Schnitt durch einen Embryo im Stadium 11 (Gastrula) mit anterior nach links. Das Ektoderm ist blau, das Mesoderm rot und das Entoderm gelb dargestellt. Einzelne Vorläuferzellpopulationen sind markiert. (B) Laterale Ansicht eines Embryos in Stadium 41/42 mit anterior nach links, das Entoderm ist farblich hervorgehoben (Zorn und Mason, 2001). (C) Laterale Ansicht eines Embryos in Stadium 46/47 mit anterior nach links. Der Gastrointestinaltrakt ist vergrößert dargestellt (Zorn und Mason, 2001). dp = dorsaler Pankreas, $\mathrm{gb}=$ Gallenblase, $\mathrm{i}=$ Darm, $\mathrm{lu}=$ Lunge, $\mathrm{lv}=$ Leber, $\mathrm{s}=$ Magen, $\mathrm{vp}=$ ventraler Pankreas.

\subsubsection{Leberentwicklung}

In Xenopus Embryonen bildet sich das Leberdiverticulum im Stadium 13,5 aus, im Stadium 22 umschließt die Leberanlage einen kleinen Hohlraum. Im Stadium 25 vergrößert sich die Leberanlage zu einer charakteristischen, Bogenförmigen Struktur. Das früheste hepatische Vorläufermarkergen ist hex, ein Homöobox Transkriptionsfaktor der Antennapedia Familie (Crompton et al., 1992). Verschiedene Differenzierungsmarker, wie beispielsweise Fibrinogen, werden in Xenopus Embryonen zwischen den Stadien 34 und 44 sowohl in der Leber als auch im Darm exprimiert (Chen et al., 2003).

Die Lebervorläuferzellen entspringen in Vertebraten einer gemeinsamen Zellpopulation mit den Vorläuferzellen des ventralen Pankreas (Deutsch et al., 2001). Diese Zellpopulation kann bereits während der Gastrulation im anterioren Entomesoderm von Maus Embryonen durch die Expression von hex identifiziert werden (Thomas et al., 1998). In der Maus konnte auch gezeigt werden, dass frühe BMP Sekretion des Septum transversum Mesenchyms im angrenzenden ventralen Vorderdarm die Expression von FoxA und Gata Transkriptionsfaktoren induziert (Rossi et al., 2001). Daraufhin gewinnt das Entoderm die Kompetenz, auf spätere FGF Signale aus der Herzanlage zu reagieren und Leber-spezifische Markergene zu 
exprimieren (Jung et al., 1999). Der Anteil der hepato-pankreatischen Zellpopulation, welcher durch das Septum transversum Mesenchym von der Herzanlage abgegrenzt wird und daher keine FGF Signale empfängt, entwickelt sich zum ventralen Pankreas. Diese Positionierung der ventralen Pankreasanlage ist abhängig von der Expression des Transkriptionsfaktors Hex (Bort et al., 2004).

\subsubsection{Pankreasentwicklung}

Das Pankreas entwickelt sich aus dem anterioren Darmepithel, aus einer dorsalen und zwei ventralen Anlagen. Die dorsale Pankreasknospe bildet sich in Xenopus im Stadium 35/36 aus, die ventralen Anlagen im Stadium 37/38. Eine der ventralen Anlagen bildet sich zurück, während sich die andere weiterentwickelt. Im Zuge der Darmrotation kommt die dorsale Anlage in Kontakt mit der verbliebenen ventralen Anlage, was die Fusion dieser Organlagen zur Folge hat [Abb. 1.2; (Afelik et al., 2004; Kelly und Melton, 2000)]. Die ventrale Anlage besteht ausschließlich aus exokrinen Zellen, frühe Insulin-produzierende Zellen werden in Xenopus nur in der dorsalen Pankreasanlage gebildet (Kelly und Melton, 2000).

Wichtige pankreatische Vorläufermarker sind der bHLH-Transkriptionsfaktor Pft1a/p48 und der Homöodomänen-Transkriptionsfaktor XIHbox8. Ptf1a/p48 wird in Xenopus ab Stadium 30 in allen pankreatischen Vorläuferzellen, sowie in der Retina und im Hinterhirn exprimiert (Afelik et al., 2006). XIHbox8 wird ebenfalls ab Stadium 30 in allen pankreatischen Vorläuferzellen, sowie dem Duodenum und im posterioren Magen exprimiert (Wright et al., 1989). Der erste endokrine Differenzierungsmarker ist Insulin, welches ab Stadium 32 ausschließlich im dorsalen Pankreas exprimiert wird. Der erste exokrine Differenzierungsmarker ist die Proteindisulfitisomerase XPDIp, welche ab Stadium 39 detektiert werden kann (Afelik et al., 2004). Ab Stadium 42 folgt eine zweite Welle der Differenzierung, welche durch die Expression weiterer exokriner und endokriner Differenzierungsmarker wie Trypsinogen und Glucagon gekennzeichnet ist (Afelik et al., 2004; Kelly und Melton, 2000). 


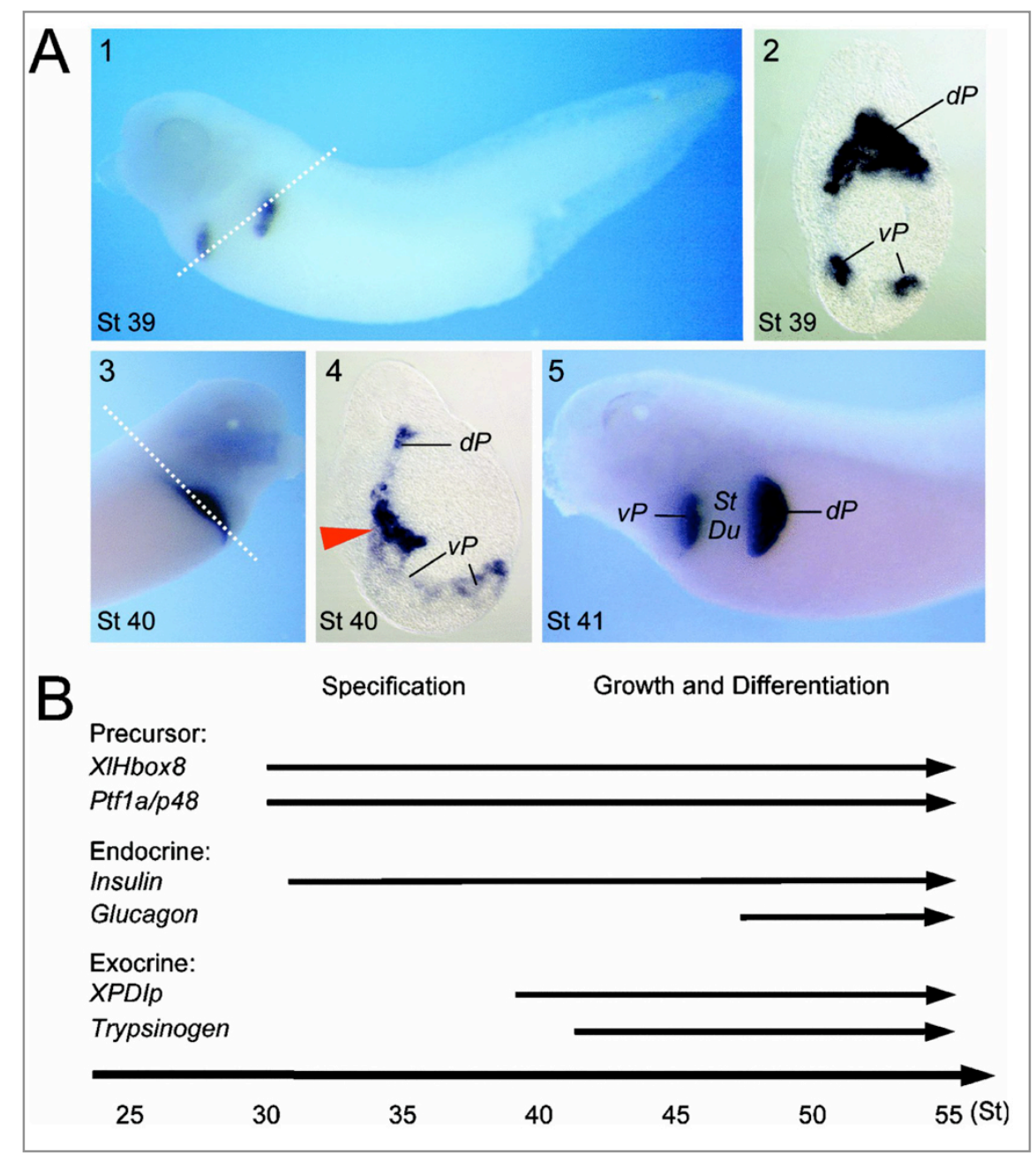

Abb. 1.2: Entwicklung und temporäres Genexpressionsprofil des Pankreas in Xenopus Embryonen (Pieler und Chen, 2006). (A) Darstellung des Fusionsprozess der Pankreasanlagen anhand der XPDIp Expression. (1) In Stadium 39 wird XPDIp ausschließlich in der dorsalen und den beiden ventralen Pankreasanlagen exprimiert. (2) Transversalschnitt des Embryos in (1) mit deutlicher Färbung der Pankreasanlagen. (3) In Stadium 40 fusionieren die dorsalen und ventralen Anlagen auf der rechten Seite des Embryos. (4) Transversalschnitt durch den Embryo in (3), die rote Pfeilspitze zeigt auf die Fusionsstelle. (5) Das reife Pankreas kommt im Zuge der Darmrotation hinter dem Magen und dem Duodenum zu liegen. $\mathrm{Dp}=$ dorsale Pankreasanlage, $\mathrm{Du}=$ Duodenum, $\mathrm{St}=$ Magen, $\mathrm{VP}=$ ventrale Pankreasanlagen. (B) Schematische Darstellung des Genexpressionsprofils pankreatischer Gene in Xenopus laevis. Ptf1a/p48 und XIHbox8 werden schon ab Stadium 30 in allen pankreatischen Vorläuferzellen exprimiert. Die frühesten Differenzierungsmarker sind Insulin und XPDIp, während andere Differenzierungsmarker erst ab Stadium 42 in der Wachstums- und Differenzierungsphase des Pankreas exprimiert werden.

Die Entwicklung des Pankreas hängt von der Sekretion verschiedener Signalmoleküle aus den umgebenden Geweben ab. So konnte Retinsäure (RA) als bereits während der Gastrulation wirkendes Signalmolekül in der Spezifierung der dorsalen Pankreasvorläuferzellpopulation identifiziert werden, wobei eine RA 
Signalwirkung sowohl über das Entoderm als auch über das Mesoderm beschrieben wurde (Chen et al., 2004a; Pan et al., 2007). Weiterhin konnte gezeigt werden, dass RA die Expression von Sonic Hedgehog (Shh), einem in verschiedenen Modellorganismen beschriebenen Inhibitor pankreatischer Genexpression [zur Übersicht siehe (Hebrok et al., 1998)], hemmt (Chen et al., 2004a). In der Maus wurden auch spätere Signale der an das pankreatische Epithel angrenzenden Blutgefäße, wie der dorsalen Aorta, als essentiell für die Entwicklung der Pankreasanlage beschrieben, wobei die Identität dieser Signale noch nicht bekannt ist (Lammert et al., 2001).

\subsection{Wnt Signaltransduktion}

Bei Wnts handelt es sich um sekretierte Glykoproteine mit morphogenetischer Aktivität. Sie besitzen eine N-terminale Cystein-reiche Domäne, wobei ein konserviertes Cystein einen für die Funktion der Wnt Proteine essentiellen Palmitoylrest trägt (Willert et al., 2003). Der Name Wnt ist eine Kombination aus Wg (wingless) und Int. Wg wurde als Segmentpolaritätsgen in Drosophila melanogaster identifiziert (Nüsslein-Volhard und Wieschaus, 1980). Int Gene wurden in Vertebraten als Gene identifiziert, die in der Nähe verschiedener „Mouse Mammary Tumor Virus“ (MMTV) Integrationsstellen liegen (Nusse und Varmus, 1982). Als erkannt wurde, dass es sich bei Wg und Int-1 um Homologe handelte, wurde der Namen Wnt geprägt. Mittlerweile kennt man $7 \mathrm{wg}$ Gene in Drosophila und 19 Vertebraten-Homologe Wnt Gene [zur Übersicht siehe (The Wnt Homepage)]. Die Beobachtung, dass Wnt Proteine nach Mikroinjektion in Xenopus Embryonen unterschiedliche Effekte auf die Ausprägung der dorso-ventralen Achse haben, führte zu der Annahme, dass mehr als ein Wnt Signaltransduktionsweg existiert. So zeigen einige Wnt Proteine, wie Wnt1 oder Wnt8, die Fähigkeit, eine dorsale Achsenduplikation zu induzieren, wohingegen Wnt5a oder Wnt11 diese Fähigkeit nicht besitzen, sondern Gastrulationsdefekte ohne Zellidentitätsänderungen hervorrufen (Glinka et al., 1997; Moon et al., 1993; Sokol et al., 1991; Tada und Smith, 2000). 


\subsubsection{Der kanonische Zweig der Wnt Signaltransduktion}

Kanonische Wnt Signaltransduktion spielt eine wesentliche Rolle in der Spezifizierung der Zellidentität, sowie bei Zellproliferation und Differenzierung, aber auch in der Achsendetermination in allen Metazoen. Eine Fehlregulation des kanonischen Wnt Signalweges wird mit der Entwicklung einer Vielzahl von Tumoren in Zusammenhang gebracht [zur Übersicht siehe (Logan und Nusse, 2004)].

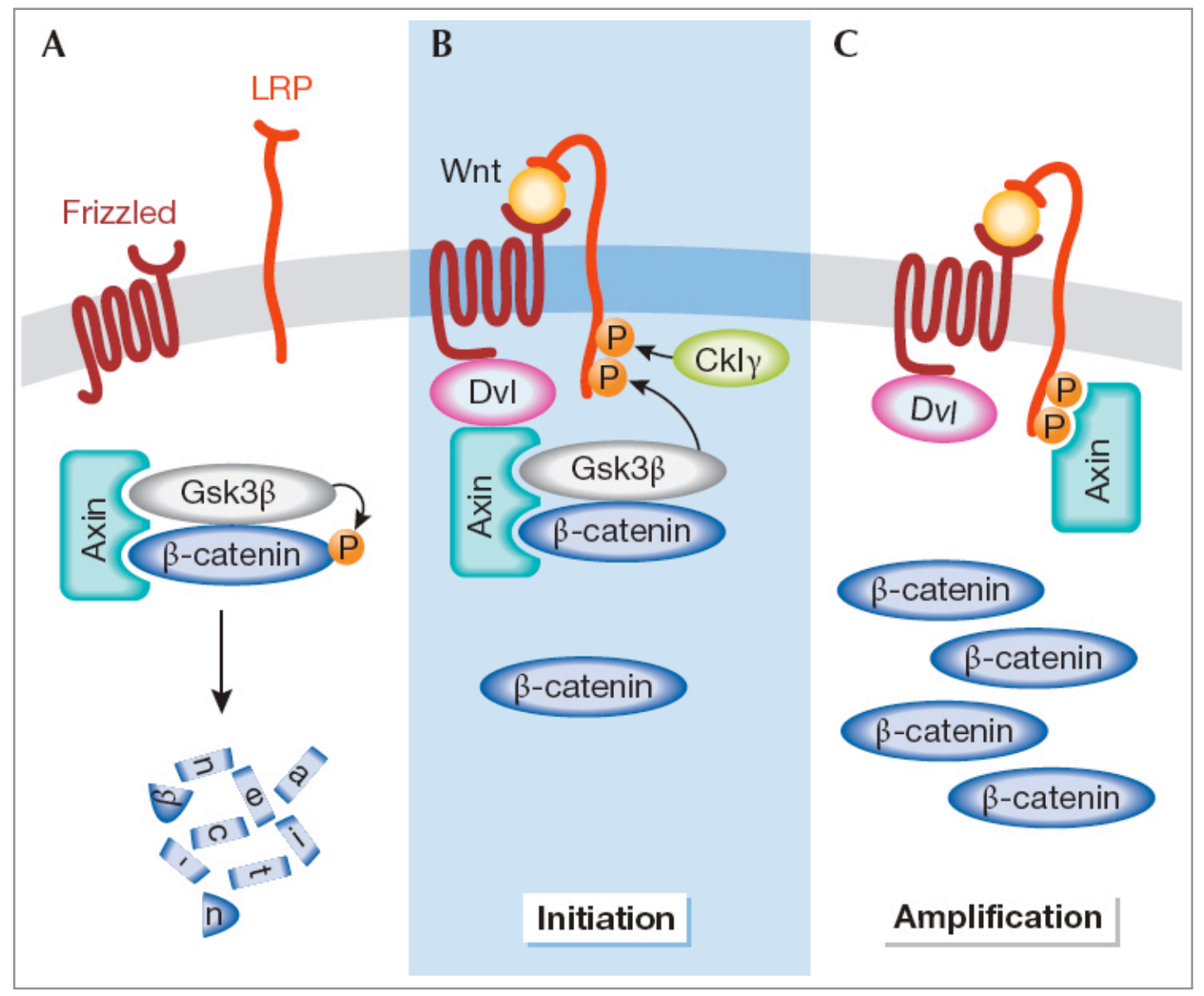

Abb. 1.3: Schematische Darstellung der kanonischen Wnt Signaltransduktion (Fuerer et al., 2008) (A) Im inaktiven Zustand wird $\beta$-Catenin durch den "Destruction Complex" phosphoryliert und der proteosomalen Degradation zugeführt. (B) Nach Bindung eines Wnt Liganden an den Frizzled Rezeptor und den LRP5/6 Ko-Rezeptor führt die Membranrekrutierung des "Destruction Complex" durch Dishevelled (Dvl) zur Phosphorylierung von LRP5/6. $\beta$-Catenin wird dadurch cytoplasmatisch stabilisiert. (C) Axin bindet an hyperphosphoryliertes LRP5/6, wodurch der "Destruction Complex“ zerfällt und $\beta$ Catenin somit in der Zelle akkumuliert.

Ein zentrales Protein des kanonischen Wnt Signalweges ist $\beta$-Catenin (Abb. 1.3). Im inaktiven Zustand befindet sich das meiste endogene $\beta$-Catenin an der Zellmembran 
mit Cadherinen assoziiert. Die Kinasen Glykogen-Synthase-Kinase $3 \beta$ (GSK3 $\beta$ ) und Caseinkinase $1 \gamma(\mathrm{CK} 1 \gamma)$ sind Teil des sogenannten "Destruction Complex“, der zusätzlich aus Axin, dem „Adenomatous Poliposis Coli“ Protein (APC) und der Proteinphosphatase 2A (PP2A) besteht. Eine sequentielle Phosphorylierung von cytoplasmatischem $\beta$-Catenin führt zur Ubiquitinylierung durch die „ $\beta$-transducing repeat containing protein“ $(\beta-\operatorname{TrCP})$ E3 Ubiquitin Ligase und der anschließenden proteolytischen Spaltung von $\beta$-Catenin (Price, 2006). Im Zellkern sind Transkriptionsfaktoren der TCF/Lef Familie an die Regulatorsequenzen von Wnt Zielgenen gebunden. Ohne nukleäres $\beta$-Catenin binden Ko-Repressoren wie Groucho/TLE1 und CtBP („C-terminal Binding Protein“) an TCF/Lef und halten die Wnt Zielgene durch eine Interaktion mit Histondeacetylasen (HDACs) transkriptionell inaktiv (Cavallo et al., 1998; Chen et al., 1999).

Wnt Proteine binden direkt an die N-terminale Cystein-reiche Domäne der Frizzled Transmembranrezeptoren. Zusätzlich bedarf es zu einer Stimulation der kanonischen Signaltransduktion der Anwesenheit der Ko-Rezeptoren LRP5/6 und Kremen1 und 2. Durch die Bindung der Wnt Proteine an ihre Rezeptoren wird die intrazelluläre Phosphorylierung von LRP5/6 durch GSK3 $\beta$ und CK1 $\gamma$ ausgelöst (Davidson et al., 2005). Hyperphosphoryliertes LRP5/6 ist in der Lage, Axin mit hoher Affinität zu binden und es so aus dem „Destruction Complex“ abzuziehen. Durch die Membranlokalisation von Axin wird die Phosphorylierung von $\beta$-Catenin gestoppt (Lee et al., 2003). Ein weiteres wichtiges Protein ist Dishevelled (Dsh/Dvl), welches nach Wnt-Frizzled Bindung phosphoryliert wird und den „Destruction Complex" an die Membran rekrutiert. Es konnte gezeigt werden, dass Fz, Dvl, Axin und die GSK3 $\beta$ an der Membran mit LRP5/6 in sogenannten „signalosomes“ kolokalisieren, und Fz, Dvl und Axin für die GSK3 $\beta$-vermittelte Phosphorylierung von LRP5/6 notwendig sind (Bilic et al., 2007; Zeng et al., 2008). Kürzlich konnte außerdem gezeigt werden, dass Dvl und Axin durch Oligomerisierung ihrer DIXDomänen zu einer Aggregation vieler aktivierter Frizzled-Komplexe führen und somit eine Amplifizierung des kanonischen Wnt Signals ermöglichen (Schwarz-Romond et al., 2007). Freies $\beta$-Catenin transloziert in den Nukleus, wo es die Ko-Repressoren von TCF/Lef verdrängt und zusammen mit den Ko-Aktivatoren Pygopus (Pyg) und Bcl9/Lgl sowie dem SWRCAP/SWR1 und dem CBP/p300 Chromatin-Remodelling 
Komplex die Transkription der Wnt Zielgene aktiviert [zur Übersicht siehe (Bienz und Clevers, 2003)].

\subsubsection{Der nicht-kanonische Zweig der Wnt Signaltransduktion}

Als nicht-kanonische Wnt Signalwege werden die verschiedenen Zweige der Wnt Signaltransduktion bezeichnet, welche nicht über die Aktivierung von $\beta$-Catenin reguliert werden. Nicht-kanonische Wnt Signale steuern Zellpolarität und Zellbewegungen, wie zum Beispiel die Gastrulationsbewegungen, ohne die Zellidentität zu beeinflussen. Obwohl auch die nicht-kanonischen Signalwege über Wnt-Frizzled-Interaktion und Dishevelled Aktivierung verlaufen, haben sie keine Auswirkung auf die Regulation der GSK3 $\beta$ oder $\beta$-Catenin.

Einer der nicht-kanonischen Wnt Signalwege reguliert die planare Zellpolarität (PCP), also die Ausrichtung einzelner Zellen in einem einschichtigen Zellverband. Einige Beispiele für Wnt/PCP Signalwirkung sind die Regulation der konvergenten Extensionsbewegungen, die Anordnung der Ommatidien im Drosophila Auge oder auch die Ausrichtung der Cilien im murinen Gehörgang [zur Übersicht (Seifert und Mlodzik, 2007)]. Auch in diesem Signalweg spielt die Aktivierung von Frizzled und Dishevelled (Dvl) eine wesentliche Rolle, jedoch kommt es im Anschluss zur Aktivierung heterotrimerer $G$ Proteine (als $G$ in Abb. 1.4 dargestellt). Nach der Aktivierung von Dvl bewirken multiple Signalwege eine Modulation des AktinCytoskeletts und der Mikrotubuli (Abb. 1.4 A). Neben Frizzled konnten auch weitere Rezeptoren wie Rezeptortyrosinkinasen (RTKs) oder PAPC als Mediatoren des Wnt/PCP Signalweges identifiziert werden (Keeble et al., 2006; Unterseher et al., 2004). Auch transmembrane Heparansulfat-Proteoglykane wie Syndecan-4, wurden mit dem Wnt/PCP Signalweg und der Regulation der konvergenten Extensionsbewegungen in Zusammenhang gebracht. So konnte gezeigt werden, dass Xenopus Syndecan-4 in Abhängigkeit von Fibronektin mit Frizzled7 interagiert und in Folge dieser Interaktion Dvl an die Plasmamembran transloziert (Munoz et al., 2006). In Vertebraten wurde außerdem eine Ko-Rezeptorfunktion für das Zelloberflächen-Heparansulfat-Proteoglykan Glypican/Knypek nachgewiesen (Ohkawara et al., 2003; Topczewski et al., 2001). 


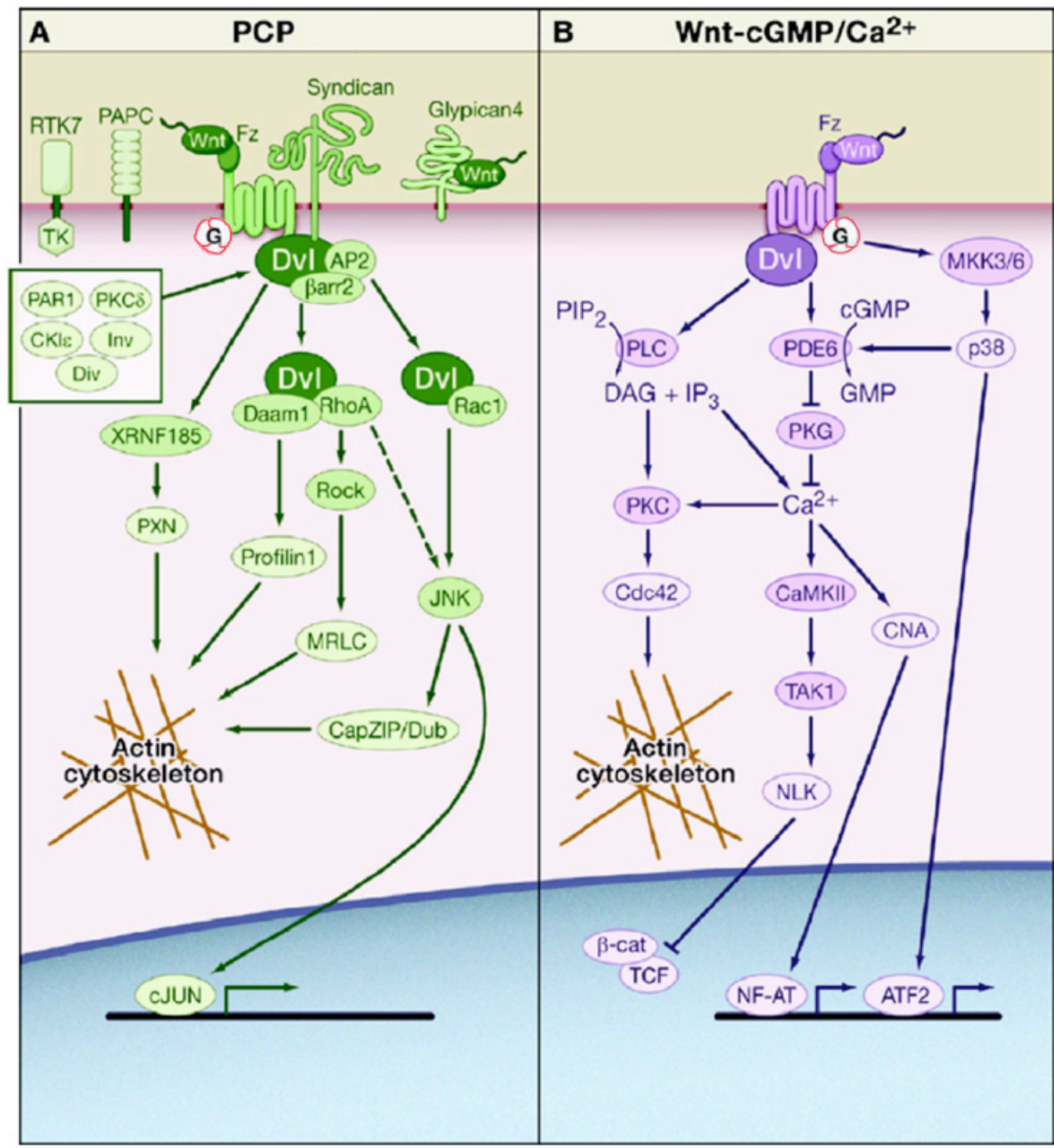

Abb. 1.4: Schematische Darstellung der beiden primären nicht-kanonischen Wnt Signalwege [modifiziert nach (Semenov et al., 2007)]. (A) Der Wnt/PCP Signalweg induziert über die Aktivierung heterotrimerer G Proteine Veränderungen im Aktin Cytoskelett und die JNK-regulierte Aktivierung von Zielgenen. (B) Nach Wnt-Frizzled Interaktion kommt es beim Wnt-cGMP/Ca ${ }^{2+}$ Signalweg zu einer Erhöhung der intrazellulären Kalziumkonzentration und einer Verringerung des cGMP Vorrats der Zelle. Enzyme wie die Proteinkinase C oder die Kalzium-Calmodulin-abhängige Proteinkinase II (CamKII) werden aktiviert und bewirken neben Cytoskelettveränderungen auch die Aktivierung verschiedener Transkriptionsfaktoren.

Weiterhin konnte gezeigt werden, dass Xwnt5a oder Xwnt11 nach Injektion in Xenopus Oozyten zu einer Erhöhung der intrazellulären Kalziumkonzentration führen (Kuhl et al., 2000). Diese Erhöhung von freiem Kalzium führt wiederum zur Aktivierung der Kalzium-Calmodulin-abhängigen Proteinkinase II (CamKII) und der Proteinkinase C (PKC) (Kühl et al., 2000; Sheldahl et al., 2003). Dieser Signalweg 
wird als Wnt-cGMP/Ca ${ }^{2+}$ Weg bezeichnet, da die Umwandlung von intrazellulärem cGMP zu GMP eine Inhibition der Proteinkinase G bewirkt und so ebenfalls zu einer Erhöhung der intrazellulären Kalziumkonzentration führt (Abb. 1.4 B). Die Aktivierung der PKC wirkt sich auf das Aktin Cytoskelett aus, während die "Nemo-like Kinase" (NLK) kanonische Wnt Signaltransduktion hemmt (Thorpe und Moon, 2004; Yamada et al., 2006). Calcineurin (CNA) und p38 bewirken die Aktivierung verschiedener NFAT und ATF2 Zielgene (Ma und Wang, 2007; Saneyoshi et al., 2002; Yoshida et al., 2004).

\subsubsection{Möglichkeit einer Synergie zwischen $\Delta$ Np63 $\alpha$ und kanonischer Wnt Signaltransduktion}

In mehrschichtigen Plattenepithelien wie der Epidermis befinden sich die Stammzellen in der Basalmembran und bewirken durch ihre hohe Teilungsrate die konstante, suprabasale Erneuerung von Zellen. Ein Transkriptionsfaktor der p53Familie, p63, ist essentiell für den Erhalt der Selbsterneuerungskapazität epithelialer Stammzellen. In terminal differenzierenden, basalen Zellen wird die p63 Expression durch die microRNA-203 unterdrückt und somit der Zellzyklus-Arrest vermittelt (Yi et al., 2008). In anderen Stammzellpopulationen, wie den Krypten-Stammzellen im Dünndarm, in den Haarfollikeln und den Brustdrüsen, konnte die kanonische Wnt Signaltransduktion als essentiell für den Erhalt des Proliferationspotentials identifiziert werden (Barker et al., 2007; Pinto und Clevers, 2005). Eine mögliche, synergistische Wirkung von p63 und kanonischer Wnt Signaltransduktion wurde bislang nicht untersucht.

p63 wurde 1988 von unterschiedlichen Laboratorien als Mitglied der p53 Familie entdeckt. Bei p53 handelt es sich um einen wichtigen Tumorsuppressor, und obwohl p63 im Vergleich zu p53 eine hohe strukturelle Identität aufweist (Abb. 1.5), so zeigt es doch deutliche funktionale Divergenz. p63 kodiert für verschiedene Isoformen, die sowohl Transkriptionsaktivator- wie Repressordomänen beinhalten. p63 kann von unterschiedlichen Promotoren abgelesen werden; ein Promotor liegt vor dem originalen Startkodon und einer im dritten Intron. Dadurch entstehen die sogenannten TA- und $\Delta \mathrm{N}$-Isoformen. Sowohl die TA- als auch die $\Delta \mathrm{N}$-lsoform 
können durch alternatives „Splicing“ ihrer C-Termini $\alpha, \beta$ und $\gamma$ Isoformen bilden. Alle p63-Proteine weisen eine DNA-Bindedomäne, eine Oligomerisationsdomäne und die $\alpha$-Isoformen zusätzlich ein „Sterile Alpha“-Motif (SAM), welches der Protein-ProteinInteraktion dient, auf. Es zeigte sich, dass TA-Isoformen die Reportergen-Expression von p53-responsiven Promotorelemente aktivieren können, während $\Delta$ Np63 Proteine dominant-negativ auf die p53-vermittelte Reportergen-Expression wirken.

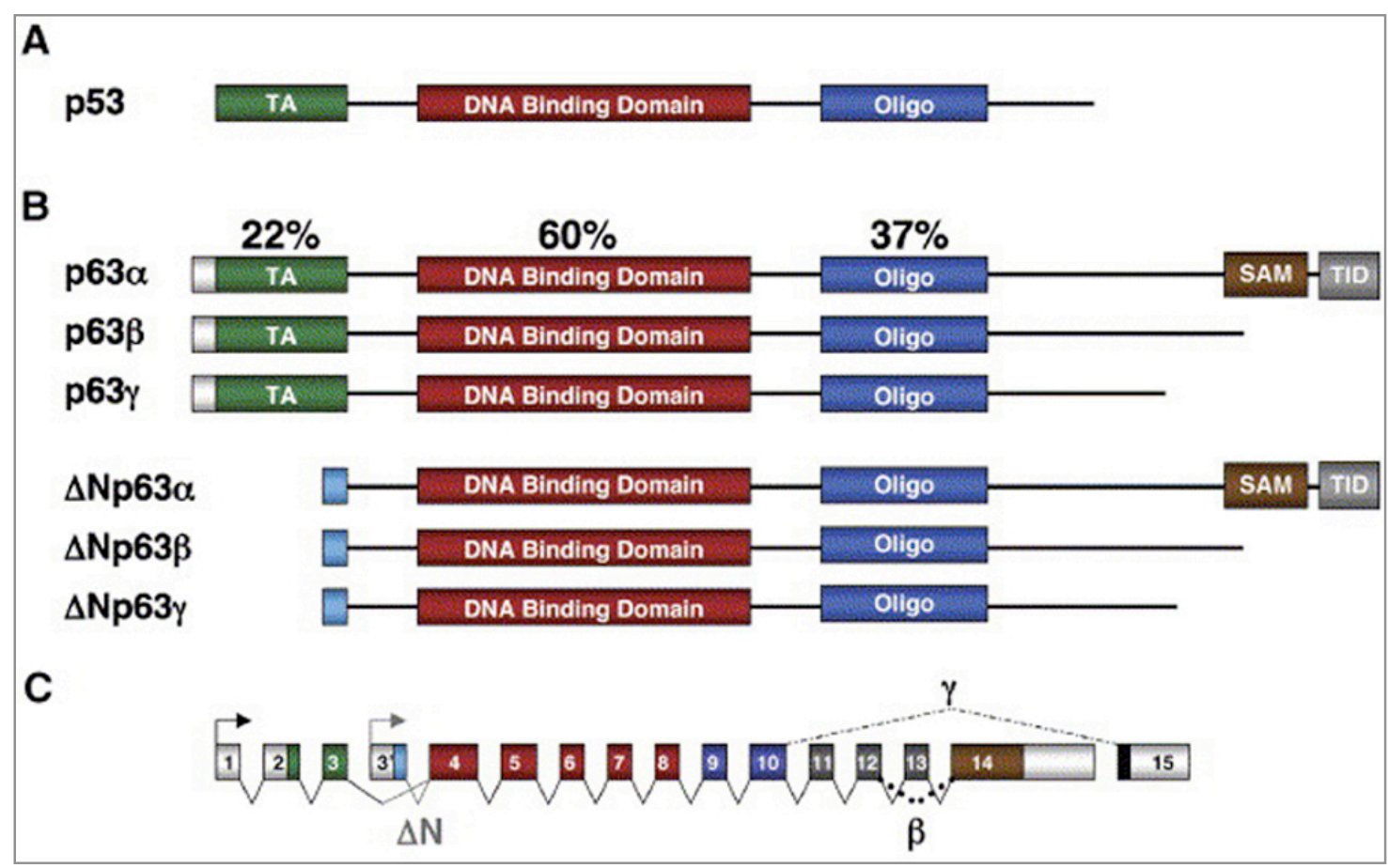

Abb. 1.5: Schematische Darstellung der funktionalen Domänen von p53 und p63 Proteinen (Barbieri und Pietenpol, 2006). (A) p53 besteht aus drei funktionalen Einheiten, der N-terminalen Transaktivierungsdomäne (TA), der DNA-Bindedomäne und einer Cterminalen Oligomerisierungsdomäne (Oligo). (B) Domänenstruktur der p63 Proteine. Die Prozentangaben beziehen sich auf identische Aminosäuren in p53 und p63. Zusätzlich weisen p63 Proteine ein C-terminales „Sterile-alpha“ Motif (SAM) und eine „transactivation inhibitory domain“ (TID) auf. (C) Genstruktur von p63. Beide Promotoren und die „Splice“Vorgänge der einzelnen Isoformen sind dargestellt.

In verschiedenen Modellsystemen wurden nach Verlust von p63 schwere Defekte der Extremitäten und das Fehlen von mehrschichtigem Plattenepithel beschrieben (Lee und Kimelman, 2002; Mills et al., 1999; Yang et al., 1999). Auch im Menschen sind Auswirkungen von Mutationen in p63 bekannt, die sogenannten EEC und AEC Syndrome. Beim EEC Syndrom kommt es zu Ectrodactylie, ektodermaler Dysplasie und Lippen-/Gaumenspalten. Beim AEC oder Hay-Weels Syndrom kommt es anstatt 
von Missbildungen der Extremitäten zu fusionierten Augenlidern. Als die in mehrschichtigen Plattenepithelien am höchsten exprimierte Isoform konnte $\Delta \mathrm{Np} 63 \alpha$ identifiziert werden (Bamberger und Schmale, 2001; Di Como et al., 2002). $\Delta$ Np63 $\alpha$ wird nicht ausschließlich in der Epidermis, sondern auch in Basalmembranen anderer mehrschichtiger Plattenepithelien, wie zum Beispiel der Mundschleimhaut oder auch der Harnblase, und in einigen komplexen Drüsen wie der Prostata und den Brustdrüsen exprimiert (Dellavalle et al., 2001; Di Como et al., 2002).

Im Zebrafisch konnte gezeigt werden, dass die $\Delta \mathrm{Np} 63 \alpha$ Expression durch BMPs („Bone Morphogenetic Proteins“) aktiviert werden kann (Bakkers et al., 2002). Weiterhin wurde für $\Delta \mathrm{Np} 63 \alpha$ eine Interaktion mit Jagged1 und Jagged2, Komponenten der Notch Signaltransduktion, beschrieben (Jiang et al., 1998; Sasaki et al., 2002). $\Delta \mathrm{Np63 \alpha}$ ist ein transkriptionaler Repressor, der für den Erhalt der Vorläuferzellen während der epithelialen Entwicklung essentiell ist (Barbieri et al., 2002). Eine Verbindung zwischen $\Delta N p 63 \alpha$ und kanonischer Wnt Signaltransduktion, welche ebenfalls für den Erhalt verschiedener Stammzellpopulationen wichtig ist (Barker et al., 2007), wurde bislang nicht untersucht, scheint jedoch auch in epithelialen Stammzellen möglich.

\subsubsection{Extrazelluläre Antagonisten der Wnt Signaltransduktion}

Extrazelluläre Wnt Antagonisten unterbinden die Liganden-Rezeptor-Interaktion durch zwei unterschiedliche Mechanismen und werden daher in zwei Klassen unterteilt.

\subsubsection{Die Dickkopf Klasse}

Die Dickkopf Klasse umfasst vier Mitglieder, Dkk-1 bis Dkk-4, sowie ein Dkk-3verwandtes Protein, Soggy (Sgy). Dickkopf Proteine besitzen zwei Cystein-reiche Domänen (Cys-1 und Cys-2), wobei die Cys-2 Domäne zehn konservierte CysteinReste beinhaltet und eine schwache Homologie zu Colipasen aufweist (Aravind und Koonin, 1998). Ihren Namen verdanken die Dickkopf Proteine der Kopfinduzierenden Wirkung von Dkk-1, da dieses Protein nach Ko-Injektion mit einem 
dominant-negativen BMP-Rezeptor eine zweite dorsale Körperachse mit kompletten Kopfstrukturen in Xenopus Embryonen induzieren kann (Glinka et al., 1998).

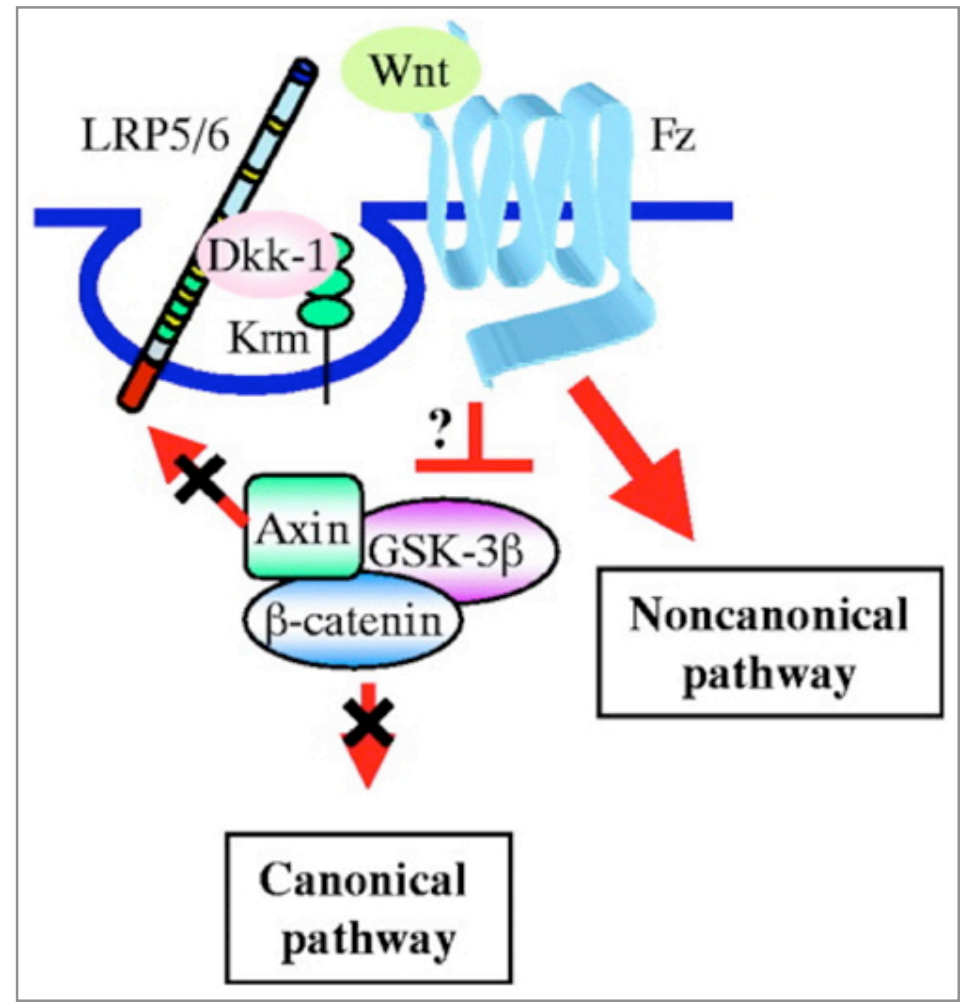

Abb. 1.6: Schematische Darstellung der Funktionsweise von Dkk Proteinen [modifiziert nach (Kawano und Kypta, 2003)]. Die Bindung von Dkk-1 an die Ko-Rezeptoren LRP5/6 und Kremen $(\mathrm{Krm})$ führt zur Internalisation des ternären Komplexes. Nur der kanonische Zweig der Wnt Signaltransduktion wird durch den Mangel an Ko-Rezeptoren inhibiert.

Dkk Proteine binden an den LRP5/6 Ko-Rezeptor, sowie an die Transmembranproteine Kremen1 und Kremen2 (Mao et al., 2002; Mao et al., 2001; Semenov et al., 2001). Der dadurch entstehende ternäre Komplex aus LRP5/6, Kremen und Dkk induziert die Endocytose des Komplexes und verringert die Anzahl an der Membran vorhandenen Wnt Rezeptoren (Mao et al., 2002). Dkk Proteine sind in der Lage, kanonische Wnt Signaltransduktion zu unterdrücken, während nichtkanonische Wnt Signale nicht auf LRP5/6 Ko-Rezeptoren angewiesen sind und in Folge dessen nicht inhibiert werden (Abb. 1.6).

\subsubsection{Die sFRP Klasse}

Zur Klasse der sogenannten „secreted Frizzled-related Proteins“ oder sFRPs zählen die sFRP Familie bestehend aus sFRP1 bis sFRP5, Sizzled, Sizzled2 und Crescent 
sowie die Proteine Cerberus und WIF-1. Die Mitglieder der sFRP Familie besitzen eine ähnliche Cystein-reiche Wnt-Bindedomäne wie die „seven-span“ Frizzled Transmembranrezeptoren (Abb. 1.7). Diese Wnt-Bindedomäne zeigt 30 bis $50 \%$ Sequenzidentität zu Frizzled Rezeptoren und weist zehn konservierte Cystein-Reste auf (Melkonyan et al., 1997). Die C-terminale Hälfte der sFRPs weist Ähnlichkeit zu Netrin auf, einem wichtigen Protein bei der axonalen Wegweisung. Eine solche Netrin-Homologiedomäne, bestehend aus zehn konservierten Cystein-Resten und hydrophoben Bereichen, wurde auch für Metalloproteasen und einige Komplementproteine beschrieben (Banyai und Patthy, 1999).

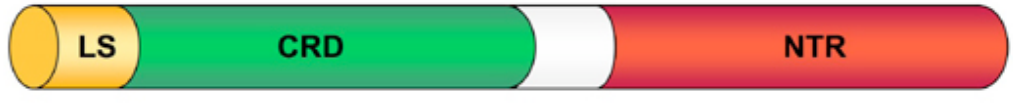

Frizzled

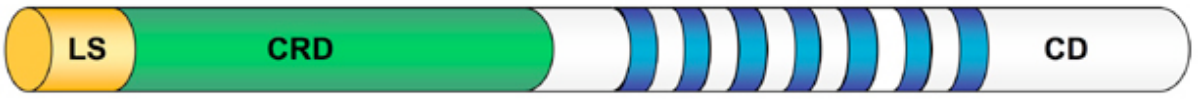

Abb. 1.7: Vergleich der Domänenstruktur von sFRP und Frizzled-Rezeptor Proteinen. Die sieben Transmembrandomänen der Frizzled Rezeptoren sind blau dargestellt. LS = Lokalisierungssequenz, CRD = Cystein-reiche Domäne, NTR = Netrin-Homologiedomäne $\mathrm{CD}=\mathrm{C}$-terminale Domäne

Basierend auf der Sequenzhomologie werden sFRP1, sFRP2 und sFRP5 sowie sFRP3 und sFRP4 jeweils als eine Untergruppe der sFRP Familie bezeichnet. Sizzled, Sizzled2 und Crescent bilden eine dritte Untergruppe (Pera und De Robertis, 2000). Für Sizzled und Sizzled2 wurde keine signifikante Interaktion mit Wnt Proteinen nachgewiesen, sie konnten als BMP-Antagonisten identifiziert werden (Lee et al., 2006).

Bei Cerberus handelt es sich um ein sekretiertes Protein, welches nicht nur Wnt, sondern auch TGF $\beta$-artige Signalmoleküle, wie beispielsweise BMP und Nodal, inhibieren kann (Piccolo et al., 1999) Cerberus weist eine sogenannte "cysteine-knot" Domäne auf, wie sie auch aus einigen Cytokinen bekannt ist (Piccolo et al., 1999). WIF-1 ist ein Wnt Antagonist, der keine Frizzled-homologe Domäne, sondern eine sogenannte WIF Domäne, wie sie auch in Rezeptor-Tyrosin-Kinasen der RYK Familie gefunden wurde, besitzt (Hsieh et al., 1999; Patthy, 2000). 


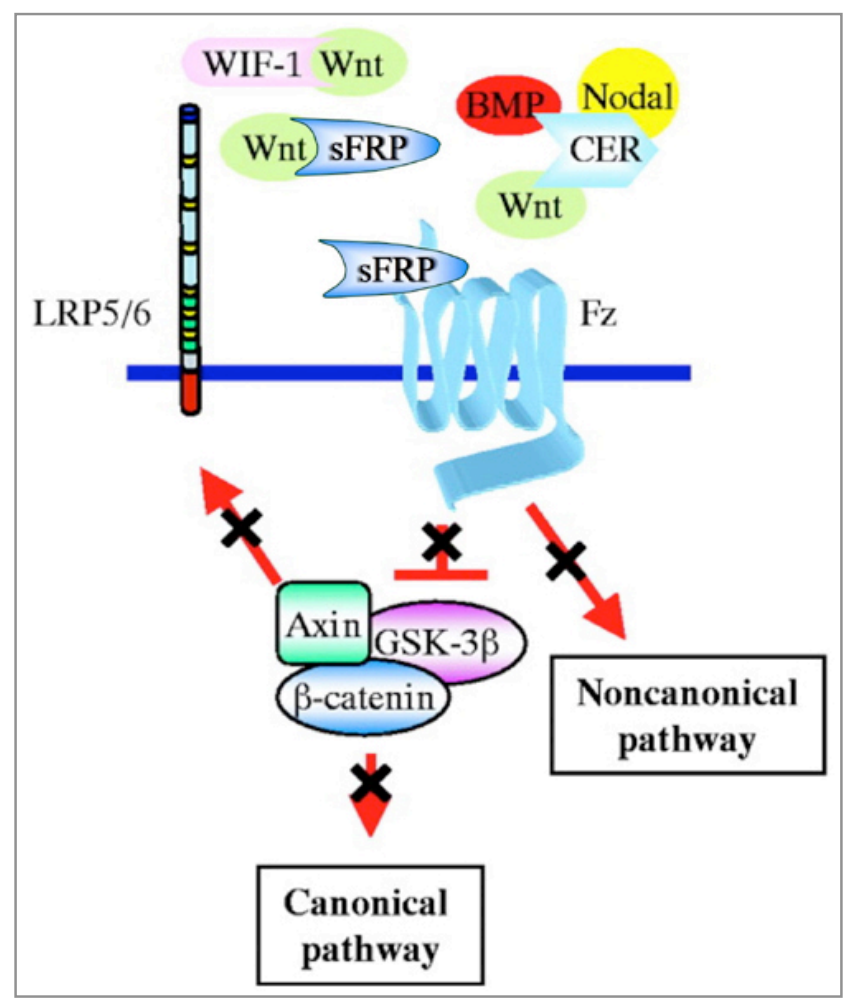

Abb. 1.8: Schematische Darstellung der Funktionsweise von „secreted Frizzledrelated" Proteinen [modifiziert nach (Kawano und Kypta, 2003)]. sFRP, WIF-1 und Cerberus (CER) Proteine binden im extrazellulären Raum direkt an ihre Liganden und verhindern dadurch die Entstehung funktionaler Rezeptor-Liganden-Komplexe. Sowohl kanonische als auch nicht-kanonische Wnt Signaltransduktion wird unterbunden.

Wie in Abb. 1.8 gezeigt, binden die sFRPs direkt an Wnt Proteine (Leyns et al., 1997; Xu et al., 1998), es konnte für sFRP1 jedoch auch die Interaktion mit einem Frizzled Rezeptor, humanem Fz6, gezeigt werden (Bafico et al., 1999). sFRP Proteine verhindern die Ausbildung eines funktionalen Wnt-Frizzled RezeptorKomplexes und sind so in der Lage, kanonische und nicht-kanonische Wnt Signale zu inhibieren (Abb. 1.8).

\subsubsection{3 sFRP5 Orthologe}

sFRP5 Orthologe wurden bereits in mehreren Modellorganismen beschrieben. Bovines sFRP5 wurde aus einer cDNA-Bank, welche für Transkripte des retinalen Pigmentepitheliums angereichert war, isoliert (Chang et al., 1999). In dieser Studie konnte eine moderate Inhibition von Xwnt8-vermittelter Achsenduplikation in Xenopus Embryonen durch Ko-Injektion von bovinem sFRP5 erzielt werden (Chang et al., 1999). Humanes sFRP5 (hSFRP5) wird ebenfalls in der Retina sowie im 
adulten Pankreas exprimiert (Chang et al., 1999). Xenopus sFRP5 wurde aus einer Herz-cDNA-Bank des Stadiums 46 gewonnen (Pilcher und Krieg, 2002). Die XsFRP5 Expression wurde in der Leberanlage sowie in Magen und Duodenum detektiert, wobei keine Expression von XsFRP5 während der Gastrulation festzustellen war (Pilcher und Krieg, 2002). Im Gegensatz dazu wird murines SFRP5 (Sfrp5) bereits während der Gastrulation im anterioren visceralen Entoderm (AVE) exprimiert (Finley et al., 2003). In späteren Stadien wird Sfrp5 in der Region des Entoderms exprimiert, welche die Leber hervorbringt (Finley et al., 2003). Kürzlich konnte jedoch in Sfrp5 „Knock-out“ Mäusen gezeigt werden, dass der Verlust von Sfrp5 keine Auswirkungen auf die Expression des Lebervorläuferzell-Markers Hex zeigt (Leaf et al., 2006).

\subsection{Die Rolle der Wnt Signaltransduktion bei der entodermalen Musterbildung in Vertebraten}

\subsubsection{Dorso-ventrale Achsenspezifikation in Xenopus Embryonen}

Der kanonische Wnt Signalweg konnte in vielen Modellorganismen als essentiell für die Achseninduktion identifiziert werden. So führt der Verlust von $\beta$-Catenin in der Maus zu Defekten in der anterior-posterioren Körperachse (Morkel et al., 2003), ebenso wie in Zebrafisch, wo der kanonische Wnt Signalweg durch den Einsatz eines dominant-negativen Frizzled Rezeptor blockiert wurde (Nasevicius et al., 1998). Diese Rolle des kanonischen Wnt Signalweges in der Achsenspezifizierung scheint evolutionär sehr konserviert zu sein, denn auch die Körperachsen der Seeanemone, welche der Gattung Cnidaria angehört, werden durch Wnt Signale determiniert (Wikramanayake et al., 2003).

In Xenopus kommt es nach dem Spermieneintritt in die animale Hälfte der Oocyte durch Mikrotubuli-Polymerisation zu einer direktionalen Verschiebung des vegetalen Kortex und des kortikalen Cytoplasmas in Richtung der prospektiven dorsalen Seite (Larabell et al., 1997). Dieser Prozess wird als kortikale Rotation bezeichnet. Schon länger ist bekannt, dass $\beta$-Catenin und Dishevelled Proteine durch die kortikale Rotation auf der dorsalen Seite angereichert werden und dort so zu einer Aktivierung 
kanonischer Wnt Signaltransduktion führen (Miller et al., 1999; Rowning et al., 1997). Außerdem ist bekannt, dass die GSK3 $\beta$ auf der dorsalen Seite des Embryos inhibiert wird (Dominguez und Green, 2000). Das legte die Vermutung nahe, dass der kanonische Wnt Signalweg auf der zukünftigen dorsalen Seite des Embryos durch einen extrazellulären Wnt Liganden aktiviert wird. Obwohl bislang ausschließlich der nicht-kanonischen Signalkaskade zugeordnet, konnte vor einigen Jahren Xwnt11 als vegetal lokalisierte Determinante des kanonischen Wnt Signalweges identifiziert werden. Nach der kortikalen Rotation löst sich die Xwnt11 mRNA aus der kortikalen Verankerung und diffundiert in das Cytoplasma der dorsalen Zellen. Dort bewirkt die Translation von Xwnt11 eine Aktivierung des kanonischen Signalweges (Tao et al., 2005).

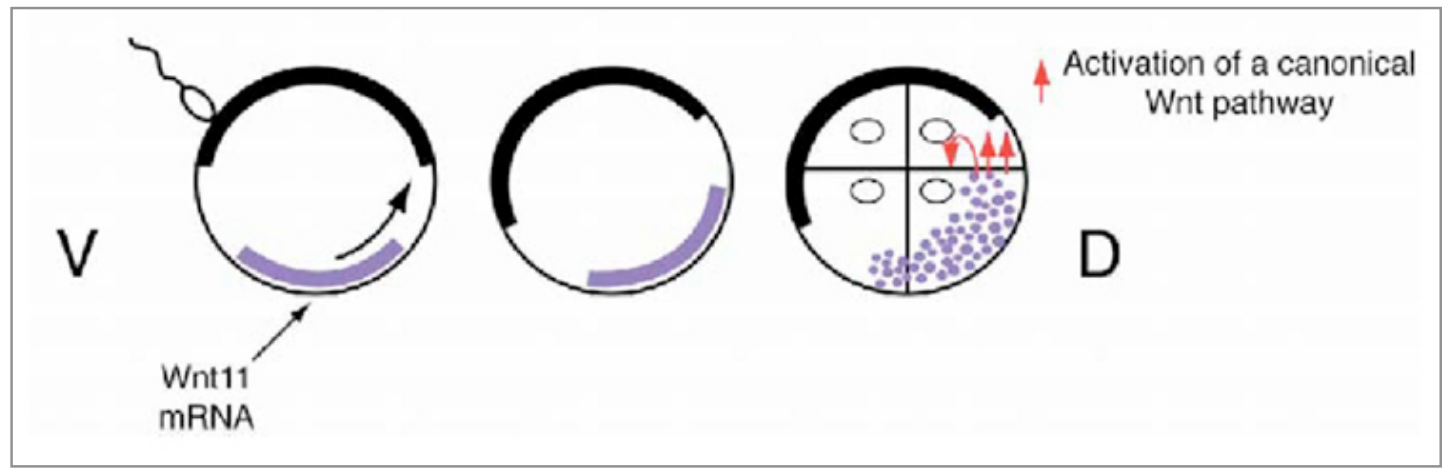

Abb. 1.9: Schematische Darstellung der dorso-ventralen Achseninduktion in Xenopus laevis (Tao et al., 2005). Vegetal lokalisierte Wnt11 mRNA wird im Zuge der kortikalen Rotation auf die prospektive dorsale Seite des Embryos transloziert. Die Wnt11 mRNA löst sich vom Kortex und diffundiert in das Cytoplasma der dorsalen Zellen. In frühen Teilungsstadien aktiviert das Wnt11 Protein (violette Punkte) den kanonischen Wnt Signaltransduktionsweg, wodurch es zu einer Stabilisierung von $\beta$-Catenin auf der doralen Seite des Embryos kommt.

Abb. 1.9 veranschaulicht das Prinzip der dorsalen Aktivierung des kanonischen Wnt Signalweges durch dorsal angereichertes Xwnt11 Protein in frühen Xenopus Teilungsstadien. Diese kanonische Signaltransduktion führt überlappend mit dem vegetalen Transkriptionsfaktor VegT und dem TGF $\beta$-artigen Liganden Vg1 zur Induktion des sogenannten Nieuwkoop Zentrums, welches wiederum durch die Sekretion von Nodal Faktoren im darüber liegenden Mesoderm den Spemann Organisator induziert. Werden Wnt Proteine, die in der Lage sind, den kanonischen Wnt Signalweg zu aktivieren, in frühen Teilungsstadien von Xenopus laevis ektopisch auf der ventralen Seite exprimiert, so hat dies die Ausbildung eines sekundären Nieuwkoop Zentrums zur Folge. Dadurch kommt es auch auf der 
ventralen Seite zur Induktion dorsaler Strukturen, welche sich in späteren Stadien durch die Duplikation der dorsal-anterioren Körperachse ausprägen (Sokol et al., 1991).

\subsubsection{Die Bedeutung der Wnt Signaltransduktion bei der Differenzierung des Gastrointestinaltrakts}

Die kanonische Wnt Signaltransduktion spielt für die Entwicklung vieler der entodermalen Organe, wie Leber, Lunge oder Pankreas, eine wichtige Rolle.

Beispielsweise konnte im Huhn gezeigt werden, dass Wnt3a über kanonische Wnt Signale die Größe und Form der entstehenden Leber wesentlich beeinflusst (Suksaweang et al., 2004). Aus Zebrafisch ist bekannt, dass mesodermal exprimiertes Wnt2b für die Proliferation hepatischer Vorläuferzellen essentiell ist (Ober et al., 2006).

Auch für die Pankreasentwicklung ließ sich ein regulatorischer Einfluss des Wnt Signalweges feststellen. So hat die Überexpression von $\beta$-Catenin in Mäuseembryonen zu einem frühen Zeitpunkt der Entwicklung (E11.5) pankreatische Hypoplasie zur Folge, während die ektopische Aktivierung des kanonischen Signalweges zu einem späteren Zeitpunkt der Entwicklung (E13.5) eine Überproliferation induziert (Heiser et al., 2006). Nach Verlust von $\beta$-Catenin durch konditionalen „Knock-Out“ wurden Defekte in der Entwicklung des exokrinen und auch des endokrinen Pankreas beschrieben (Dessimoz et al., 2005; Murtaugh et al., 2005). Aber auch für nicht-kanonische Wnt Signale konnte eine Funktion in der Pankreasentwicklung beschrieben werden. So ist die Wnt5a vermittelte Signaltransduktion essentiell für die Migration endokriner Vorläuferzellen im Zebrafisch (Kim et al., 2005b).

Die Inhibition der kanonischen Wnt Signaltransduktion scheint eine essentielle Rolle in der Lungenentwicklung zu spielen, da die Überexpression einer konstitutiv aktiven Form von $\beta$-Catenin im Lungenepithel von Mäuseembryonen die ektopische Expression intestinaler Markergene induzierte (Okubo und Hogan, 2004). Auch die Abgrenzung des Magens vom Duodenum bedarf der Inhibierung des Wnt 
Signalweges. Es konnte gezeigt werden, dass die vom HomöoboxTranskriptionsfaktor Barx1 induzierte Synthese und Sekretion der Wnt Antagonisten sFRP1 und sFRP2 zur Spezifizierung des Magen-Epithels notwendig ist (Kim et al., 2005a). Weiterhin führt ein gemeinsamer Funktionsverlust von TCF1 und TCF4 im Magen-Duodenumbereich zur anterioren Transformation (Gregorieff et al., 2004).

Zusammenfassend kann festgehalten werden, dass eine genaue räumliche und zeitliche Regulation der Wnt Signalwege durch sekretierte Antagonisten einen wesentlichen Beitrag zur Etablierung einzelner Organanlagen zu leisten scheint.

\subsection{Zielsetzung der Arbeit}

Im Rahmen dieser Arbeit soll die Rolle des sekretierten Wnt Antagonisten XsFRP5 während der Entwicklung entodermaler Organe in Xenopus Embryonen untersucht werden. Verschiedene Strategien wie Ko-Immunopräzipitation und Achsenduplikations-Experimente sollen Aufschluss über die Identität der mit XsFRP5 interagierenden Xwnt Proteine geben. Die Auswirkungen des Funktionsverlustes von XsFRP5 nach Injektion von „antisense” Morpholino Oligonukleotiden auf die Musterbildung des Gastrointestinaltrakts soll anhand der Expression entodermaler Markergene analysiert werden. Eine mögliche Korrelation dieser Daten mit Ergebnissen, welche durch die entodermale ektopische Aktivierung des kanonischen Wnt Signalwegs erzielt wurden, soll überprüft werden. Der Einfluss von ektopisch exprimiertem XsFRP5 auf die Embryonalentwicklung wird ebenfalls untersucht. Zusätzlich soll ein möglicher Zusammenhang zwischen $\Delta \mathrm{Np63 \alpha}$ und der kanonischen Wnt Signaltransduktion anhand von Achsenduplikations-Experimenten aufgeklärt werden. 


\section{Material}

\subsection{Organismen}

\subsubsection{Xenopus laevis}

Der afrikanische Krallenfrosch Xenopus laevis gehört zur Familie der zungenlosen Froschlurche (Pipidae) der Ordnung Anura. Pigmentierte und Albinofrösche wurden von der Firma Nasco (Ft. Atkinson, USA) erworben und gemäß den Tierschutzbestimmungen gehalten und behandelt. Die Bestimmung der Embryonalstadien erfolgte nach Nieuwkoop und Faber, 1967.

\subsubsection{Escherichia coli}

Es wurde der folgende E. coli-Stamm von Stratagene $\mathrm{GmBH}$ (Heidelberg, Deutschland) verwendet:

XL1-Blue: recA1, endA1, gyrA96, thi-1, hsdR17, supE44, $\operatorname{relA1,~} \operatorname{lac}\left[\mathrm{F}^{\prime}\right.$ proAB, lacl ${ }^{q} \mathrm{Z} \Delta \mathrm{M} 15, \operatorname{Tn} 10\left(\right.$ Tet $\left.\left.^{\mathrm{r}}\right)\right]^{\mathrm{c}}$

\subsection{Chemikalien}

Chemikalien wurden von folgenden Firmen bezogen:

Biomol, Boehringer Mannheim, Gibco BRL, Merck, Roche, Roth, Sigma-Aldrich

\subsection{Gebrauchswaren und Geräte}

Gebrauchswaren und Geräte wurden von folgenden Firmen bezogen:

Applied Biosystems, Biometra, Eppendorf, Falcon, Heinemann, Heraeus, Granich, Liebherr, Mytrom, Qiagen, Sarstedt, Sartorius, Scientific Industries, Schott, Schütt, Sorvall, Zeiss, Ziegra

\subsection{Computer-Software}

Textverarbeitung: Microsoft Office 2004 
Bild- und Graphikbearbeitung: Adobe Photoshop 7.0, ImageQuant Version 5.2 (Amersham Biosciences)

Nukleotid- und Aminosäuresequenzbearbeitung: VectorNTI (Invitrogen)

Blast-Datenbanksuchmaschine: (Altschul et al., 1990)

\subsection{Enzyme}

Alle Restriktionsendonukleasen wurden von Fermentas bezogen.

CIAP (Calf Intestinal Alkaline Phosphatase): Fermentas

GoTaq DNA-Polymerase: Promega Deutschland GmbH

Pfu DNA-Polymerase: Stratagene

Pyrophosphatase: Roche

T4 DNA-Ligase: Fermentas

Sp6, T3 und T7 RNA-Polymerasen: Stratagene $\mathrm{GmbH}$

Reverse Transkriptase: Roche

RNase A, RNase T1: Fermentas

RNase-Out: Invitrogen

\subsection{Molekulargewichtsstandards}

\subsubsection{DNA Marker}

FastRuler $^{\mathrm{TM}}$ DNA Ladder (low range, middle range, high range), Fermentas (St. Leon-Roth)

\subsubsection{Protein Marker}

Precision Plus Protein Dual Color Proteinmolekulargewichtsstandard, Biorad (München) 


\subsection{Reaktionssysteme (Kits)}

\subsubsection{DNA}

QIAprep ${ }^{R}$ PCR Purification Kit: Qiagen $\mathrm{GmbH}$

QIAEX ${ }^{R}$ Gel Extraction Kit: Qiagen $\mathrm{GmbH}$

QIAquick $^{R}$ Spin Mini Kit: Qiagen $\mathrm{GmbH}$

QIAGEN Plasmid Mini / Midi Kit: Qiagen GmbH

illustra $^{T M}$ GFX ${ }^{T M}$ PCR DNA und Gel Bund Purification Kit: GE Healthcare

illustra $^{T M}$ plasmidPrep Mini Spin Kit: GE Healthcare

pGEM ${ }^{R}$-T / pGEM ${ }^{R}$-Teasy Kit: Promega Deutschland GmbH

$\mathrm{T}_{\mathrm{n}} \mathrm{T}$-Coupled Reticulocyte Lysate System: Promega Deutschland GmbH

Big Dye Terminator Kit: Applied Biosystems

\subsubsection{RNA}

RNAqueous ${ }^{\mathrm{R}}$-Micro Kit: Ambion Inc.

Sp6, T3 und T7 mMESSAGE mMACHINE Kit: Ambion Inc.

RNeasy ${ }^{R}$ Mini Kit: Qiagen $\mathrm{GmbH}$

illustra $^{T M}$ RNA Spinmini Kit: GE Healthcare

\subsubsection{Proteine}

SuperSignal ${ }^{R}$ West Dura Extended Duration Substrate: Pierce Biotechnology

\subsection{Vektoren und Konstrukte}

\subsection{1 pGEM-T und Derivate}

pGEM ${ }^{R}-T$ und pGEM ${ }^{R}$-Teasy: Promega Deutschland GmbH. 


\subsection{2 pCS2+ und Derivate}

pCS2+: Dieser Vektor eignet sich zur Expression mikroinjizierter DNA und RNA in Xenopus Embryonen sowie zur in vitro Transkription und Translation. (http://sitemaker.umich.edu/dlturner.vectors).

pCS2+/MT: Dieses Derivat von pCS2+ enthält sechs N-terminale c-Myc Epitope (Rupp et al., 1994).

pCS2+/3'HA: Das Hämagglutinase-Epitop (HA-Tag) wurde, wie unter Punkt 3.2.7 beschrieben, in das mit Xbal linearisierte und dephosphorylierte pCS2+ Plasmid ligiert. Durch die Ligation der 3' Bcul-Schnittstelle des dimerisierten HA-Fragments in die Xbal-Schnittstelle von pCS2+ ging diese Restriktionsschnittstelle verloren. Die 5' gelegene Xbal-Schnittstelle blieb erhalten und konnte in Folge zur Insertion verschiedener Fragmente N-terminal zum HA-Epitop benutzt werden.

pCS2+/5'GR: Die Ligandenbindedomäne (LBD) des humanen Glucocorticoidrezeptors (GR) wurde durch PCR (GR-BamHI-fw: 5'-CGG ATC CAT GAC CTC TGA AAA TCC TGG TAA C-3', GR-Clal-rev: 5'-CCA TCG ATC TTT TGA TGA AAC AGA AG-3') amplifiziert, verdaut und in den mit BamHI und Clal geschnittenen und dephosphorylierten pCS2+ Vektor ligiert. Die GR-LBD enthält ein Startkodon.

pCS2+/GR: Die GR-LBD wurde in die Xhol / Xbal-Schnittstellen des pCS2+ Vektors kloniert (Y. Chen, unveröffentlicht).

\subsection{3 Überexpressionskonstrukte und Konstrukte für whole-mount in situ Hybridisierungssonden}

Die jeweiligen Schnittstellen für Restriktionsendonukleasen in den PCROligonukleotiden sind fett gedruckt. 


\subsubsection{Konstrukte, die im Rahmen dieser Arbeit erhalten oder generiert wurden}

pCDNA3/XsFRP2: Dieses Konstrukt enthält den kompletten offenen Leserahmen (ORF) von Xenopus sFRP2 (NM_001087194; Pera und DeRobertis, 2000). Zur Mikroinjektion geeignete CapRNA wurde vom Xhol-linearisierten Plasmid unter Verwendung der T7 Polymerase synthetisiert. Eine „antisense” DIG-markierte Sonde für die in situ Hybridisierung wurde vom EcoRI-linearisierten Plasmid duch die SP6 Polymerase synthetisiert.

pBSK/XsFRP5: Der gesamte offene Leserahmen (ORF) von Xenopus sFRP5 im pBSK-Vektor wurde von Paul Krieg erhalten (Pilcher und Krieg, 2002). Die „Accession“-Nummer von XsFRP5 in der NCBI-Datenbank lautet AY164461.

pCS2+/XsFRP5: Der ORF von XsFRP5 (AY164461) wurde mittels PCR aus pBSK/XsFRP5 amplifiziert, mit Clal / Xhol geschnitten und in den mit Clal / Xhol geschnittenen und dephosphorylierten pCS2+ Vektor ligiert. Die eingesetzten Oligonukleotide waren XsFRP5-EcoRI-fw (5'- CCA TCG ATA TGC GAT TTC AGT GGA ATA ATT TTT G-3') und XsFRP5-Xhol-rev (5'- CCG CTC GAG CGG AAG GAA CCC AAG TGT GAT CC-3'). Die in vitro Transkription von CapRNA erfolgte mit der SP6 Polymerase vom Notl-geschnittenen Plasmid.

pCS2+/XsFRP5-HA: Das Hämagglutinase-Epitop (HA-Tag) wurde, wie unter Punkt 3.2.7 beschrieben, in das mit Xbal geschnittene und dephosphorylierte pCS2+/XsFRP5 Konstrukt ligiert. Die das HA-Epitop enthaltenden Oligonukleotide waren HA-Xbal/Bcul-fw (5'- CTA GAC TAC CCT TAC GAT GTA CCG GAT TAC GCA A -3') und HA-Xbal/Bcul-rev (5'- CTA GTT GCG TAA TCC GGT ACA TCG TAA GGG TAG T -3'). Für die in vitro Synthese von CapRNA wurde das Konstrukt mit Notl geschnitten und durch die SP6 Polymerase abgelesen.

pCMV-SPORT6-5512233: Dieser Vollängenklon wurde bei Open Biosystems bestellt (Katalognummer MXL1736-9506888) und enthält den gesamten offenen Leserahmen (ORF) von Xenopus sFRP5 (CF285348.1). 
pCS2+/UTR-MT-UFP: Der 5' untranslatierte Bereich (UTR) von Xenopus sFRP5 (AY164461) wurde mit den folgenden Oligonukleotiden aus pCMV-SPORT65512233 amplifiziert: 5'UTR_BamHI_fw (CGGATCCTCTCTCCTTACAGCTG) und 5'UTR_BamHI_rev (CGGATCCGTATCGCATGATTTCTC). Der 5' UTR wurde „in frame" zum Startkodon des Myc-Epitops in die BamHI-Schnittstelle des pCS2+/MTUFP Vektors ligiert. Für die Synthese von CapRNA wurde das Plasmid mit Notl geschnitten und mit der SP6 Polymerase abgelesen.

pGEMT/XsFRP5: Der XsFRP5 ORF wurde PCR-amplifiziert (XsFRP5-5'-Clal: 5'CCA TCG ATA TGC GAT TTC AGT GGA ATA ATT TTT G-3', XsFRP5-3'-Xhol: 5'CCG CTC GAG CGG AAG GAA CCC AAG TGT GAT CC-3') und nach Herstellerangaben in den $\mathrm{PGEM} \mathrm{R}^{\mathrm{R}} \mathrm{T}$ Vektor kloniert.

pCS2+/hFz5: Der komplette ORF des humanen Frizzled 5 Rezeptor (NM_003468; He et al., 1997) wurde von Michael Kühl erhalten. Für die Transkription von CapRNA wurde das Plasmid mit Nsil linearisiert und durch die SP6 Polymerase abgelesen.

pXT7/Xwnt2b: Der komplette ORF von Xenopus Wnt2b entstammt dem Labor von Sergei Sokol (Landesman und Sokol, 1997). Für die Transkription von CapRNA wurde das Plasmid mit Sall geschnitten und durch die T7 Polymerase abgelesen. Für die in vitro Transkription einer Digoxigenin-markierten Sonde wurde das Plasmid mit HindIII geschnitten und durch die SP6 Polymerase abgelesen.

pCS2+/MT-Xwnt2b: Der Xenopus Wnt2b ORF wurde aus dem pXT7/Xwnt2b Konstrukt mittels PCR amplifiziert. Die verwendeten Oligonukleotid-Sequenzen lauten myc-Xwnt2b-EcoRI-fw (5'- CCG AAT TCA ATG CAT TTT GCT TAT ATT TTA ATA C-3') und myc-Xwnt2b-Xhol-rev (5'- CAC TCG AGT GTT TGG TCT AGC CAT TC-3'). Das geschnittene PCR-Produkt wurde in den mit EcoRI / Xhol geschnittenen und dephosphorylierten pCS2+/MT Vektor ligiert. Für die in vitro Synthese von CapRNA wurde das Konstrukt mit Notl geschnitten und durch die SP6 Polymerase abgelesen. 
pCS2+/MT-Xwnt3a: Der Xenopus Wnt3a ORF wurde mittels folgender Oligonukleotide aus pGEM ${ }^{\mathrm{R}}-2 / \mathrm{Wnt}-3 a$ (Wolda et al., 1993) durch PCR amplifiziert: myc-Xwnt3a-EcoRI-fw (5'- CGA ATT CAA TGG GCT GCT TTG GST ATT TG-3') und myc-Xwnt3a-Xbal-rev (5'- CCT CTA GAC TTG CAG GTG TGA ACG TC-3'). Das geschnittene PCR-Produkt wurde in das mit EcoRI / Xbal geschnittene und dephosphorylierte pCS2+/MT Plasmid ligiert. Zur in vitro Synthese von CapRNA wurde das Konstrukt mit Notl geschnitten und durch die SP6 Polymerase abgelesen.

pSP64T/Xwnt4-MT: Dieses Konstrukt enthält den ORF von Xenopus Wnt4 (NM_001087728) und stammt aus dem Labor von Randy Moon (Maurus et al., 2005). Es enthält ein C-terminales Myc-Epitop. Vom Sall-geschnittenen Plasmid wurde mittels der SP6 Polymerase CapRNA geschrieben.

pCS2+/MT-Xwnt4: Der Xenopus Wnt4 ORF wurde mittels PCR aus pSP64T/Xwnt4MT amplifiziert. Die verwendeten Oligonukleotide sind myc-Xwnt4-Xhol-fw2 (5'- GAT CT GAG ATG ACC CCA GAG T-3') und myc-Xwnt4-Xbal-rev (5'- CAT CTA GAC CGG CAT GTG TGC ATT TC-3'). Das geschnittene PCR-Produkt wurde in das mit Xhol und Xbal geschnittene und dephosphorylierte pCS2+/MT Plasmid ligiert. CapRNA wurde von dem Notl-geschnittenen Plasmid durch die SP6 Polymerase synthetisiert.

pSP64T/Wnt5a: Dieses Konstrukt mit dem kompletten Xenopus Wnt5a ORF wurde von Moon et al. (1993) publiziert und von Michael Kühl erhalten. Zur in vitro Synthese von CapRNA wurde das Konstrukt mit Xbal geschnitten und durch die SP6 Polymerase abgelesen.

pCS2+/MT-Xwnt5a: Der Xenopus Wnt5a ORF wurde durch PCR aus pSP64T/Wnt5a mit den Oligonukleotiden 5'-Xwnt5a-EcoRI-fw (5'- CGA ATT CAA TGA GAA AGA ATC TGT G-3') und $3^{\prime}-X$ wnt5a-Xhol-rev (5'- CAC TCG AGC TAC TTG CAT GCA AAC TG-3') amplifiziert. Das geschnittene PCR-Produkt wurde in das mit EcoRI und Xhol geschnittene und dephosphorylierte pCS2+/MT Plasmid ligiert. CapRNA wurde vom Notl-geschnittenen Plasmid durch die SP6 Polymerase synthetisiert. 
pCS2+/MT-Xwnt8: Der Xenopus Wnt8 ORF wurde aus pSP64T/X-wnt8-myc (Christian et al., 1991) mit den Oligonukleotiden myc-Xwnt8_EcoRI_fw (CCG AAT TCA ATG CAA AAC ACC ACT TTG) und myc-Xwnt8_Xhol_rev (CAC TCG AGT CTC CGG TGG CCTCTG TTC) PCR-amplifiziert, geschnitten und in den ebenfalls mit EcoRI / Xhol-geschnittenen pCS2+/MT Vektor ligiert. Für die in vitro CapRNA Synthese wurde das Plasmid mit Notl linearisiert und durch die SP6 Polymerase abgelesen.

pSP64T/Xwnt8b: Dieses Konstrukt enthält den kompletten Xenopus Wnt8b ORF (NM_001090285) sowie die ersten 30 Aminosäuren von Xenopus Wnt8 als Nterminale Signalsequenz (Cui et al., 1995). CapRNA wurde von dem Sallgeschnittenen Plasmid durch die SP6 Polymerase synthetisiert.

pGEM/Xwnt8b(2.2): Dieses Konstrukt von Jan Christian enthält den Xenopus Wnt8b (Cui et al., 1995) ORF (NM_001090285). Um die in vitro Transkription einer Digoxigenin-markierten in situ Sonde zu ermöglichen, wurde das Plasmid mit Ncol geschnitten und mit der SP6 Polymerase abgelesen.

pCS2+/MT-Xwnt8b: Der Xenopus Wnt8b ORF (NM_001090285) wurde mit den Oligonukleotiden myc-Xwnt8b_Xhol_fw (CCC TCG AGA TGC AAA ACA CCACTT TG) und myc-Xwnt8b_Nhel_rev (CCC CGC TAG CAA GTT TCT TCT TAA G) PCRamplifiziert, restriktionsendonukleolytisch gespalten und in den ebenfalls mit Xhol / Xbal-geschnittenen pCS2+/MT Vektor ligiert.

pCS2+/MT-Xwnt11: Aus dem Plasmid pGEM $^{\mathrm{R}}-7$ Zf(+)/Wnt11 wurde der Xenopus Wnt11 ORF (Ku und Melton, 1993) mit folgenden Oligonukleotiden PCR-amplifiziert: myc-Xwnt11_EcoRI_fw (CGA ATT CAA TGG CTC CGA CCC GTC AC) und mycXwnt11_Xhol_rev (CAC TCG AGT TGC AGA CAT ACC TCT C). Das geschnittene PCR-Produkt wurde in den ebenfalls mit EcoRI / Xhol-geschnittenen pCS2+/MT Vektor ligiert. Die in vitro Transkription von CapRNA erfolgte vom Notl-linearisierten Plasmid durch die SP6 Polymerase.

pBS/Xwnt11R: Der Volllängen-cDNA Klon von Xenopus Wnt11R (NM_001093610) stammt aus dem Labor von Paul Krieg (Garriock et al., 2005). Eine Digoxigenin- 
markierte Sonde für die whole-mount in situ Hybridisierung wurde vom Notllinearisierten Plasmid mit T7 Polymerase hergestellt.

pCS2+/Xwnt11R: Der ORF von Xenopus Wnt11R (NM_001093610) wurde mit den Oligonukleotiden Xwnt11R_fw (CCC ATC GAT ATG AAG ATT TAT TTT CTG) und Xwnt11R_rev (CAC TCG AGT TTG CAC ACA TAC C) aus pBS/Xwnt11R amplifiziert, geschnitten und in den ebenfalls Clal / Xbal-geschnittenen pCS2+ Vektor ligiert. Die Transkription von CapRNA erfolgte von dem Notl-geschnittenen Plasmid durch die SP6 Polymerase.

pCS2+/MT-Xwnt11R: Mit Hilfe der Oligonuklotide myc-Xwnt11R_Xhol_fw (CAC TCG AGA TGA AGA TTT ATT TTC TG) und myc-Xwnt11R_Xbal_rev (CAT CTA GAT CAT TTG CAC ACA TAC CG) wurde der Xenopus Wnt11R ORF (NM_001093610) aus pBS/Xwnt11R amplifiziert, geschnitten und in den ebenfalls Xhol / Xbal-geschnittenen pCS2+/MT Vektor ligiert. Die Transkription von CapRNA erfolgte von dem Notl-geschnittenen Plasmid durch die SP6 Polymerase.

pSP64T/Lef1: Dieses Konstrukt enthält murines Lef1 [NM_010703; (Behrens et al., 1996)]. In vitro CapRNA konnte nach Linearisierung mit Xbal durch die SP6 Polymerase synthetisiert werden.

pCS2+/Lef1-GR: Murines Lef1 (NM_010703) wurde mit den Oligonukleotiden Lef1Clal-fw (5'-CAT CGA TAT GCC CCA ACT TTC CGG AG-3') und Lef1-Xhol-rev (5'GAC TCG AGG ATG TAG GCA GCT GTC ATT C-3') aus pSP64T/Lef1 amplifiziert, mit Clal und Xhol verdaut und in den ebenfalls geschnittenen und dephosphorylierten pCS2+/GR Vektor kloniert. CapRNA wurde nach Linearisierung mit Notl durch die SP6 Polymerase synthetisiert.

pSP64T/Lef $\triangle B D:$ Dieses Konstrukt enthält C-terminal trunkiertes, murines Lef1 [(NM_010703; Behrens et al., 1996)]. In vitro CapRNA konnte nach Linearisierung mit Xbal durch die SP6 Polymerase synthetisiert werden. 
pCS2+/Lef $\Delta$ BD-GR: Unter Verwendung der folgenden Oligonukleotide wurde $\mathrm{N}$ terminal trunkiertes, murines Lef1 (NM_010703) amplifiziert: Lef $\Delta \mathrm{BD}$-Clal-fw (5'-CAT CGA TAT GGG CCT GTA CAA CAA GG-3') und Lef1_Xhol_rev (5'-GAC TCG AGG ATG TAG GCA GCT GTC ATT C-3'). Das PCR-Produkt wurde mit Clal und Xhol geschnitten und in den ebenfalls geschnittenen und dephosphorylierten pCS2+/GR Vektor kloniert. CapRNA wurde nach Linearisierung mit Notl durch die SP6 Polymerase synthetisiert.

pSP64T/Lef $\triangle$ HMG: Dieses Konstrukt enthält N-terminal trunkiertes, murines Lef1 [(NM_010703; Behrens et al., 1996)]. In vitro CapRNA konnte nach Linearisierung mit Xbal durch die SP6 Polymerase synthetisiert werden.

pCS2+/Lef $\Delta$ HMG-GR: Durch Verwendung der folgenden Oligonukleotide wurde Cterminal trunkiertes, murines Lef1 (NM_010703) amplifiziert: Lef1_Clal_fw (5'-CAT CGA TAT GCC CCA ACT TTC CGG AG-3') und Lef1-Xhol-rev (5'-GAC TCG AGG ATG TAG GCA GCT GTC ATT C-3'). Das PCR-Produkt wurde mit Clal und Xhol geschnitten und in den ebenfalls geschnittenen und dephosphorylierten pCS2+/GR Vektor kloniert. CapRNA wurde nach Linearisierung mit Notl durch die SP6 Polymerase synthetisiert.

pCS2+/ $\beta$-CateninS33A: Murines $\beta$-Catenin (NM_007614) enthält mehrere Punktmutationen, welche zu den folgenden Aminosäuresäure-Substitutionen führen: Serin33 $\rightarrow$ Alanin, Serin37 $\rightarrow$ Alanin, Tyrosin41 $\rightarrow$ Alanin; und wird so nicht mehr der proteasomalen Degradation zugeführt (Aberle et al., 1997). CapRNA wurde nach Linearisierung mit Notl durch die SP6 Polymerase synthetisiert.

pCS2+/ $\beta$-CatS33A-GR: Stabilisiertes $\beta$-CateninS33A wurde mit Hilfe der Oligonukleotide $\beta$-CatS33A-BamHI-fw (5'-CGG ATC CAT GGC TAC TCA AGC TG$\left.3^{\prime}\right)$ und $\beta$-CatS33A-Clal-rev (5'-CAT CGA TCA GGT CAG TAT CAA ACC-3') amplifiziert, mit BamHI und Clal geschnitten und in den ebenfalls geschnittenen und dephosphorylierten pCS2+/GR Vektor ligiert. CapRNA wurde nach Linearisierung mit Notl durch die SP6 Polymerase synthetisiert. 


\subsubsection{Konstrukte zur Herstellung von CapRNA oder markierten „antisense” Sonden aus dem Laborbestand}

Tabelle 2.1: Konstruktliste zur in vitro Transkription von CapRNA (sense) und Digoxigenin-markierten Sonden ("antisense")

\begin{tabular}{|c|c|c|c|}
\hline Konstrukt & Referenz & $\begin{array}{l}\text { Linearisierung } \\
\text { mit }\end{array}$ & $\begin{array}{c}\text { Transkription } \\
\text { mit }\end{array}$ \\
\hline $\mathrm{pCS} 2+/ \Delta \mathrm{Np} 63 \alpha$ & Y. Chen, unveröffentlicht & Notl & SP6 („sense“) \\
\hline $\mathrm{pCS} 2+/ \beta-\mathrm{Gal}$ & (Bier et al., 1989) & Notl & SP6 („,sense“) \\
\hline pGEMT/Nkx2.1 & (Hollemann und Pieler, 2000) & Notl & T7 (,antisense”) \\
\hline pGEMT/XPtf1a/p48 & (Afelik et al., 2006) & Notl & T7 (,antisense”) \\
\hline pGEMT/XIHbox8 & (Afelik et al., 2006) & Notl & T7 („,antisense”) \\
\hline $\mathrm{pBSK} / \mathrm{Hex}$ & (Newman et al., 1997) & Notl & T7 (,antisense”) \\
\hline pBK-CMV/XPDIp & (Afelik et al., 2004) & BamHI & T7 (,antisense”) \\
\hline pCS2+/fibrinogen $\alpha$ & (Chen et al., 2003) & Ncol & T3 (,antisense”) \\
\hline pBSK/Sox2 & (Chalmers et al., 2000) & EcoRI & T7 (,antisense”) \\
\hline
\end{tabular}

\subsection{Oligonukleotide}

\subsubsection{RT-PCR Oligonukleotide}

Die Oligonukleotide wurden in einer Konzentration von $100 \mu \mathrm{M}$ in $\mathrm{dH}_{2} \mathrm{O}$ bei $-20^{\circ} \mathrm{C}$ gelagert.

Tabelle 2.2: Liste aller in dieser Arbeit zur Anwendung gekommener Oligonukleotide für die RT-PCR Analyse

\begin{tabular}{|c|c|c|c|}
\hline Name & $5^{\prime}-3^{\prime}$ Sequenz & $\mathrm{T}_{\mathrm{M}}\left({ }^{\circ} \mathrm{C}\right)$ & Zyklenzahl \\
\hline XsFRP5 vorwärts & AGGTCCTTAAAGCAGGGAAG & \multirow{2}{*}{60} & \multirow{2}{*}{36} \\
\hline XsFRP5 rückwärts & GCGATGGTGGCACTTAAAG & & \\
\hline Histon H4 vorwärts & CGGGATAACATTCAGGGTATCACT & \multirow{2}{*}{56} & \multirow{2}{*}{26} \\
\hline Histon H4 rückwärts & ATCCATGGCGGTAACTGTCTTCCT & & \\
\hline XTwist vorwärts & AGAACCTGGAGCTGGATC & \multirow{2}{*}{56} & \multirow{2}{*}{30} \\
\hline XTwist rückwärts & GGCTTCAAAGGCACGACT & & \\
\hline Ptf1a/p48 vorwärts & GAGAAGCGACTGTCCAAG & \multirow{2}{*}{54} & \multirow{2}{*}{33} \\
\hline Ptf1a/p48 rückwärts & CATCAGTCCATGAGAGAG & & \\
\hline
\end{tabular}




\begin{tabular}{|c|c|c|c|}
\hline Name & $5^{\prime}-3^{\prime}$ Sequenz & $\mathrm{T}_{\mathrm{M}}\left({ }^{\circ} \mathrm{C}\right)$ & Zyklenzahl \\
\hline XIHbox8 vorwärts & ААТССАССАААТСССАСАССТ & \multirow{2}{*}{56} & \multirow{2}{*}{36} \\
\hline XIHbox8 rückwärts & GCCTCAGCGACCCAATAGAA & & \\
\hline Insulin vorwärts & ATGGCTCTATGGATGCAGTG & \multirow{2}{*}{56} & \multirow{2}{*}{35} \\
\hline Insulin rückwärts & AGAGAACATGTGCTGTGGCA & & \\
\hline XPDIp vorwärts & GGAGGAAAGAGGGACCAA & \multirow{2}{*}{60} & \multirow{2}{*}{33} \\
\hline XPDIp rückwärts & GCGCCAGGGCAAAAGTG & & \\
\hline Hex vorwärts & GGTTCCAGAACAGAAGAG & \multirow{2}{*}{56} & \multirow{2}{*}{30} \\
\hline Hex rückwärts & CCTTTGTCGCCTTCAATG & & \\
\hline Ttr vorwärts & GGAATCCCCGCTGCCAATC & \multirow{2}{*}{56} & \multirow{2}{*}{36} \\
\hline Ttr rückwärts & ATGAGAAGGAGTAGGGGGTGAGC & & \\
\hline Sox2 vorwärts & GAGGATGGACACTTATGCCCAC & \multirow{2}{*}{59} & \multirow{2}{*}{26} \\
\hline Sox2 rückwärts & GGACATGCTGTAGGTAGGCGA & & \\
\hline Xwnt2b vorwärts & ACTGGGAGCAAGGGTTATCTGTG & \multirow{2}{*}{65} & \multirow{2}{*}{32} \\
\hline Xwnt2b rückwärts & GCCCGTGCATCTTTCAATCTTTTC & & \\
\hline Xwnt3a vorwärts & TTGCGCTGAGGGATCTGCTACC & \multirow{2}{*}{65} & \multirow{2}{*}{32} \\
\hline Xwnt3a rückwärts & CCCCGGGATTCTCGATGTTTCT & & \\
\hline Xwnt4 vorwärts & ACTGGCTGTACCTGGCAAAACTGT & \multirow{2}{*}{65} & \multirow{2}{*}{32} \\
\hline Xwnt4 rückwärts & AAATGACTGGGAAAAGGCGACTC & & \\
\hline Xwnt5a vorwärts & TGGGCTATCGCAGGGTCAGAAGAA & \multirow{2}{*}{70} & \multirow{2}{*}{32} \\
\hline Xwnt5a rückwärts & CACAGCCGCCCCATAGCCAGT & & \\
\hline Xwnt8 vorwärts & TGTGGCCGGGTCTGAACTTATTTT & \multirow{2}{*}{65} & \multirow{2}{*}{32} \\
\hline Xwnt8 rückwärts & GTCATCTCCGGTGGCCTCTGTTCT & & \\
\hline Xwnt8b vorwärts & CCGGACGAAAGGCAGTAAAGAGTA & \multirow{2}{*}{65} & \multirow{2}{*}{32} \\
\hline Xwnt8b rückwärts & TAACGGCTAAACCACAGTCACCAC & & \\
\hline Xwnt11 vorwärts & CCGGGTGGCCTGGAATGAGAGC & \multirow{2}{*}{65} & \multirow{2}{*}{32} \\
\hline Xwnt11 rückwärts & CACAGGCACGCGCAATGGTATGG & & \\
\hline Xwnt11R vorwärts & GATTCACGCAGCATAATGGC & \multirow{2}{*}{63} & \multirow{2}{*}{32} \\
\hline Xwnt11R rückwärts & GTGCTGGGTCTGATTCAACG & & \\
\hline
\end{tabular}

\subsubsection{Sequenzierungsoligonukleotide}

Die Oligonukleotide wurden in einer Konzentration von $100 \mu \mathrm{M}$ in $\mathrm{dH}_{2} \mathrm{O}$ bei $-20^{\circ} \mathrm{C}$ gelagert. 
Tabelle 2.3: Liste der in dieser Arbeit zur Anwendung gekommenen Sequenzierungsoligonukleotide

\begin{tabular}{|c|c|}
\hline Name des Oligonukleotides & $\mathbf{5}^{\prime} \mathbf{-} \mathbf{3}^{\prime}$ Sequenz des Oligonukleotides \\
SP6 & TTAGGTGACACTATAGAATAC \\
\hline T3 & AATTAACCCTCACTAAAGGG \\
\hline T7 (pCS2+) & TCTACGTAATACGACTCACTATAG \\
\hline T7 (pGEM-T) & TAATACGACTCACTATAGGGCGA \\
\hline SP6 (pCMV-Sport6) & CTATTTAGGTGACACTATAG \\
\hline T7 (pCMV-Sport6) & TAATACGACTCACGTATAGGG \\
\hline Lef1-internal 1 & GTC AGA TGT CAA CTC CAA GC \\
\hline Lef1-internal2 & GAA GCC TCA ACA CGA ACA GAG \\
\hline
\end{tabular}

\subsubsection{Morpholino Oligonukleotide}

Morpholino Oligonukleotide wurden von der Firma Gene Tools erworben. Die Morpholinos wurden in RNAse-freiem Wasser ad $300 \mathrm{mM}$ gelöst, aliquotiert und bei $80^{\circ} \mathrm{C}$ gelagert. Das ATG von Xenopus sFRP5 in der korrespondierenden Sequenz der Morpholino Oligonukleotide ist fett gedruckt. Die fünf „Missmatch“-Basen im MMXsFRP5-Morpholino sind unterstrichen dargestellt.

Tabelle 2.4: Liste der verwendeten „,antisense” Morpholino Oligonukleotide

\begin{tabular}{|c|c|}
\hline Name des Morpholinos & 5'-3' Sequenz des Morpholinos \\
\hline XsFRP5-Mo1 & ATCGCATGATTTCTCCAAAAAGTGG \\
\hline MM-XsFRP5-Mo1 & AT $\underline{G} G C A T \underline{C} A T \underline{A T C T C} \underline{G} A A A A A \underline{C} T G G$ \\
\hline XsFRP5-Mo2 & TTTAACCCAAAGGCTTATCCTCCTG \\
\hline
\end{tabular}

\subsection{Antikörper}

\subsubsection{Primäre Antikörper}

Tabelle 2.5: Aufstellung der zur Anwendung gebrachten primären Antikörper

\begin{tabular}{|c|c|c|c|c|}
\hline Antikörper & Firma & Katalognummer & WB & ColP \\
\hline Goat anti-Myc IgG & Abcam/Biozol & ab19234 & $1: 10.000$ & - \\
\hline Mouse anti-HA IgG & Covance & MMS-101 P & $1: 1.000$ & $1: 150$ \\
\hline Mouse anti-Actin IgG & Chemicon & MAB1501 & $1: 5.000$ & - \\
\hline
\end{tabular}




\subsubsection{Sekundäre Antikörper}

Tabelle 2.6: Aufstellung der zur Anwendung gebrachten sekundären Antikörper

\begin{tabular}{|c|c|c|c|}
\hline Antikörper & Firma & Katalognummer & WB \\
\hline Donkey anti-Goat IgG-HRP & Santa Cruz & sc-2020 & $1: 10.000$ \\
\hline Goat anti-Mouse IgG-HRP & Santa Cruz & sc-2005 & $1: 5.000$ \\
\hline
\end{tabular}

\subsection{Medien und Stammlösungen}

100x Denhardts: 2\% (w/v) BSA, 2\% (w/v) PVP, 2\% (v/v) Ficoll

DEPC- $\mathrm{H}_{2} \mathrm{O}: 0,1 \%$ (V/V) Diethylpyrocarbonat, vor dem Autoklavieren über Nacht rühren

EDTA-Lösung: 1M EDTA, pH 8,0

EGTA-Lösung: 0,5M EDTA

Ethidiumbromid-Lösung: $10 \mathrm{mg} / \mathrm{ml}$ Ethidiumbromid

Kaliumchlorid-Lösung: $1 \mathrm{M} \mathrm{KCl}$

Lithiumchlorid-Lösung: $4 \mathrm{M} \mathrm{LiCl}$

1M Tris-Puffer (pH 7,5 - 9,0): 1M Tris- $\mathrm{HCl}$

Tween 20-Lösung: 20\% (V/V) Tween

Magnesiumchlorid-Lösung: $1 \mathrm{M} \mathrm{MgCl}_{2} \cdot 6 \mathrm{H}_{2} \mathrm{O}$

Magnesiumsulfat-Lösung: $1 \mathrm{M} \mathrm{MgSO}_{4} 7 \mathrm{H}_{2} \mathrm{O}$

5M Natriumchlorid: $5 \mathrm{M} \mathrm{NaCl}$

SDS-Lösung: 10\% (w/v) Natrium-Dodecyl-Sulfat 


\section{Methoden}

\subsection{Arbeiten mit Bakterien}

\subsubsection{Anzuchtbedingungen}

Luria-Bertani-Medium: $32 \mathrm{~g} L B-M e d i u m ~ / ~ L ~ d H_{2} \mathrm{O}$ (autoklaviert, bei $4^{\circ} \mathrm{C}$ gelagert) Ampicillin: $100 \mu \mathrm{g} / \mathrm{ml} \mathrm{dH}_{2} \mathrm{O}$

E. coli Flüssigkulturen (LB / Amp) wurden bei $220 \mathrm{Upm}$ und $37^{\circ} \mathrm{C}$ über Nacht inkubiert. Die Anzucht von E. coli auf Agarplatten (LB / Amp) erfolgte bei $37^{\circ} \mathrm{C}$ über Nacht.

\subsubsection{Herstellung chemisch-kompetenter E. coli Zellen}

Chemisch-kompetente E. coli Zellen wurden nach der Hanahan-Methode hergestellt (Sambrook und Russel, 2001).

\subsubsection{Chemische Transformation von Bakterienzellen}

Die Transformation von Plasmid-DNA in chemisch-kompetente E. coli Zellen erfolgte wie in Sambrook und Russel (2001) beschrieben.

\subsubsection{Anlegen von Glyzerol-Stammkulturen}

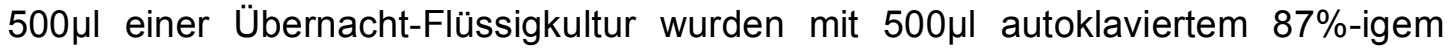
Glyzerol versetzt, gemischt und bei $-80^{\circ} \mathrm{C}$ aufbewahrt. 


\subsection{Arbeiten mit DNA}

\subsubsection{Präparation von Plasmid-DNA im analytischen und präparativen Maßstab}

\subsubsection{TELT-Präparation}

TELT-Lösung: 50mM Tris-HCl pH7,5, 62,5mM EDTA, 2,5M LiCl, 0,4\% Triton X-100

Lysozym: $10 \mathrm{mg} / \mathrm{ml}$ Lysozym in $\mathrm{dH}_{2} \mathrm{O}$

$3 \mathrm{ml}$ einer Übernachtkultur wurden abzentrifugiert und das Sediment anschließend in $150 \mu \mathrm{l}$ TELT-Lösung resuspendiert. Nach Zugabe von 15 $\mu \mathrm{l}$ Lysozym wurde der Ansatz 5 Minuten bei Raumtemperatur, 2 Minuten bei $90^{\circ} \mathrm{C}$ und anschließend 5 Minuten auf Eis inkubiert. Nach einer zehnminütigen Zentrifugation in einer Tischzentrifuge wurde der Überstand in ein neues Röhrchen überführt und die DNA durch Zugabe von $150 \mu \mathrm{l}$ Isopropanol bei $-20^{\circ} \mathrm{C}$ ausgefällt. Nach 30 Minuten Zentrifugation wurde das Sediment mit 500 $\mu$ l 70\% Ethanol gewaschen. Nach erneuter Zentrifugation wurde der Überstand verworfen und das Sediment bei Raumtemperatur getrocknet. Die DNA wurde in P1 Puffer von Qiagen aufgenommen und 2 Stunden bei RT inkubiert. Anschließend wurde die RNA ein weiteres Mal in Isopropanol ausgefällt, mit Ethanol gewaschen und das Sediment in $\mathrm{dH}_{2} \mathrm{O}$ aufgenommen.

\subsubsection{Mini-Präparation}

Die Präparation von DNA aus einer $5 \mathrm{ml}$ Übernachtkultur erfolgte mittels des QIAGEN Plasmid Mini / Midi Kit (Qiagen $\mathrm{GmbH}$ ) nach Herstellerangaben.

\subsubsection{Midi-Präparation}

Die Präparation von DNA aus einer $50 \mathrm{ml}$ Übernachtkultur erfolgte mittels des QIAGEN Plasmid Mini / Midi Kit (Qiagen $\mathrm{GmbH}$ ) nach Herstellerangaben. Die erhaltene Plasmid-DNA wurde auf eine Konzentration von $1 \mu \mathrm{g} / \mu \mathrm{l}$ verdünnt. 


\subsubsection{Konzentrationsbestimmung von Nukleinsäuren}

Die Konzentration von DNA- und RNA-Lösungen wurde in einem Spektralphotometer (Amersham Biosciences) bei 260nm Wellenlänge gegen einen Leerwert ermittelt. Die Konzentration ergab sich aus der $\mathrm{OD}_{260}$ wie folgt:

$\mathrm{OD}_{260}=1 \quad$ entspricht $50 \mu \mathrm{g}$ dsDNA

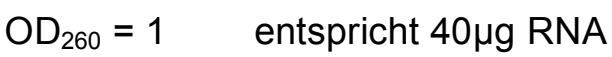

Es wurde das automatische Programm des Photometers genutzt, um die Konzentration zu bestimmen. Um eine Kontamination der Nukleinsäure-Lösung mit Proteinen auszuschließen, sollte der Quotient von $O D_{260} / O D_{280}$ zwischen 1,8 für DNA und 2,0 für RNA liegen.

\subsubsection{Nicht-denaturierende Agarose-Gelelektrophorese}

10x TAE: 400mM Tris Base, 200mM Essigsäure, 1mM EDTA

Gelauftragspuffer: $30 \%(\mathrm{v} / \mathrm{V})$ Glyzerol, 0,25\% Bromphenolblau, 0,25\% Xylencyanol in $\mathrm{dH}_{2} \mathrm{O}$

Die Agarose-Gele (1 - 2\%) wurden nach Sambrook und Russel (2001) hergestellt. Nach der Auftrennung der DNA- oder RNA-Proben wurden diese durch die Inkorporation von Ethidiumbromid sichtbar gemacht.

\subsubsection{Isolierung von DNA-Fragmenten aus Agarosegelen}

Die Isolierung von DNA aus Agarosegelen erfolgte mit dem QIAEX ${ }^{R}$ Gel Extraction Kit (Qiagen $\mathrm{GmbH}$ ) und dem illustra ${ }^{\mathrm{TM}} \mathrm{GFX}^{\mathrm{TM}}$ PCR DNA und Gel Bund Purification Kit (GE Healthcare) nach Herstellerangaben.

\subsubsection{Aufreinigung von PCR Fragmenten und Restriktionsansätzen}

Die Aufreinigung von PCR Fragmenten und Restriktionsansätzen erfolgte mit dem QIAprep $^{R}$ PCR Purification Kit (Qiagen $\mathrm{GmbH}$ ) sowie dem illustra ${ }^{\mathrm{TM}}$ GFX $^{\mathrm{TM}}$ PCR DNA und Gel Bund Purification Kit (GE Healthcare) nach Herstellerangaben. 


\subsubsection{Restriktionsendonukleolytische Spaltung von DNA}

\subsubsection{Spaltung von PCR-Termini}

Die Klonierungsprimer waren entsprechend der Tabelle 1.21. „Cleavage Efficiency Close to the Termini of PCR Fragments“ (Fermentas Katalog, 2006/2007) mit 5' Überhängen versehen worden. Nach einer Aufreinigung der PCR-Produkte erfolgte die endonukleolytische Spaltung über Nacht.

\subsubsection{Spaltung von Vektoren und Plasmiden}

Zur analytischen wie präparativen Restriktionsspaltung von DNA wurde diese mit $1 U$ bis maximal $5 \mathrm{U}$ einer Restriktionsendonuklease im entsprechenden 10x Reaktionspuffer bei $37^{\circ} \mathrm{C}$ für mindestens 1 Stunde inkubiert.

\subsubsection{Linearisierung von „sense“ und ",antisense“ Matrizen für die RNA- Synthese}

$10 \mu \mathrm{g}$ „Template“-DNA wurde in einem $50 \mu \mathrm{l}$ Ansatz mit $4 \mathrm{U}$ des entsprechenden Restriktionsenzyms sowie des mitgelieferten 10x Puffers (Fermentas) über Nacht bei $37^{\circ} \mathrm{C}$ inkubiert.

\subsubsection{Dephosphorylierung von DNA-Fragmenten}

Um die Religation kompatibler DNA-Enden zu verhindern, wurden die Vektoren während des Restriktionsverdaus mit 1 U CIAP (Calf Intestinal Alkaline Phosphatase) inkubiert (Sambrook und Russel, 2001).

\subsubsection{Oligomerisierung kurzer DNA-Fragmente}

Kurze Oligonukleotide, die mit überhängenden Enden versehen waren, wurden separat in einer Kinase-Reaktion phosphoryliert: 


$\begin{array}{ll}\text { Oligonukleotid }(5 \mu \mathrm{g} / \mu \mathrm{l}) & 2 \mu \mathrm{l} \\ \text { 10x Puffer }(+\mathrm{ATP}) & 2 \mu \mathrm{l} \\ \text { HPLC- } \mathrm{H}_{2} \mathrm{O} & 15 \mu \mathrm{l} \\ \text { PNK NEB T4 Kinase } & 1 \mu \mathrm{l}\end{array}$

Die Kinase-Reaktion wurde wie folgt im Thermozykler durchgeführt:

$\begin{array}{ll}30 \text { Minuten } & 37^{\circ} \mathrm{C} \\ 20 \text { Minuten } & 65^{\circ} \mathrm{C} \\ \infty & 12^{\circ} \mathrm{C}\end{array}$

Die Dimerisierung der phosphorylierten Oligonukleotide erfolgte nach folgendem Ansatz:

$\begin{array}{ll}\text { Oligo fw } & 2 \mu \mathrm{l} \\ \text { Oligo rev } & 2 \mu \mathrm{l} \\ 500 \mathrm{mM} \mathrm{Tris-HCl} \mathrm{pH} 7,5 & 2 \mu \mathrm{l} \\ 500 \mathrm{mM} \mathrm{NaCl} & 2 \mu \mathrm{l} \\ \mathrm{H}_{2} \mathrm{O} & 12 \mu \mathrm{l}\end{array}$

Fünf Minuten Inkubation in einem $90^{\circ} \mathrm{C}$ Wasserbad, gefolgt von einer langsamen Abkühlungsphase, dienten der Dimerisierung der gegenläufigen Oligonukleotide. Der Probenansatz musste sofort zur Ligation benutzt werden.

\subsubsection{Ligation von DNA-Fragmenten}

Die Ligation kompatibler DNA-Fragmenten erfolgte unter Verwendung von T4 DNA Ligase (Fermentas) in einem 10 $\mu$ l Ansatz unter Verwendung des mitgelieferten 10x Puffers (Fermentas). Der Vektor und das zu inserierende Fragment wurden dazu in Verhältnissen von 1:1 bis 1:10 eingesetzt. Die Ligation erfolgte bei Raumtemperatur für 2 Stunden bzw. bei $16^{\circ} \mathrm{C}$ über Nacht (nach Sambrook und Russel, 2001). 


\subsubsection{Polymerasekettenreaktion (PCR)}

\subsubsection{Analytischer Maßstab}

Um nach der Transformation auf positive Bakterienklone zu testen, wurden einige Zellen einer Kolonie mit Hilfe des „GoTaq“ Reaktionssystems (Promega) einer PCRReaktion unterzogen.

\subsubsection{Präparativer Maßstab}

Alle Klonierungsoligonukleotide wurden mit Schnittstellen für Restriktionsendonukleasen versehen, um so für die folgenden Klonierungsschritte passende Fragmente generieren zu können (Sambrook und Russel, 2001). Für die Präparation der PCR-Produkte wurde jeweils ein $80 \mu$ I Ansatz eingesetzt.

\subsubsection{Sequenzierung}

Die Sequenzierung von DNA erfolgte mit dem Big Dye Terminator Kit von Applied Biosystems. Die Proben wurden in einem ABI 3100 Automated Capillary DNA Sequencer ausgewertet (Applied Biosystems).

\subsection{Arbeiten mit RNA}

Zum Arbeiten mit RNA wurden ausschließlich DNAse- und RNAse-freie Gefäße und Lösungen verwendet.

\subsection{1 in vitro Synthese von RNA}

\subsubsection{1 in vitro Transkription von Monomethylguanosin-Cap-RNA zur Mikroinjektion in Xenopus Embryonen}

Zur in vitro Transkription von CapRNA wurde das mMESSAGE mMACHINE Kit mit SP6 oder T7 RNA-Polymerasen (Ambion) verwendet. Das übliche Volumen eines Transkriptionsansatzes betrug $10 \mu \mathrm{l}$ und die Reaktion erfolgte für 3 Stunden bei 
$37^{\circ} \mathrm{C}$. Anschließend wurde die "Template“-DNA durch Zugabe von $1 \mu$ l RNAse-freier DNAse für 15 Minuten bei $37^{\circ} \mathrm{C}$ verdaut.

\subsubsection{2 in vitro Transkription Digoxigenin-markierter RNA-Sonden}

Alle in dieser Arbeit eingesetzten „antisense”-Sonden wurden durch Verwendung von Digoxigenin-gekoppelten UTP markiert.

Die in vitro Transkription erfolgte nach folgendem Ansatz für 3 Stunden bei $37^{\circ} \mathrm{C}$ :

$\begin{array}{rll}5 \mu \mathrm{l} & 5 \mathrm{x} \text { Transkriptionspuffer } & \text { (Fermentas) } \\ 4 \mu \mathrm{l} & \text { Digoxigenin-11-dUTP Mix } & \text { (Roche) } \\ 1 \mu \mathrm{l} & \text { DTT }(0,75 \mathrm{M}) & \text { (Merck) } \\ 5 \mu \mathrm{l} & \text { linearisiertes Plasmid (ca. 170ng/ } \mathrm{l}) & \\ 0,5 \mu \mathrm{l} & \text { RNase-Out } & \text { (Invitrogen) } \\ 0,5 \mu \mathrm{l} & \text { Pyrophospatase } & \text { (Fermentas) } \\ 0,5 \mu \mathrm{l} & \text { RNA-Polymerase } & \text { (Fermentas) } \\ 33,5 \mu \mathrm{l} & \text { DEPC- } \mathrm{H}_{2} \mathrm{O} & \end{array}$

Anschließend wurde die Template-DNA durch Zugabe von $1 \mu$ RNAse-freier DNAse für 15 Minuten bei $37^{\circ} \mathrm{C}$ verdaut.

\subsubsection{Aufreinigung von RNA}

Die Aufreinigung der in vitro transkribierten RNA erfolgte mittels des RNeasy ${ }^{R}$ Mini Kit (Qiagen $\mathrm{GmbH}$ ) oder des illustra ${ }^{\mathrm{TM}}$ RNA Spinmini Kit (GE Healthcare) nach Herstellerangaben.

\subsubsection{Whole-mount in situ Hybridisierung}

Ethanol-Reihe: 100\% Ethanol, 75\% Ethanol in Wasser, 50\% Ethanol in Wasser, 25\% Ethanol in PTw

10x PBS: 1,75M NaCl, $1 \mathrm{M} \mathrm{KCl,65mM} \mathrm{Na} \mathrm{HPO}_{4}, 18 \mathrm{mM} \mathrm{KH} \mathrm{PO}_{4}, \mathrm{pH} \mathrm{7,4}$

PTw: 0,1\% (v/v) Tween-20 in 1x PBS

PTw/FA: 4\% (v/v) Formaldehyd in Ptw

Proteinase K: $5 \mu \mathrm{g} / \mathrm{ml}$ Proteinase $\mathrm{K}$ in PTw

Hybridisierungs-Mix: 50\% Formamid (deionisiert), $1 \mathrm{mg} / \mathrm{ml}$ Torula-RNA, $10 \mu \mathrm{g} / \mathrm{ml}$ Heparin, 1x Denhardts, 0,1\% Tween-20, 0,1\% CHAPS, 10mM EDTA in 5x SSC 
20x SSC: $3 \mathrm{M} \mathrm{NaCl}, 0,3 \mathrm{M}$ Natriumcitrat

RNase-Lösung: $10 \mu \mathrm{g} / \mathrm{ml}$ RNAse $A, 0,01 \mathrm{U} / \mathrm{ml}$ RNAse $T 1$ in $2 x$ SSC

5x MAB: 500mM Maleinsäure, 750mM NaCl, pH 7,5

MAB/BMB: $2 \%$ BMB in $1 \times M A B$

MAB/BMB/HS: $2 \%$ BMB, 20\% Pferdeserum (HS) in 1x MAB

Antikörper-Lösung: 2\% BMB, 20\% Pferdeserum (HS), 1:2.000 Verdünnung des an Alkalische Phosphatase gekoppelent anti-Digoxigenin Antikörpers in 1x MAB

APB: $100 \mathrm{mM}$ Tris- $\mathrm{HCl}$ (pH 9,0), 50mM MgCl $2,100 \mathrm{mM} \mathrm{NaCl}, 0,1 \%$ Tween-20

Färbelösung: $80 \mu \mathrm{g} / \mathrm{ml} N B T, 175 \mu \mathrm{g} / \mathrm{ml} B C I P$ in $A P B$

BCIP: $50 \mathrm{mg} / \mathrm{ml}$ in $100 \%$ Dimethylformamid, bei $-20^{\circ} \mathrm{C}$ gelagert

NBT: $100 \mathrm{mg} / \mathrm{ml}$ in $70 \%$ Dimethylformamid, bei $-20^{\circ} \mathrm{C}$ gelagert

Die whole-mount in situ Hybridisierung wurde im Wesentlichen wie beschrieben durchgeführt (Harland, 1991; Hollemann et al., 1999). Alle „antisense“ RNA-Sonden wurden mit Digoxigenin-11-dUTP markiert. Die Inkubationsschritte erfolgten, sofern nicht anders angegeben, bei Raumtemperatur auf einem Horizontalschüttler.

\subsubsection{Fixierung von Xenopus Embryonen und Explantaten}

10x MEM: $1 \mathrm{M}$ Mops, 20mM EGTA, 10mM $\mathrm{MgSO}_{4}, \mathrm{pH} \mathrm{7,4}$ (steril filtriert und im Dunkeln gelagert)

MEMFA: 4\% (v/v) Formaldehyd in 1x MEM

10x PBS: $1,75 \mathrm{M} \mathrm{NaCl}, 1 \mathrm{M} \mathrm{KCl}, 65 \mathrm{mM} \mathrm{Na}_{2} \mathrm{HPO}_{4} 12 \mathrm{H}_{2} \mathrm{O}, 18 \mathrm{mM} \mathrm{KH}_{2} \mathrm{PO}_{4}, \mathrm{pH} 7,2-7,4$

Xenopus Embryonen verschiedener Entwicklungsstadien wurden in MEMFA eingelegt. Embryonen, die keiner whole-mount in situ Hybridisierung unterzogen werden sollten, wurden für mindestens eine Stunde fixiert, zur Auswertung in $1 \mathrm{x}$ MEM überführt und anschließend in MEMFA dauergelagert.

Embryonen, die einer in situ Hybridisierung unterzogen werden sollten, wurden eine Stunde in MEMFA fixiert, mit 100\% Ethanol gewaschen und anschließend bei $-20^{\circ} \mathrm{C}$ gelagert. Embryonen, deren Entoderm explantiert werden sollte, wurden 45 Minuten anfixiert, in 1x PBS gewaschen und das Entoderm explantiert. Die Explantate wurden entweder einer $\beta$-Galaktosidase Färbung unterzogen oder sofort für 15 Minuten refixiert und in Ethanol gelagert. 


\subsubsection{2 $\beta$-Galaktosidase Färbung von Embryonen}

10x PBS: 1,75M NaCl, $1 \mathrm{M} \mathrm{KCl,65mM} \mathrm{Na} \mathrm{HPO}_{4} 12 \mathrm{H}_{2} \mathrm{O}, 18 \mathrm{mM} \mathrm{KH}_{2} \mathrm{PO}_{4}, \mathrm{pH} 7,2-7,4$

10x MEM: $1 \mathrm{M}$ Mops, 20mM EGTA, 10mM $\mathrm{MgSO}_{4}, \mathrm{pH} \mathrm{7,4}$ (steril filtriert und im Dunkeln gelagert)

$\mathrm{K}_{3} \mathrm{Fe}(\mathrm{CN})_{6}: 0,5 \mathrm{M}$ in $\mathrm{dH}_{2} \mathrm{O}$ (im Dunkeln gelagert)

$\mathrm{K}_{4} \mathrm{Fe}(\mathrm{CN})_{6}: 0,5 \mathrm{M}$ in $\mathrm{dH}_{2} \mathrm{O}$ (im Dunkeln gelagert)

X-Gal: 40mg/ml 5-Bromo-4-chloro-3-indolyl-b-D-Galaktosidase (X-Gal) in Formamid (bei $-20^{\circ} \mathrm{C}$ im Dunkeln gelagert)

MEMFA: 4\% ( $/ \mathrm{v})$ Formaldehyd in 1x MEM

$\beta$-gal Färbelösung: $5 \mu \mathrm{M} \mathrm{K}_{3} \mathrm{Fe}(\mathrm{CN})_{6}, 5 \mu \mathrm{M} \mathrm{K}_{4} \mathrm{Fe}(\mathrm{CN})_{6}, 2 \mu \mathrm{M} \mathrm{MgCl}, 1 \mathrm{mg} / \mathrm{ml} X-\mathrm{Gal}$ in $1 \times P B S$

Mit $\beta$-gal „sense“-RNA als „Lineage tracer“ ko-injizierte Embryonen oder Explantate wurden für 45 Minuten in MEMFA fixiert, 3x je 10 Minuten in 1x PBS gewaschen und anschließend im Dunkeln für maximal zwei Stunden in der Färbelösung inkubiert. Nach weiteren 3 Waschschritten für je 10 Minuten in 1x PBS wurden die Embryonen oder Explantate 30 Minuten in MEMFA refixiert, mit Ethanol gewaschen und bis zur in situ Hybridisierung bei $-20^{\circ} \mathrm{C}$ gelagert.

\subsubsection{Whole-mount in situ Hybridisierung}

Die Embryonen und Explantate wurden mittels einer Ethanolreihe rehydriert und in PTw umgepuffert. Nach dreimaligem Waschen in PTw für je 10 Minuten wurde eine Proteinase K-Behandlung durchgeführt, um die Membranen der Embryonen und Explantate permeabler für die RNA-Sonden zu machen. 
Tabelle 3.1: Inkubationszeiten für den Proteinase K-Verdau

\begin{tabular}{|c|c|c|}
\hline Stadium & Dauer (Minuten) & Temperatur $\left({ }^{\circ} \mathbf{C}\right)$ \\
\hline $44-46$ & 32 & 37 (bei 30Upm) \\
\hline $40-41$ & 30 & RT \\
\hline 40 (Explantate) & 4 & RT \\
\hline $37-39$ & 25 & RT \\
\hline $32-35$ & 22 & RT \\
\hline $25-27$ & 15 & RT \\
\hline $17 / 18$ & 10 & RT \\
\hline
\end{tabular}

Die Embryonen und Explantate wurden je zweimal in 0,1\% Triethanolamin gewaschen, um den Proteinase K-Verdau abzubrechen. Durch Zugabe von 12,5 $\mu \mathrm{l}$ Acetanhydrid wurden die Embryonen acetyliert. Nach 5 Minuten Inkubation wurden weitere 12,5 $\mu$ l Acetanhydrid zur Lösung pipettiert.

Anschließend wurden die Embryonen und Explantate in PTw/FA für 20 Minuten refixiert. Fünf weitere je fünfminütige Waschschritte in PTw folgten. Die Embryonen oder Explantate in $1 \mathrm{ml} \mathrm{PTw}$ wurden mit $250 \mu \mathrm{l}$ Hybridisierungs-Mix versetzt und leicht

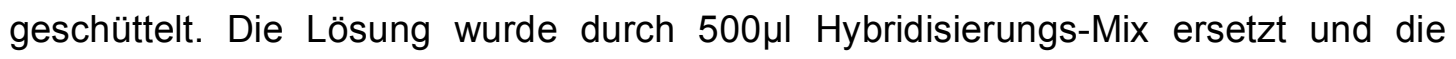
Embryonen für 10 Minuten bei $65^{\circ} \mathrm{C}$ inkubiert. Anschließend wurden die Embryonen und Explantate mit $1 \mathrm{ml}$ Hybridisierungs-Mix für sechs Stunden bei $65^{\circ} \mathrm{C}$ prähybridisiert. Danach wurde der Hybridisierungs-Mix durch die Digoxigeninmarkierten Sonden ersetzt und die Embryonen über Nacht bei $65^{\circ} \mathrm{C}$ inkubiert.

Am zweiten Tag wurde die RNA-Sonde gesammelt und bei $-20^{\circ} \mathrm{C}$ gelagert. Nachdem einmal mit $1 \mathrm{ml}$ Hybridisierungs-Mix für 10 Minuten bei $65^{\circ} \mathrm{C}$ gewaschen wurde, folgten drei 15 -minütige Waschschritte in $2 x S S C$ bei $65^{\circ} \mathrm{C}$. Es folgte ein einstündiger RNAse-Verdau in 2xSSC bei $37^{\circ} \mathrm{C}$, um einzelsträngige RNA abzubauen. Ein Waschschritt in 2x SSC für 5 Minuten und zwei Waschschritte in $0,2 x$ SSC für je eine halbe Stunde bei $65^{\circ} \mathrm{C}$ folgten. Anschließend wurden die Embryonen in 1x MAB umgepuffert. Die Embryonen wurden in MAB/BMB für 20 Minuten und in MAB/BMB/HS für 40 Minuten inkubiert, um unspezifische Bindungsstellen für den anti-Digoxigenin-Antikörper zu blockieren. Die AntikörperInkubation erfolgte für vier Stunden. Es folgten drei zehnminütige Waschschritte in 1x MAB, anschließend wurden die Embryonen über Nacht in $1 \mathrm{x}$ MAB bei $4^{\circ} \mathrm{C}$ inkubiert. 
Am dritten Tag wurden die Embryonen weitere fünfmal für je fünf Minuten in 1x MAB gewaschen. Die Kappen der Glasröhrchen wurden ausgewechselt und die Embryonen dreimal in APB gewaschen. Anschließend wurde die Färbelösung auf die Embryonen und Explantate pipettiert und bis zu fünf Tage bei $4^{\circ} \mathrm{C}$ im Dunkeln inkubiert.

\subsubsection{Reduktion der Hintergrundfärbung sowie Bleichung pigmentierter Embryonen und Explantate}

Methanol-Reihe: 100\% Methanol, 50\% Methanol in Wasser

Bleichlösung: 50\% (v/v) Formamid, 2\% (v/v) Wasserstoffperoxid in 5x SSC

Die Farbreaktion wurde durch einen fünfminütigen Waschschritt in Wasser beendet. Zwei Minuten in 100\% Methanol führte zur Dehydrierung der Embryonen. Eine Rehydrierung in 50\% Methanol und danach in Wasser löste überschüssige Farbablagerungen $\mathrm{ab}$ und reduzierte dadurch die Hintergrundfärbung. Die Embryonen und Explantate wurden in MEMFA eingelegt und bei $4^{\circ} \mathrm{C}$ aufbewahrt.

Sollte natürliches Pigment der Embryonen bzw. Explantate gebleicht werden, wurden sie 30 Minuten in MEMFA fixiert und anschließend zweimal in 5x SSC gewaschen. Die folgende Behandlung in Wasserstoffperoxid führte zur Bleichung des Pigments. Sie wurde bis zum Erreichen des gewünschten Pigmentverlustes durchgeführt, wonach die Embryonen und Explantate wiederum zweimal in 5x SSC gewaschen wurden. Anschließend wurden die Embryonen in MEMFA bei $4^{\circ} \mathrm{C}$ gelagert.

\subsubsection{Vibratomschnitte}

Gelatine-Albumin-Lösung: 4,88mg/ml Gelatine, 0,3g/ml BSA, 0,2 $\mathrm{mg} / \mathrm{ml}$ Sukrose in 1x PBS. Die Gelatine wurde durch Erhitzen auf $60^{\circ} \mathrm{C}$ verflüssigt und das Albumin und die Sukrose wurden zugegeben. Anschließend wurde die Lösung filtriert $\left(0,45 \mu \mathrm{m}\right.$ Porengröße, Sartorius) und bei $-20^{\circ} \mathrm{C}$ gelagert.

Mowiol: $5 g$ Mowiol wurde über Nacht in 20ml 1x PBS gerührt. Nach Zugabe von $10 \mathrm{ml}$ Glyzerol wurde eine weitere Nacht gerührt. Nach einer Zentrifugation von 30 
Minuten bei $20.000 \mathrm{~g}$ wurde der Überstand auf $\mathrm{pH} \mathrm{7,0}$ eingestellt und bei $-20^{\circ} \mathrm{C}$ gelagert.

Gelatine-Albumin wurde durch Zugabe von Glutaraldehyd ausgehärtet und die Präparate, welche in 1x PBS überführt worden waren, auf dem Gelatine-Albumin Sockel platziert. Umgebende Flüssigkeit wurde vollständig abgesaugt und die Präparate mit Gelatine-Albumin-Glutaraldehyd-Lösung überschichtet. $30 \mu \mathrm{M}$ Vibratomschnitte wurden, wie in Hollemann et al. (1999) beschrieben, an einem Leica VT1000M Vibratom hergestellt.

\subsubsection{Präparation von DNA-freier Gesamt-RNA}

\subsubsection{1 aus verschiedenen Embryonalstadien}

Je zwei Xenopus Embryonen verschiedener Stadien wurden in einem Eppendorf Gefäß ohne Flüssigkeit in flüssigem Stickstoff schockgefroren und bis zur Extraktion der Gesamt-RNA bei $-80^{\circ} \mathrm{C}$ gelagert. Die Extraktion der Gesamt-RNA erfolgte entweder nach Herstellerangaben mit dem RNAqueous ${ }^{R}$-Micro Kit (Ambion Inc.) oder wurde wie folgend beschrieben mit Trizol (Invitrogen) durchgeführt:

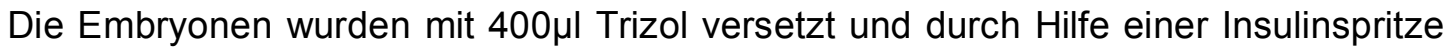
vollständig lysiert. Anschließend wurden die Proben für 30 Sekunden gevortext. Es wurden $80 \mu \mathrm{l}$ Chloroform pro $400 \mu \mathrm{l}$ Trizolgemisch zugefügt und weitere 30 Sekunden gevortext. Die Proben wurden 10 Minuten bei $13.000 \mathrm{Upm}$ und $4^{\circ} \mathrm{C}$ zentrifugiert und der Überstand in ein neues Röhrchen überführt. Es wurden $200 \mu$ l Chloroform zugefügt und wiederum für 30 Sekunden gevortext. Die Proben wurden für 5 Minuten bei 13.000Upm und $4^{\circ} \mathrm{C}$ zentrifugiert und der Überstand in ein neues Röhrchen überführt. Nach Zugabe von $200 \mu$ I Isopropanol erfolgte die Fällung für eine Stunde bei $-20^{\circ} \mathrm{C}$. Die Proben wurden für 30 Minuten bei $13.000 \mathrm{Upm}$ und $4^{\circ} \mathrm{C}$ zentrifugiert und mit $400 \mu \mathrm{l}$ Ethanol gewaschen. Nach 5 Minuten Zentrifugation bei $13.000 \mathrm{pm}$ und $4^{\circ} \mathrm{C}$ wurde der Überstand verworfen, die Sedimente bei Raumtemperatur

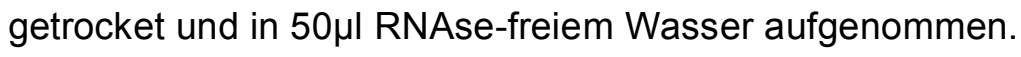




\subsubsection{2 aus adulten Geweben und Organen}

Adulte Organe und Gewebe wurden aus Xenopus Männchen im Zuge der TestisPräparation entnommen, nach einer Waschung in $1 \mathrm{x} \mathrm{MBSH}$ sofort in flüssigem Stickstoff schockgefroren und bei $-80^{\circ} \mathrm{C}$ gelagert. Die RNA aus adulten Geweben wurde mit Trizol (Invitrogen) extrahiert. Dazu wurden die Organe oder Gewebe in einem Mörser unter steter Zugabe von flüssigem Stickstoff zermahlen und nach vollständiger Zerkleinerung in einen Glaskolben mit Trizol überführt. Das Gewebe wurde durch Minzeration vollständig in Trizol aufgelöst. Anschließend wurde die Gesamt-RNA wie unter Punkt 3.3.4.1 beschrieben extrahiert.

\subsubsection{3 aus animalen Kappen-Explantaten}

Die RNA aus animalen Kappen wurde entweder mit dem RNAqueous ${ }^{\mathrm{R}}$-Micro Kit von Ambion oder mit Trizol (Invitrogen) extrahiert. Bei Verwendung des Ambion Kits wurde entsprechend der Herstellerangaben gearbeitet. Für die Extraktion mit Trizol

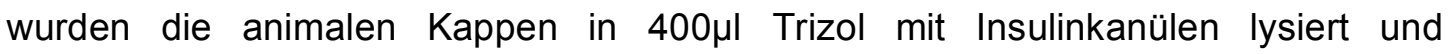
anschließend wie unter Punkt 3.3.4.1 beschrieben weiterbehandelt.

\subsubsection{Semiquantitative Reverse Transkriptase Polymerase- Kettenreaktion (RT-PCR)}

Die extrahierte Gesamt-RNA wurde mit Hilfe von „Rundom hexamers“ und Reverser Transkriptase in cDNA umgeschrieben. Anschließend wurden die erhaltenen „Pools“ an cDNA mit Gen-spezifischen Oligonukleotiden (siehe Punkt 2.9.1.) auf die Expression spezifischer Transkripte hin untersucht (Sambrook und Russel, 2001).

\subsection{Arbeiten mit Proteinen}

\subsection{1 in vitro Transkription und Translation („TnT“)}

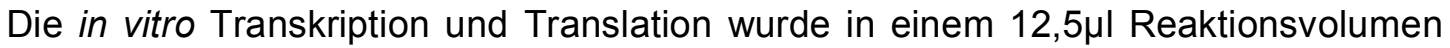
mit dem $T_{N} T^{R}$ Coupled Reticulocyte Lysate System (Promega) nach Herstellerangaben durchgeführt. Die Proteine wurden mittels denaturierender SDS- 
Gelelektrophorese aufgetrennt (Harlow und Lane, 1988) und mit Hilfe eines Autoradiogramms detektiert.

\subsubsection{Ko-Immunopräzipitation}

ColP-Puffer: 100mM NaCl, 10mM Tris-HCl (pH 7,5), 0,5\% (v/v) NP-40, 1x Proteinase-Inhibitor-Tablette („,complete EDTA-free“, Roche)/50ml

6x SDS-Gelauftragspuffer: 125mM Tris pH6,8, 30\% Glyzerol, 10\% SDS, 0,6M DDT, 0,012\% Bromphenolblau

Die Ko-Immunopräzipitation wurde wie in Harlow und Lane (1988) beschrieben durchgeführt. Es wurden jeweils 25 Embryonen eingesetzt, wobei $10 \%$ des Zelllysats als „Input" abgenommen wurden und eine Inkubation der Proben mit $20 \mu$ ProteinG Sepharose vor der eigentlichen Immunpräzipitation die unspezifisch an ProteinG Sepharose bindenden Proteine entfernen sollte.

\subsubsection{Western Blot}

10x Lämmli-Puffer: 250mM Tris pH8,3, 192mM Glycin, 1\% (w/v) SDS

Transfer Puffer: 39mM Glycin, 48mM Tris-HCl (pH 7,5), 0,04\% SDS, 20\% Methanol „Blocking" Puffer: 5\% (w/v) in TBS

10x TBS: 200mM Tris- $\mathrm{HCl}(\mathrm{pH} 7,5), 1,5 \mu \mathrm{M} \mathrm{NaCl}, 0,5 \%(v / v)$ Tween-20

TBST: $0,5 \%$ Tween-20 in 1x TBS

1. Antikörperlösung: 1:1.000 bis 1:10.000 Verdünnung des primären Antikörpers in „Blocking" Puffer

2. Antikörperlösung: 1:10.000 bis 1:20.000 Verdünnung des sekundären Antikörpers gekoppelt an die Horseradish Peroxidase (HRP) in „Blocking “ Puffer

Proteine wurden durch denaturierende SDS-Gelelektrophorese aufgetrennt und

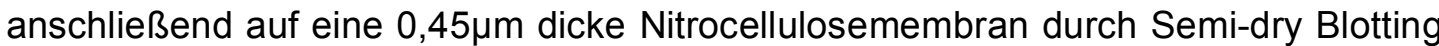
übertragen (Harlow und Lane, 1988). Die Membran wurde für eine Stunde im Milchpulverhaltigen „Blocking“ Puffer und über Nacht mit den primären AntikörperLösungen bei $4^{\circ} \mathrm{C}$ auf einer rotierenden Scheibe inkubiert. Nach dreimaligem 10minütigen Waschen in TBST wurde die Membran in den sekundären Antikörper- 
Lösungen für eine Stunde bei Raumtemperatur inkubiert. Nach weiteren drei 10minütigen Waschschritten wurde die Membran mit dem SuperSignal ${ }^{R}$ West Dura Extended Duration Substrate (Pierce) behandelt, um die Proteine auf einem lichtsensitiven Film sichtbar zu machen (Harlow und Lane, 1988).

\subsection{Manipulierung von Xenopus Embryonen}

5x MBSH: 440mM NaCl, $12 \mathrm{mM} \mathrm{NaHCO} 3,5 \mathrm{mM} \mathrm{KCl}$, 50mM Hepes, 4,1 $\mathrm{mM} \mathrm{MgSO}_{4}$, 2,05mM CaCl $2,1,65 \mathrm{mM} \mathrm{Ca}\left(\mathrm{NO}_{3}\right)_{2}$

2\% Cysteinhydroclorid-Lösung: 2\% (w/v) Cys-HCl in 0,1x MBSH, pH8,0

Ficoll: $10 \%(w / v)$ Ficoll, sterilfiltriert

Natriumdihydrogenphosphat-Lösung: $1 \mathrm{M} \mathrm{NaH}_{2} \mathrm{PO}_{4} 1 \mathrm{H}_{2} \mathrm{O}$

Di-Natriumhydrogenphosphat-Lösung: 0,5M Na${ }_{2} \mathrm{HPO}_{4} 2 \mathrm{H}_{2} \mathrm{O}$

Nilblau-Lösung: 179,2ml 0,5M Na $2 \mathrm{HPO}_{4}, 10,4 \mathrm{ml} 1 \mathrm{M} \mathrm{NaH} \mathrm{PO}_{4}$, eine Spatelspitze Nilblau-Chlorid in $1 / \mathrm{dH}_{2} \mathrm{O}$, bei $50^{\circ} \mathrm{C}$ einen halben Tag rühren lassen, sterilfiltrieren

\subsubsection{Stimulation der Eiablage}

Xenopus Weibchen wurden am Vorabend des Injektionstages mit 800 bis $1000 \mathrm{U}$ humanem Choriongonadotropin (HCG) injiziert und bei $16^{\circ} \mathrm{C}$ über Nacht inkubiert. Am Morgen des nächsten Tages war mit der Eiablage zu rechnen. Für Animale Kappenexplantate wurden die Frösche am Vorabend mit 50U HCG vorstimuliert und am nächsten Morgen mit $1000 U$ induziert. Die Eiablage war 6 Stunden nach der Injektion zu erwarten.

Die Xenopus Weibchen wurden einmal pro Stunde am Rücken massiert und das Gelege in einer Petrischale aufgefangen. Testis-Lösung mit den in 1x MBSH unbeweglichen Spermien wurde in der Petrischale mit Wasser auf 0,1x MBSH verdünnt und die Oozyten damit befruchtet. Nach zehnminütiger Inkubation wurde das Gelege mit 0,1x MBSH überschichtet (Sive et al., 2000).

Um eine Mikromanipulation der Embryonen zu ermöglichen, wurde die Gallerhülle der Embryonen vor der ersten Zellteilung durch Behandlung mit 2\%-iger Cysteinhydrochlorid-Lösung abgelöst. Die Embryonen wurden danach mehrfach mit 0,1x MBSH gespült. Albinoembryonen wurden zur leichteren Bestimmung des Stadiums mit dem Vitalfarbstoff Nilblau-Lösung angefärbt. 


\subsubsection{Präparation von Xenopus Testes}

Ein Xenopus Männchen wurde dekapitiert und mit einer Schere die Bauchdecke geöffnet. Die Testes wurden entnommen und sorgfältig von Fettgewebe und Blutgefäßen befreit. Die Testes wurden einmal in $1 \mathrm{xMBSH}$ gewaschen und anschließend bei $4^{\circ} \mathrm{C}$ in $1 \times \mathrm{xMSH}$ gelagert (Sive et al., 1998).

\subsubsection{Mikroinjektion}

Injektionspuffer: 1\% (v/v) Ficoll, 1x MBSH

Die Glaskapillaren für die Mikroinjektion wurden an einem Nadelzieher gezogen (PN30, Science Products) und die Mikroinjektion an einem Mikromanipulator (Pneumatic PicoPump PV 820, World Precision Instruments) durchgeführt. Das Injektionsvolumen betrug $4 \mathrm{nl} /$ Blastomere und wurde anhand einer $\mu \mathrm{M}$-Skala eingestellt. Für die Mikroinjektion wurden die Embryonen in Injektionspuffer überführt und nach der Injektion für eine weitere Stunde darin inkubiert. Zur weiteren Kultivierung wurden die Embryonen in 0,1x MBSH überführt.

\subsubsection{Achsenduplikations-Assay}

Die pigmentierten Embryonen wurden marginal bis vegetal in eine ventrale Blastomere im Vierzellstadium injiziert. Eine Auswertung der Injektion erfolgte zwischen Stadium 30 und 35 , als die stark pigmentierte Anhaftdrüse sowie die Augenwülste deutlich zu erkennen waren. Dorsale Achsenduplikation führte entweder zur Induktion einer zweiten Körperachse mit vollständigen Kopfstrukturen oder zu einer zusätzlichen partiellen Achse bestehend aus Rumpfstrukturen.

\subsubsection{Entoderm-Injektion}

Embryonen im Vier- oder Achtzellstadium wurden vegetal in alle vier Blastomere injiziert, um eine optimale Verteilung der Morpholino Oligonukleotide in das prospektive Entoderm zu erreichen. 


\subsubsection{Animale Kappenexplantate}

Penicillin/Streptomycin: $10.000 \mathrm{U} / \mathrm{ml}$ Penicillin, 10mg / $\mathrm{ml}$ Streptomycin in 0,9\% Natriumchlorid (100x Stock-Lösung)

Animale Kappen wurden unter Verwendung einer „Gastromaster“-Spitze aus dem Dach des Blastocoels von Embryonen im Stadium 8 bzw. 9 geschnitten. Die weitere Kultivierung erfolgte in 0,8x MBSH / 0,1x Penicillin/Streptomycin auf mit Agar beschichteten Kulturschalen $(0,7 \%(\mathrm{w} / \mathrm{v})$ Agar in $0.8 \mathrm{x} \mathrm{MBSH})$ bei $16 \mathrm{bzw} .18^{\circ} \mathrm{C}$ bis zum Erreichen des gewünschten Entwicklungsstadiums. Die Explantate wurden in flüssigem Stickstoff tiefgefroren und bis zur Extraktion der Gesamt-RNA bei $-80^{\circ} \mathrm{C}$ gelagert (Sive et al., 2000).

\subsubsection{Gastrointestinale Explantate}

Die Präparation gastrointestinaler Explantate erfolgte im Stadium 40. Dazu wurde mit zwei Präzisionspinzetten die Bauchdecke geöffnet, der Ösophagus durchtrennt und der Gastrointestinaltrakt von der umgebenden Haut sowie den dorsalen mesodermalen Strukturen abgelöst (Chalmers und Slack, 1998).

\subsubsection{Behandlung der Embryonen oder animalen Kappenexplantate mit Chemikalien}

\subsubsection{Retinsäure und Retinsäure-Antagonist BMS453-Behandlung}

10mM Retinsäure: all-trans Retinsäure (Sigma) in 100\% Ethanol

10mM BMS453: 4,01mg „Bristol Meyers Squibb“ (BMS) 453 in 1ml 100\% Dimethylsulfoxid (DMSO)

Die Behandlung der animalen Kappenexplantate mit $5 \mu \mathrm{M}$ Retinsäure erfolgte für

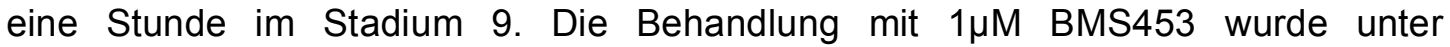
Lichtabschluß ebenfalls für eine Stunde im Stadium 9 durchgeführt. Alle 
Versuchszugehörigen Explanate wurden entweder mit Ethanol oder mit DMSO behandelt.

\subsubsection{Dexamethason-Behandlung}

1000x Dex: 4mg Dexamethason / ml 100\% Ethanol

Die Freisetzung der von „Heat Shock“ Proteinen komplexierten Glucocorticoid Receptor-fusionierten Proteine wurde durch Zugabe von 1x Dex / 0,1x MBSH induziert. Die Embryonen wurden während der Behandlung unter Lichtabschluß inkubiert. Für Achsenduplikationsexperimente mit Lef1-GR wurde Dexamethason spätestens im 16-Zell-Stadium zugegeben und die Induktion am nächsten Morgen abgebrochen. 


\section{Ergebnisse}

\subsection{Biochemische und funktionale Charakterisierung des sekretierten Wnt Antagonisten Xenopus sFRP5}

\subsubsection{XsFRP5 zeigt während der Embryonalentwicklung ein sehr dynamisches Expressionsmuster}

Der sekretierte Wnt Antagonist sFRP5 wurde aus einer Xenopus Herz-cDNA-Bank isoliert und eine erste Expressionsanalyse bereits im Jahr 2002 von Pilcher und Krieg veröffentlicht. Die Autoren beschrieben die Leber-spezifische Expression von XsFRP5 während früher Schwanzknospenstadien und einen dynamischen Wechsel der XsFRP5 Expression in den Grenzbereich zwischen Magen und Duodenum in frühen Kaulquappenstadien. Desweiteren wurde eine überlappende Expression von XsFRP5 mit dem frühen Leber-Markergen hex, einem HomöoboxTranskriptionsfaktor, beschrieben (Pilcher und Krieg, 2002).

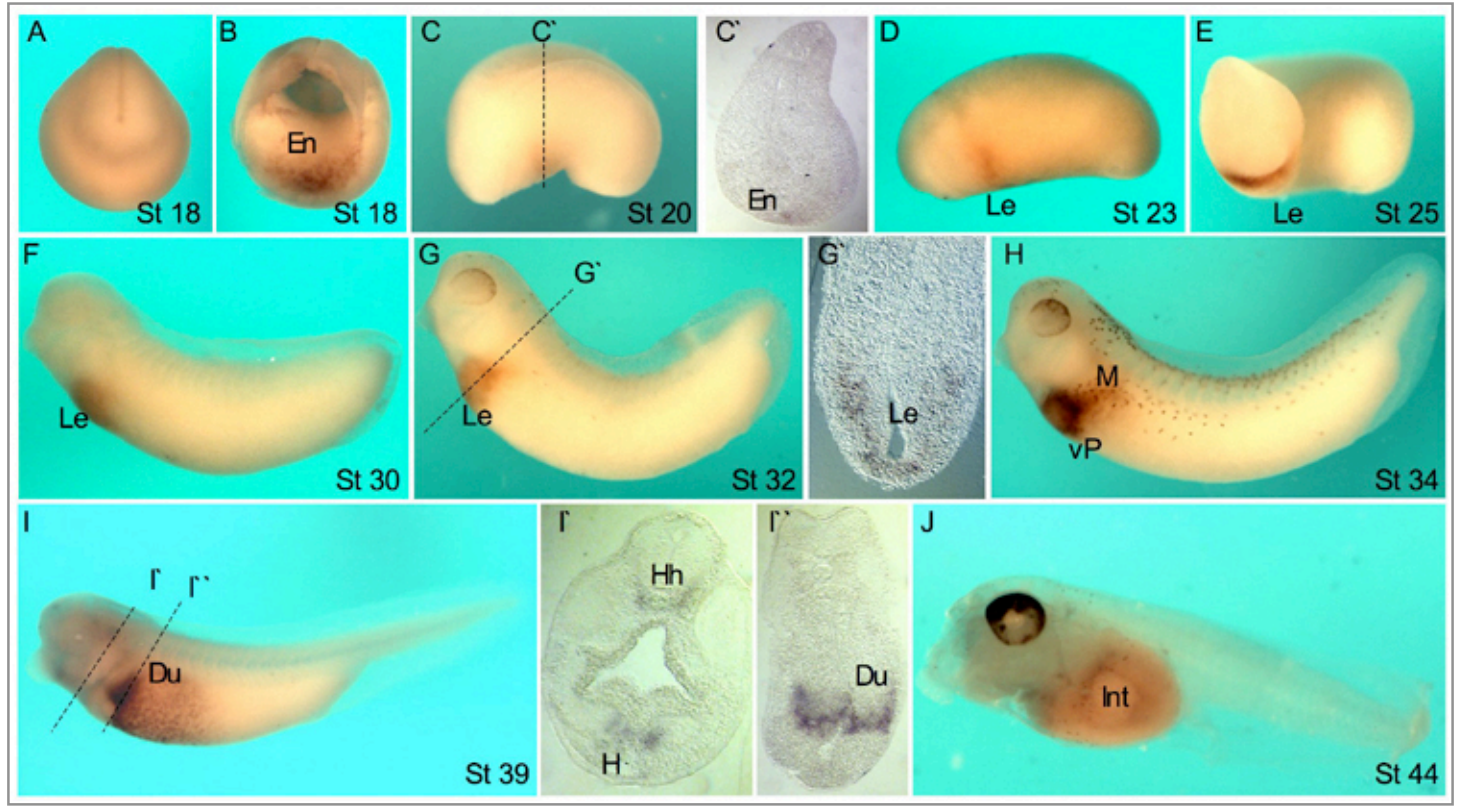

Abb. 4.1: XsFRP5 zeigt ein ausgeprägt dynamisches Expressionsverhalten in Xenopus Embryonen. (A-J) Verschiedene Embryonalstadien wurden mittels whole-mount in situ Hybridisierung auf die Expression von XsFRP5 mRNA untersucht. (C', G', I', I') Vibratomschnitte dienen der Veranschaulichung interner Expressionsdomänen. (A, $B, C^{\prime}, G^{\prime}$, I', I') Anterior nach vorne. (C, D, E, F, G, H, I, J) Laterale Ansicht mit anterior nach links. Du = Duodenum, $\mathrm{En}=$ Entoderm, $\mathrm{H}=$ Herzanlage, $\mathrm{Hh}=$ Hinterhirn, Int = Intestinaltrakt, $\mathrm{Le}=$ Leberanlage, $\mathrm{M}=$ Magen, $\mathrm{St}=$ Stadium, $\mathrm{vP}=$ ventrales Pankreas 
Im Rahmen unserer weiterführenden Analyse konnte das embryonale und adulte Expressionsmuster von XsFRP5 zeitlich und räumlich präzisiert werden. So kann die XsFRP5 Expression bereits deutlich früher als zuvor beschrieben im ventralen Entoderm des späten Neurulastadiums in einer Region detektiert werden, welche die Vorläuferzellen der Leberanlage sowie des ventralen Pankreas beinhaltet (Abb. 1.1 A, B). Zusätzlich wurde zur bereits beschriebenen Expression in Leber und MagenDarm-Bereich eine Färbung der Herzanlage und des Hinterhirns festgestellt (Abb. $\left.1.1 \mathrm{I}, \mathrm{I}^{\prime}, \mathrm{I}^{\prime \prime}\right)$.

Eine temporäre Expressionsanalyse mittels RT-PCR, die in unterschiedlichen Embryonalstadien durchgeführt wurde, bestätigte, dass XsFRP5 bereits während der Neurulation in Xenopus Embryonen stark exprimiert wird (Abb. 4.2 A). Eine schwache Expression von XsFRP5 konnte bereits im Gastrulastadium (Stadium 10) nachgewiesen werden. Wie auch aus der whole-mount in situ Hybridisierung ersichtlich, bleibt die Expression von XsFRP5 bis in späte Embryonalstadien erhalten. XsFRP5 Transkripte wurden weiterhin in einer Vielzahl von adulten Geweben detektiert, wobei festzustellen ist, dass lediglich die Epidermis sowie die Ovarien kein XsFRP5 enthalten. Die fehlende Expression von XsFRP5 in den Ovarien ist konsistent mit der Beobachtung, dass XsFRP5 nicht als maternales Transkript vorliegt und somit auch nicht vor der „Mid-Blastula-Transition“ (MBT) in den Embryonalstadien detektiert werden konnte.

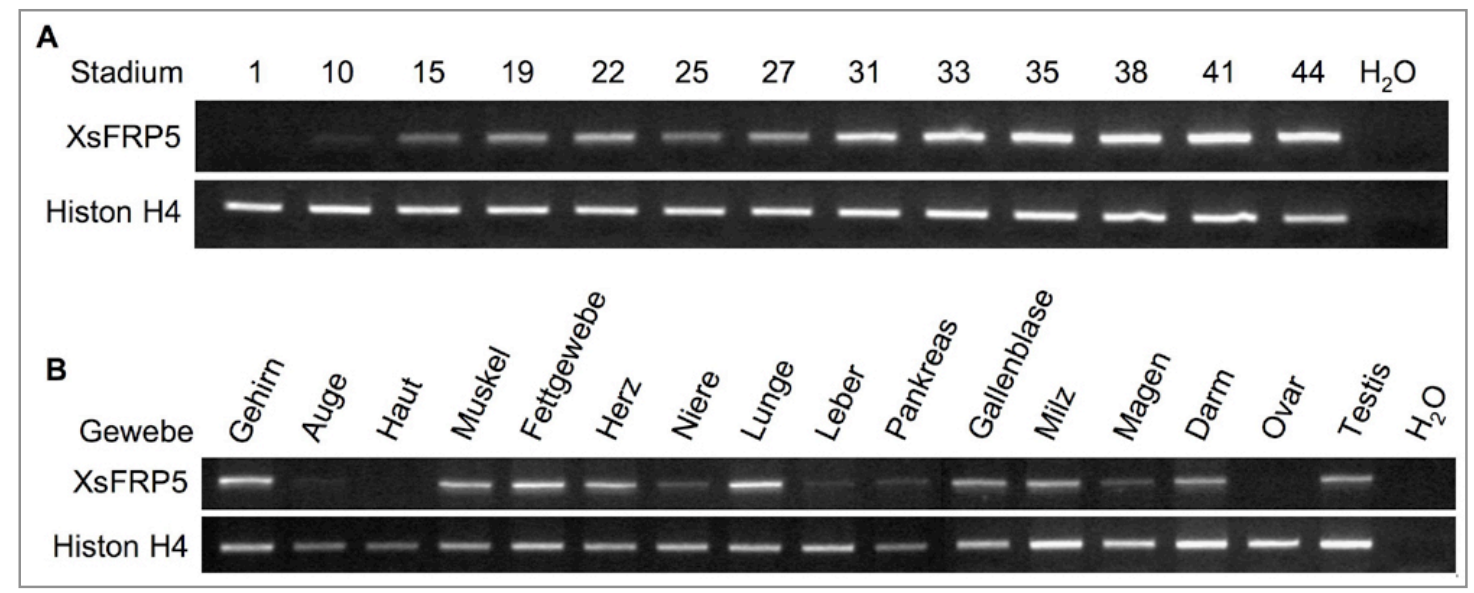

Abb. 4.2: Die Expression von XsFRP5 beginnt während der Gastrulation und bleibt in späten Embryonalstadien wie auch in vielen adulten Geweben erhalten. (A) RT-PCR Analyse der XsFRP5 Expression in verschiedenen Embryonalstadien. (B) RT-PCR Analyse der XsFRP5 Expression in adulten Geweben und Organen. Histon H4-spezifische RT-PCR diente als Kontrolle. 
Für bovines SFRP5 wurde eine Expression im retinalen Pigmentepithelium und für humanes sFRP5 im Pankreas nachgewiesen (Chang et al., 1999); beide Gewebe zeigen auch im Frosch eine Expression von sFRP5, jedoch sind es nicht die Gewebe mit der höchsten Zahl an Transkripten (Abb. 4.2 B). Chang et al. (1999) konnten zusätzlich eine schwache Expression in Herz, Leber und Muskelzellen detektieren; diese Gewebe zeigen auch im Frosch deutliche XsFRP5 Expression.

\subsubsection{Biochemische Interaktionsstudien von XsFRP5 mit verschiedenen Xenopus Wnt Proteinen}

\subsubsection{Ko-Injektion von XsFRP5 inhibiert die Wnt-vermittelte dorsale Achsenduplikation}

Bereits im Jahr 1999 wurde für das bovine sFRP5 eine schwache Interaktion mit Xenopus Wnt8 nachgewiesen (Chang et al., 1999). Für XsFRP5 waren außer des Expressionsmusters keine funktionalen Daten bekannt, wenngleich auch von einer Aktivität als Wnt Antagonist ausgegangen wurde (Pilcher und Krieg, 2002). Da einige Mitglieder der sFRP Familie überraschend als BMP Antagonisten charakterisiert wurden (Lee et al., 2006), sollte das Potential von XsFRP5 als Inhibitor von Wntvermittelter Achsenduplikation in Xenopus Embryonen direkt untersucht werden. Zu diesem Zweck wurden verschiedene Xenopus Wnt Proteine ausgewählt, jeweils vier dem kanonischen Signalweg zugeordnete und vier der nicht-kanonischen Signaltransduktion zugeordnete Kandidaten. Es wurde außerdem auf eine Auswahl der bislang als für die Embryonalentwicklung am wichtigsten beschriebenen Wnt Proteine Wert gelegt. Alle diese Wnt Proteine wurden auf der ventralen Seite von Embryonen in frühen Teilungsstadien überexprimiert, um durch die ektopische Aktivierung kanonischer Wnt Signaltransduktion die Induktion eines sekundären Spemann Organisators und weiterführend einer zweiten Körperachse zu bewirken. Für die vier nicht-kanonischen Wnt Liganden, welche selbst nicht in der Lage sind, dorsale Achsenduplikation zu vermitteln, wurde der humane Frizzled5 Rezeptor (hFz5) ko-injiziert (He et al., 1997). Das Überangebot dieses dem kanonischen Signalweg zugeordneten Rezeptors führt durch die Bindung nicht-kanonischer Wnt Proteine zu einer Stimulation der kanonischen Wnt Signaltransduktion. Die Ko- 
Injektion ansteigender Mengen an XsFRP5 sollte im Fall einer Interaktion die Verminderung der Wnt-vermittelten Achsenduplikation zur Folge haben.

Die kanonischen Wnt Proteine Xwnt2b, Xwnt3a, Xwnt8 und Xwnt8b zeigen eine 80 bis 90\%-ige Induktion zweiter Körperachsen (Abb. $4.3 \mathrm{~A}-\mathrm{D}$ ). Dabei wurde nicht zwischen der Induktion kompletter dorsaler Strukturen (inklusive Anhaftdrüse und Augenfelder) und einer partiellen Achsenduplikation unterschieden. Ko-Injektion einer niedrigen Dosis an XsFRP5 zeigte, dass Xwnt2b- und Xwnt8b-vermittelte Achseninduktion bereits nahezu vollständig unterdrückt werden konnte (Abb. 4.3 A, D), während Xwnt8b lediglich zu 50\% und Xwnt3a kaum inhibiert wurde. Ko-Injektion einer höheren Dosis an XsFRP5 unterband auch die Xwnt8-vermittelte Achsenduplikation, während Xwnt3a nicht signifikant in seiner Funktion beeinträchtigt wurde (Abb. 4.3 C, B). Hieraus wird deutlich, dass XsFRP5 verschiedene kanonische Wnt-Liganden mit deutlich unterschiedlicher Effektivität inhibieren kann.

Die Injektion der nicht-kanonischen Wnt Proteine Xwnt4, Xwnt5a, Xwnt11 und Xwnt11R führte alleine, wie erwartet, nicht zur Induktion zweiter Körperachsen (Abb. $4.3 \mathrm{E}-\mathrm{H})$. Die Injektion von $\mathrm{hFz5}$ alleine führte $\mathrm{zu}$ einer schwachen Achsenduplikation und definierte somit einen Grundwert, welcher durch die KoInjektion der nicht-kanonischen Wnt Proteine deutlich erhöht wurde. Um eine klare Aussage über eine Interaktion zwischen XsFRP5 und den nicht-kanonischen Wnt Proteinen zu ermöglichen, wurde XsFRP5 in drei verschiedenen Dosen ko-injiziert. Es zeigte sich, dass Xwnt4 bereits bei einer Ko-injektion der geringsten Dosis an XsFRP5 beinahe völlig inhibiert werden konnte (Abb. $4.3 \mathrm{E}$ ), während die Xwnt5aund Xwnt11R-vermittelte Achsenduplikation nur bei hohen XsFRP5-Konzentrationen auf das Niveau hFz5-vermittelter Induktion reduziert werden konnte. Xwnt11 wird auch bei der höchsten hier eingesetzten Dosis an XsFRP5 deutlich schwächer inhibiert. 


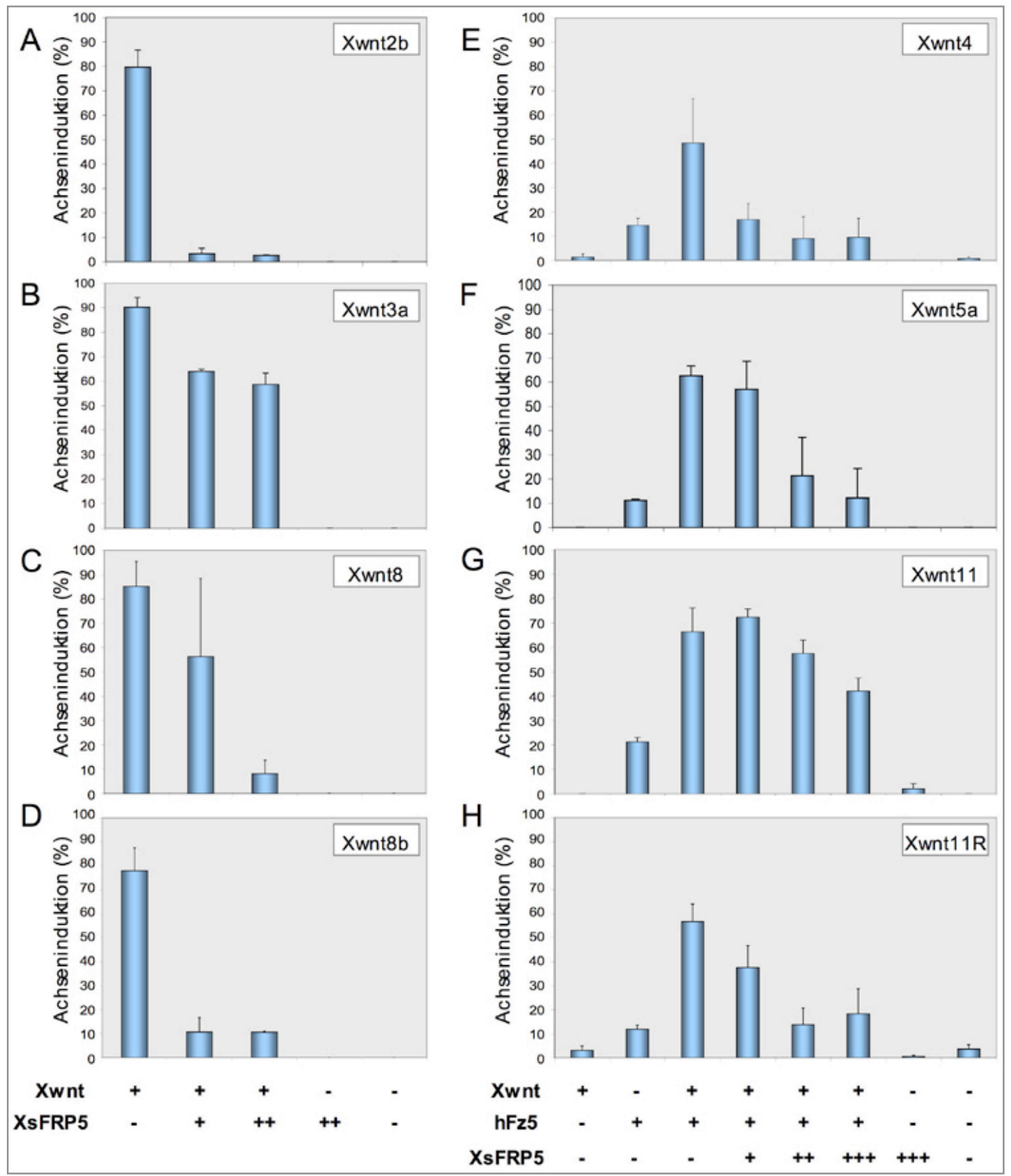

Abb. 4.3: XsFRP5 ist in der Lage, Xwnt-vermittelte dorsale Achsenduplikation zu unterdrücken. 10pg bzw. 50pg XsFRP5 mRNA wurden zu 60pg Xwnt2b mRNA (A) sowie zu je 10pg Xwnt3a (B), Xwnt8 (C) und Xwnt8b mRNA (D) ko-injiziert, um eine robuste Achseninduktion zu erzielen. Je 5pg Xwnt4 (E), Xwnt5a (F), Xwnt11 (G) und Xwnt11R (H) wurden mit und ohne 50pg hFz5 sowie $10(+), 50(++)$ und 100pg (+++) XsFRP5 injiziert. Es wurden insgesamt 397 Embryonen (A), 306 Embryonen (B), 419 Embryonen (C) und 232 Embryonen (D), 413 Embryonen (E), 277 Embryonen (F), 405 Embryonen (G) in jeweils 2 unabhängigen Experimenten und 867 Embryonen $(\mathrm{H})$ in 3 unabhängigen Experimenten untersucht. 
Anhand dieser Resultate wird deutlich, dass XsFRP5, ähnlich wie für die kanonischen Wnt Liganden beschrieben, auch verschiedene nicht-kanonische Wnt Liganden mit unterschiedlicher Effektivität inhibieren kann. Zusammenfassend kann also festgehalten werden, dass XsFRP5 die Aktivität aller hier eingesetzten Wnt Proteine inhibieren kann, unabhängig davon, ob sie den kanonischen oder nichtkanonischen Wnt Signalweg stimulieren, dass es jedoch unterschiedliche Affinitäten in der Interaktion der verschiedenen Wnts mit XsFRP5 zu geben scheint.

\subsubsection{Ko-Immunopräzipitation von XsFRP5 und unterschiedlichen Xwnt Proteinen}

Die in den Achsenduplikations-Experimenten erhaltenen Ergebnisse zeigen, dass XsFRP5 in der Lage ist, Xwnt-vermittelte Achsenduplikation zu inhibieren. Ob diese antagonistische Wirkung durch eine direkte Bindung an die Xwnt Proteine oder durch die Bildung nicht-funktionaler XsFRP5-Frizzled Komplexe zustande kam, ist unklar. Eine direkte Interaktion zwischen XsFRP5 und verschiedenen Xwnt Proteinen sollte durch ein Ko-Immunopräzipitation untersucht werden. Zu diesem Zweck wurde XsFRP5 mit einem Hämagglutinase-Epitop (HA-Tag) versehen und die Xwnt Proteine an das Myc-Epitop (MT) fusioniert. Nach Überexpression der unterschiedlich Epitop-markierten Proteine in Xenopus Embryonen, wurden diese lysiert und $10 \%$ des Lysats für die Input-Fraktion (I) abgenommen. Als Ladekontrolle diente Aktin, welches durch einen Maus anti-Aktin Antikörper separat in allen InputFraktionen bei einer Größe von ca. 45 kDa nachgewiesen wurde (Abb. 4.4 Bahnen $\left.1^{\prime}-25^{\prime}\right)$. Die Proben wurden in der Folge mit Protein G-Sepharose Kügelchen präinkubiert, um alle Proteine, welche unspezifisch an Protein $G$ binden, durch Zentrifugation aus den Proben entfernen zu können. Das erhaltene Sediment wurde als Pellet-Fraktion $(P)$ im folgenden Western Blot untersucht. Die KoImmunopräzipitation erfolgte unter Verwendung eines Maus anti-HA Antikörpers und anschließender Inkubation mit Protein G-Sepharose-Kügelchen. Das so erhaltene Sediment wurde als IP bezeichnet.

XsFRP5-HA kann in zwei Protein-Banden detektiert werden, bei einer Größe von ungefähr 33 und 35kDa (Abb. 4.4). Dieser Größenunterschied von 2kDa beruht vermutlich auf einer nicht vollständig prozessierten Form von XsFRP5, welche noch 
das Signalpeptid mit einer Größe von 2kDa trägt. Wie aus Bahnen 1 bis 3 ersichtlich wird, sind die verwendeten Antikörper spezifisch für die Epitop-markierten Proteine, da in den Proben nicht-injizierter Kontrollembryonen keine Banden detektiert werden konnten. Wie in Abb. 4.4 gezeigt, ko-präzipitieren alle Xwnt Proteine mit XsFRP5, jedoch lassen sich anhand der Bandenstärke in den IP-Fraktionen Unterschiede in der Bindungsstärke zwischen XsFRP5 und einzelnen Wnt Proteinen erkennen.

MT-Xwnt2b konnte bei einer Größe von 50kDa detektiert werden (Abb. 4.4 Bahnen 4, 6). XsFRP5-HA interagiert mit MT-Xwnt2b, jedoch liegt die Effizienz der Interaktion bei nur ungefähr 2\% des im Input vorhanden Wnt Proteins (Abb. 4.4 Bahn 6). MT-Xwnt3a hingegen konnte effizienter ko-präzipitiert werden, gemessen an der Bandenstärke von XsFRP5-HA zu MT-Xwnt3a in der IP-Fraktion wurden ca. 10\% des gesamt vorhandenen MT-Xwnt3a gebunden. Auffällig ist, dass mehrere Banden für MT-Xwnt3a in der Input-Fraktion in Größen zwischen 45 und 70kDa detektiert wurden, XsFRP5-HA jedoch nur mit einer dieser Banden spezifisch interagiert (Abb. 4.4 Bahnen 7-9). Für das Auftreten multipler Banden bei Wnt Proteinen gibt es mehrere Erklärungen. Da die Überexpression der Proteine in Xenopus Embryonen erfolgte, wurden die Epitop-markierten Proteine höchstwahrscheinlich ebenso modifiziert wie endogene Wnt Proteine, bei denen es sich um palmitoylierte Glykoproteine handelt. Wahrscheinlich wurden auch unprozessierte Vorläuferstufen aus dem ER nach Lyse der Zellen weiter aufgearbeitet und führen so zu den unterschiedlichen Bandenmustern, die für die einzelnen Wnt Proteine beobachtet werden konnten (Abb. 4.4 Bahnen 10, 13, 16, 22, 25). Auch für MT-Xwnt4 und MTXwnt5a konnte gezeigt werden, dass XsFRP5 spezifisch mit einer Proteinbande interagiert, wenngleich die Interaktion nicht so stark zu sein scheint wie für MTXwnt3a gezeigt, sondern bei ca. $5 \%$ des gesamten MT-Xwnt4 Proteins und bei ca. 1\% für MT-Xwnt5a liegt (Abb. 4.4 Bahnen 12, 15). MT-Xwnt4 wurde auch in der Sediment-Fraktion $(P)$ detektiert, was auf eine schwache unspezifische Bindung an Protein G schließen lässt (Abb. 4.4 Bahn 11). MT-Xwnt8 zeigt die stärkste Interaktion mit XsFRP5, wobei in diesem Fall zwei Proteinbanden von MT-Xwnt8 mit einer Effizienz von ca. 15\% mit XsFRP5-HA ko-präzipitiert werden konnten (Abb 4.4 Bahnen 16-18). Für MT-Xwnt8b konnte nur eine Bande von ca. 75 kDa detektiert werden. Obwohl Xwnt8b in den Achsenduplikations-Experimenten sehr effizient von XsFRP5 inhibiert worden war, konnten hier nur kaum detektierbare Mengen an MT- 
Xwnt8b ko-präzipitiert werden (Abb. 4.4 Bahnen 19-21). MT-Xwnt11 zeigt ein sehr komplexes Bandenmuster, welches vermutlich ebenfalls durch unterschiedliche Modifikationen des Proteins hervorgerufen wird. XsFRP5-HA führte in diesem Fall zur Ko-Präzipitation von vier MT-Xwnt11 Banden im Bereich zwischen 55 und 70 kDa (Abb. 4.4 Bahnen 22-24). Für MT-Xwnt11R zeigte sich ebenfalls eine Interaktion mit XsFRP5-HA, hoch spezifisch für eine der verschiedenen detektierten Xwnt11RBanden mit einem Molekulargewicht von ungefähr 60 kDa (Abb. 4.4 Bahnen 25-27). 


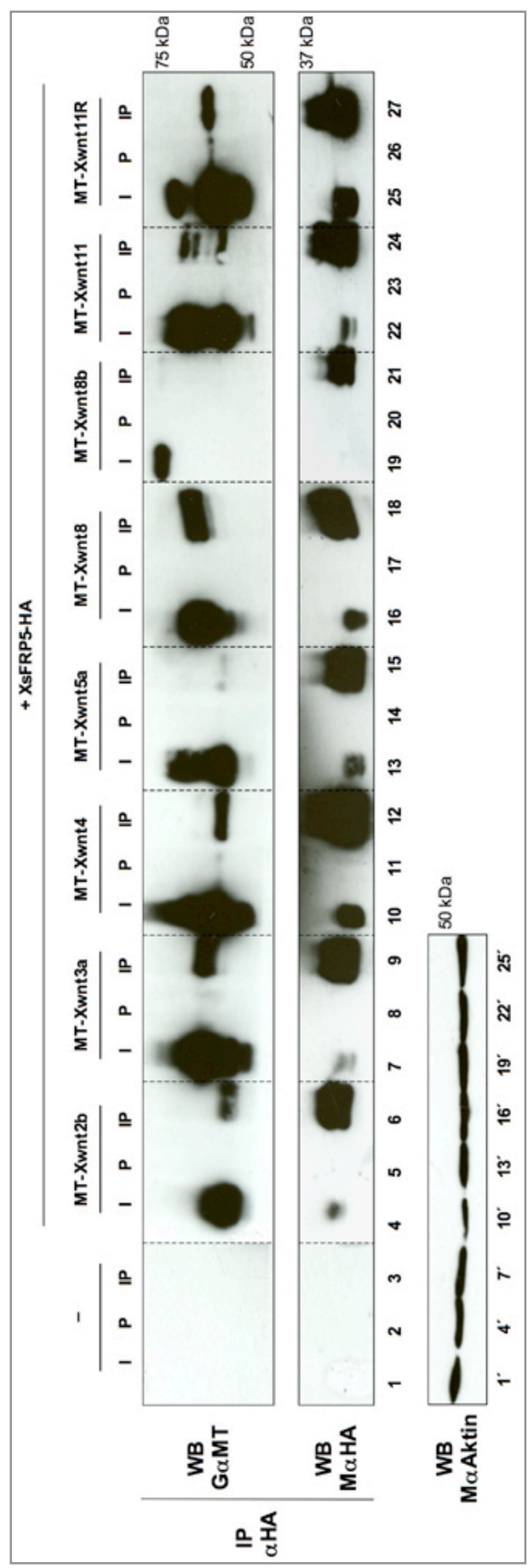

Abb. 4.4: XsFRP5 ko-präzipitiert mit allen untersuchten Xwnt Proteinen, zeigt jedoch eine unterschiedliche Präferenz einzelner Proteinbanden. Embryonen wurden im Zweizell-Stadium mit je 500pg XsFRP5-HA mRNA und 500pg MT-Xwnt mRNA injiziert und in Stadium 10,5 für die Ko-Immunopräzipitation gesammelt. $I=10 \%$ Input, $P=$ Sediment aus der Prä-Inkubation mit Protein G-Sepharose, IP = Immunopräzipitation mit dem $\alpha \mathrm{HA}$ Antikörper. Pro IP-Bahn wurde das Äquivalent aus 10 Embryonen geladen. Ein Western Blot (WB) mit dem GaMT Antikörper detektiert MT-Xwnt Proteine von 45 bis $75 \mathrm{kDa}$. Ein WB mit dem MaHA Antikörper zeigt zwei Banden von XsFRP5-HA, vermutlich mit oder ohne Signalpeptid bei ca. $35 \mathrm{kDa}$. Aktin konnte im WB bei ca. $45 \mathrm{kDa}$ detektiert werden. 
Um eine Auswahl der relevantesten Interaktionspartner zu erleichtern, wurden die in den Achsenduplikations-Experimenten und in der Ko-Immunopräzipitation erhaltenen Daten in Tabelle 4.1 gegenübergestellt. Dabei wurden die Xwnt Proteine nach ihrem Verhalten in den Achsenduplikations-Experimenten in drei Gruppen unterteilt: solche, die schon bei geringsten Mengen an XsFRP5 effizient inhibiert werden konnten $(++)$, solche, die bei höheren Dosen inhibiert werden konnten $(+)$ und solche, die durch XsFRP5 nicht effizient in ihrer Funktion beeinträchtigt wurden $((+))$. Da alle untersuchten MT-Xwnt Proteine mit XsFRP5 ko-präzipitierten, wurden sie in drei Gruppen unterteilt: solche, die nach Abschätzung der Bandenstärken von XsFRP5-HA und MT-Xwnts in der IP-Fraktion stark interagierten (++), solche, die eine moderate Bindung zeigten $(+)$ und solche, die nur sehr schwach zu binden schienen $((+))$

Tabelle 4.1: Zusammenfassung der erhaltenen Daten aus den Interaktionsstudien von XsFRP5 mit verschiedenen Xwnt Proteinen.

\begin{tabular}{|c|c|c|c|c|c|c|c|c|c|}
\hline & Xwnt & $2 b$ & $3 a$ & 4 & $5 a$ & 8 & $8 b$ & 11 & $11 R$ \\
\hline interagiert mit & Achsenduplikation & ++ & $(+)$ & ++ & + & + & ++ & $(+)$ & + \\
\hline XsFRP5 in der & Ko-IP* & ++ & ++ & ++ & $(+)$ & ++ & $(+)$ & + & + \\
\hline
\end{tabular}

${ }^{*}$ Ko-IP = Ko-Immunopräzipitation

Auffällig ist, dass XsFRP5-HA in der Ko-Immunopräzipitation auch jene Xwnts effizient bindet, welche in den Achsenduplikationsexperimenten nicht effektiv inhibiert worden sind, nämlich Xwnt3a und Xwnt11. Diese Diskrepanz lässt sich möglicherweise dadurch erklären, dass XsFRP5 Xwnt Liganden durch eine Bindung nicht nur von einer Interaktion mit Frizzled Transmembranrezeptoren abhalten kann, sondern diese Wnt Protein möglicherweise im extrazellulären Bereich stabilisiert. So würden sFRPs nur bei einer geringen Menge an verfügbaren Fz Rezeptoren als Antagonisten fungieren (Kawano und Kypta, 2003).

Die in den Achsenduplikations-Experimenten und der Ko-Immunopräzipitation erhaltenen Ergebnisse sollten Rückschlüsse auf die Interaktionspartner von XsFRP5 erlauben. Jedoch konnte kein Xwnt Protein als präferierter Interaktionspartner für XsFRP5 identifiziert werden. Vielmehr ist XsFRP5 in der Lage, verschiedene der 
untersuchten Xwnts stark zu binden und effizient zu inhibieren. Sowohl die Achsenduplikations-Experimente wie auch die Ko-Immunopräzipitationsdaten legen nahe, dass XsFRP5 im Rahmen seiner dynamischen Expression während der Organogenese verschiedenen Xwnt Proteinen entgegenwirken kann.

\subsubsection{3 Überexpression von XsFRP5 in ganzen Embryonen führt zu Defekten der anterior-posterioren Körperachse}

Eine weitere Möglichkeit, die Interaktion von XsFRP5 mit nicht-kanonisch wirkenden, endogenen Wht Liganden zu untersuchen, besteht in der Analyse der Effekte von XsFRP5 Überexpression auf die Gastrulation. Hierzu wurde XsFRP5 mRNA vegetal in frühe Teilungsstadien injiziert, um eine Expression des Proteins im prospektiven Entoderm zu begünstigen. Es zeigte sich, dass die frühe Überexpression von XsFRP5, die der endogenen Expression weit voraus eilt, zu einer starken Verlangsamung der Gastrulationsbewegungen führt (Abb. 4.5 A-D). Dieser Phänotyp gleicht einem sogenannten „Convergent Extension“-Phänotyp, wie er schon für die Inhibition verschiedener an der nicht-kanonischen Wnt Signaltransduktion beteiligter Proteine beschrieben worden ist (Kühl et al., 2001; Lu et al., 2004; Tahinci et al., 2007; Yamanaka et al., 2002). Diese Verlangsamung der Gastrulation ist von der injizierten Dosis an XsFRP5 abhängig (Abb. $4.5 \mathrm{D}$ ), wobei eine Missbildung des Blastoporus (wie in Abb. 4.5 C gezeigt) nicht dosis-abhängig verstärkt werden konnte. Eine Kultivierung injizierter Embryonen bis ins frühe Schwanzknospenstadium zeigte, dass diese Embryonen im Vergleich mit nichtinjizierten Kontrollen eine stark verkürzte Körperachse aufweisen (Abb. 4.5 E, F). Auch dieser Phänotyp korreliert mit einer Störung der konvergenten Extension und kann somit auf einen Defekt der durch den Wnt/PCP Signalweg gesteuerten planaren Zellpolarität zurückgeführt werden. Als das hierfür essentielle Wnt Protein wurde Xwnt5a beschrieben (Moon et al., 1993). Diese Beobachtung bestätigt die oben beschriebene Interaktion (Punkt 4.1.2.1 und 4.1.2.2) von XsFRP5 mit Xwnt5a, wobei die frühe ektopische Sekretion von XsFRP in Ento- und Mesoderm hier zum Auftreten eines „Convergent Extension“-Phänotyps führt. 

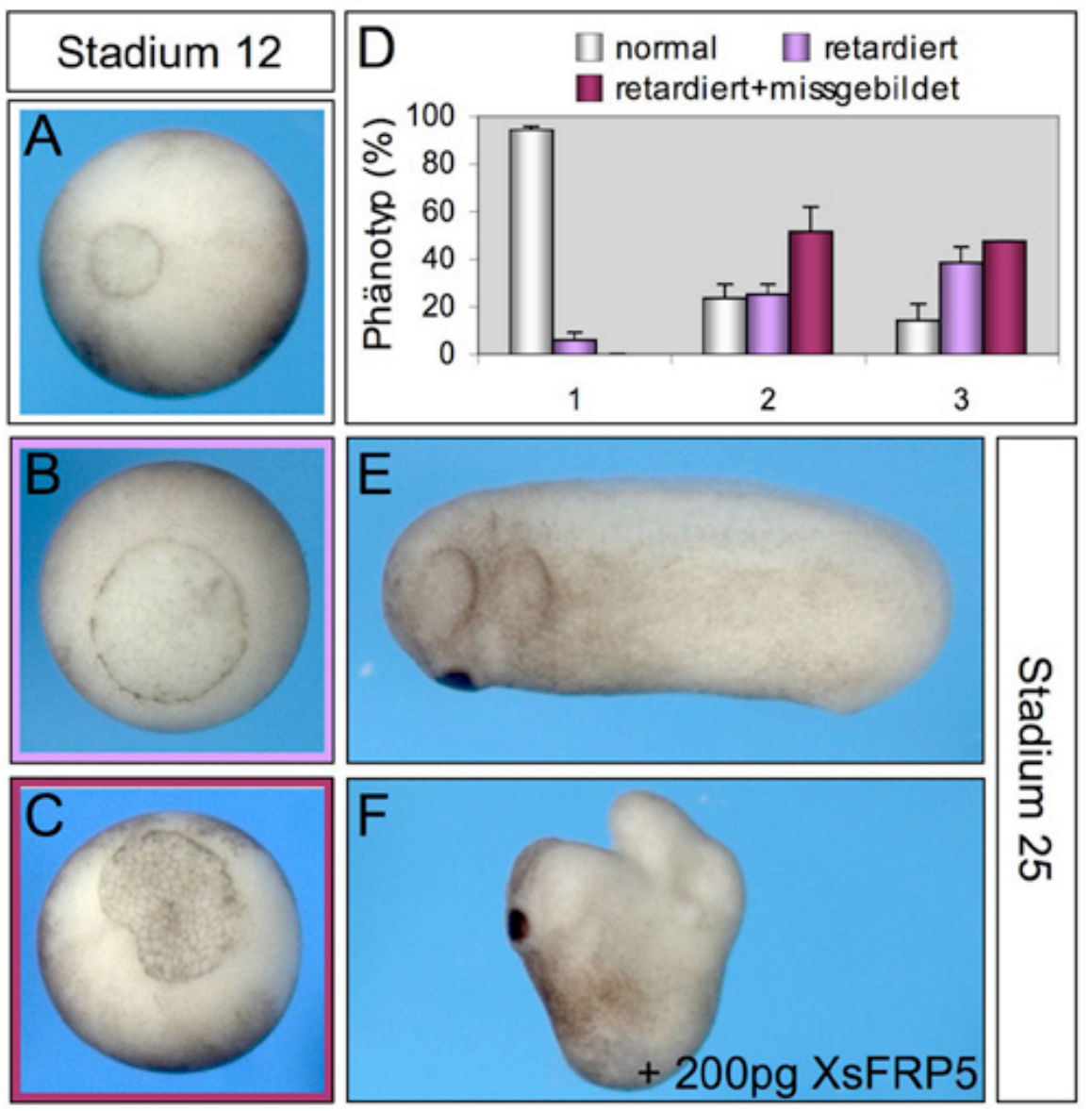

Abb. 4.5: Frühe Überexpression von XsFRP5 verlangsamt die Gastrulationsbewegungen und induziert Defekte in der konvergenten Extension. Injektion von 200pg XsFRP5 mRNA führt zur Retardierung (B) und Missbildung (C) des Blastoporus im Vergleich zu einem nicht injizierten Zwillingsembryo (A). Statistische Auswertung der Blastoporusgröße und Form in Kontrollembryonen (1), mit 100pg XsFRP5 mRNA (2) injizierten Embryonen sowie mit 200pg XsFRP5 mRNA (3) injizierten Embryonen (D). Nach Injektion von 200pg XsFRP5 mRNA zeigt ein Zwillingsembryo zu (E) eine drastische Verkürzung der anterior-posterioren Körperachse (F). Posteriore Ansicht mit dorsal nach oben $(A-C)$. Laterale Ansicht mit anterior nach links (E, F).

Da für weiterführende Analysen im Hinblick auf die Organentwicklung Embryonen im späten Schwanzknospen- bzw. Kaulquappenstadium benötigt werden, ist eine Injektion von XsFRP5 in frühe Teilungsstadien in dieser Hinsicht nicht zielführend. 


\subsubsection{Funktionelle Charakterisierung von XsFRP5 während der Organogenese}

Auf Grund der dynamischen Expression in der Leber und an der Grenze zwischen Magen und Duodenum wurde die Funktion von XsFRP5 im Kontext der entodermalen Organogenese weiter untersucht.

\subsubsection{Der Funktionsverlust von XsFRP5 nach Injektion von „antisense” Morpholino Oligonukleotiden führt zu einer Reduktion der ventralen Pankreasanlage und zu einer Vergrößerung des Magens}

Die Auswirkungen des Funktionsverlustes eines Proteins können in Xenopus laevis mit Hilfe sogenannter „antisense” Morpholino Oligonukleotide untersucht werden. Durch die Bindung dieser komplementären Morpholino Oligonukleotide an die mRNA wird die Translation des Proteins unterdrückt. Um effektiv zu sein, sollte das Morpholino Oligonukleotid zu 100\% komplementär zur Zielsequenz sein und direkt am Startkodon oder aber im 5' untranslatierten Bereich (5'-UTR) binden. Durch eine Analyse der Xenopus laevis und tropicalis EST-Datenbanken konnte für XsFRP5 die Existenz eines Pseudoallels in Xenopus laevis nachgewisen werden. Die im Folgenden beschriebenen Morpholino Oligonukleotide wurden in ihrer Sequenz so gewählt, dass die Translation aller Allele von XsFRP5 inhibiert werden kann. Wie in Abb. 4.6 A gezeigt, wurden zwei verschiedene Morpholino Oligonukleotide gegen XsFRP5 gewählt, wobei XsFRP5-Mo1 im Bereich des Startkodons, und XsFRP5Mo2 50bp aufwärts im 5'-UTR bindet. Zusätzlich wurde ein „miss-match“-Morpholino mit fünf willkürlichen Basenaustauschen in der sonst der XsFRP5-Mo1 entsprechenden Sequenz als Kontrolle gewählt. Der Sequenzabschnitt des 5'-UTRs von XsFRP5, welcher die Morpholino-Bindestellen aufweist, ist in Abb. 4.6 B dargestellt. Die Sequenzunterschiede zwischen dem „Expressed Sequence Tag“ (EST) von XsFRP5 und seinem Pseudoallel wurden rot markiert. Die MorpholinoBindestellen liegen in Bereichen 100\%-iger Sequenzidentität, wie durch die schwarzen Balken veranschaulicht. Das XsFRP5 Startkodon wurde fett gedruckt dargestellt. 


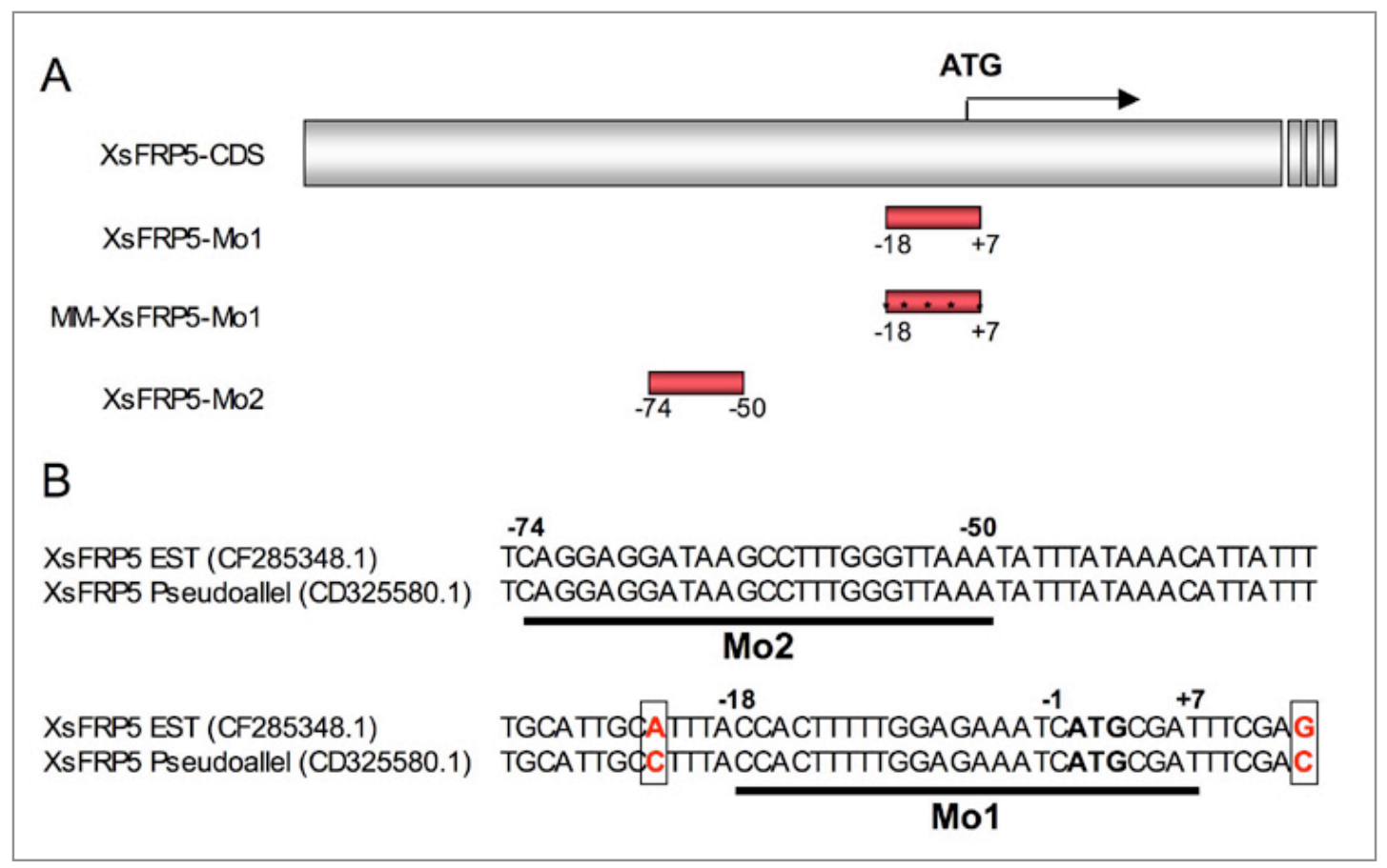

Abb. 4.6: Verschiedene ,,antisense” Morpholino Oligonukleotide wurden komplementär zu XsFRP5 und seinem Pseudoallel gewählt. (A) Der XsFRP5-Mo1 und der MM-XsFRP5Mo1, welcher sich durch fünf Basenaustausche vom Mo1 unterscheidet, wurden komplementär zur Region um das Startkodon gewählt. XsFRP5-Mo2 bindet im 5' untranslatierten Bereich (5'-UTR) von XsFRP5. (B) Eine Datenbankanalyse zeigte Unterschiede in der Basensequenz des $5^{\prime}$-UTRs zwischen dem XsFRP5 EST und dem Pseudoallel (in rot dargestellt). Die Morpholino-Bindestellen liegen zwischen diesen Bereichen (schwarze Balken). Das Startkodon ist fett gedruckt. Die NCBI DatenbankNummern für den EST und das Pseudoallel sind in Klammern angegeben.

Die Morpholino Oligonukleotide wurden in vitro und in vivo auf ihre Effektivität untersucht. Um die Effektivität der XsFRP5-Morpholinos in vitro zu analysieren, wurde eine gekoppelte Transkriptions- und Translationsreaktion durchgeführt, im Zuge derer ${ }^{35}$ S-Methionin in das XsFRP5 Protein inkorporiert wurde. Es wurden ansteigende Konzentrationen der XsFRP5-Morpholinos eingesetzt. Sowohl der XsFRP5-Mo1, wie auch der XsFRP5-Mo2, konnten die Translation von XsFRP5 effizient inhibieren, während der MM-XsFRP5-Mo1 nur eine sehr leichte Reduktion der XsFRP5 Translationseffizienz bewirken konnte. Eine Kombination aus XsFRPMo1 und Mo2 stellte sich als besonders effizient in der Blockierung der Translation heraus (Abb. 4.7 A). Zur in vivo Analyse wurde ein Fusionskonstrukt bestehend aus dem XsFRP5 5'-UTR von -311bp bis $+7 \mathrm{bp}$ „in frame“ vor dem Leserahmen für sechs Myc-Epitope und das „Green Fluorescent Protein“ (GFP) generiert. Dieses wurde 
animal in frühe Teilungsstadien injiziert und die Embryonen im Gastrulastadium auf GFP Expression untersucht (Abb. 4.7 B). XsFRP5-Mo1 und Mo2 unterbinden eine Expression des GFP Proteins völlig. Der MM-XsFRP5-Mo1 hingegen konnte die Translation von GFP nicht verhindern. Zur Kontrolle wurden alle drei Morpholino Oligonuleotide mit GFP ohne Fusion des XsFRP5 5'UTR ko-injiziert. Dabei konnte kein Rückgang der GFP Fluoreszenz verzeichnet werden, ein weiteres Indiz für die Spezifität der Morpholinos für XsFRP5.

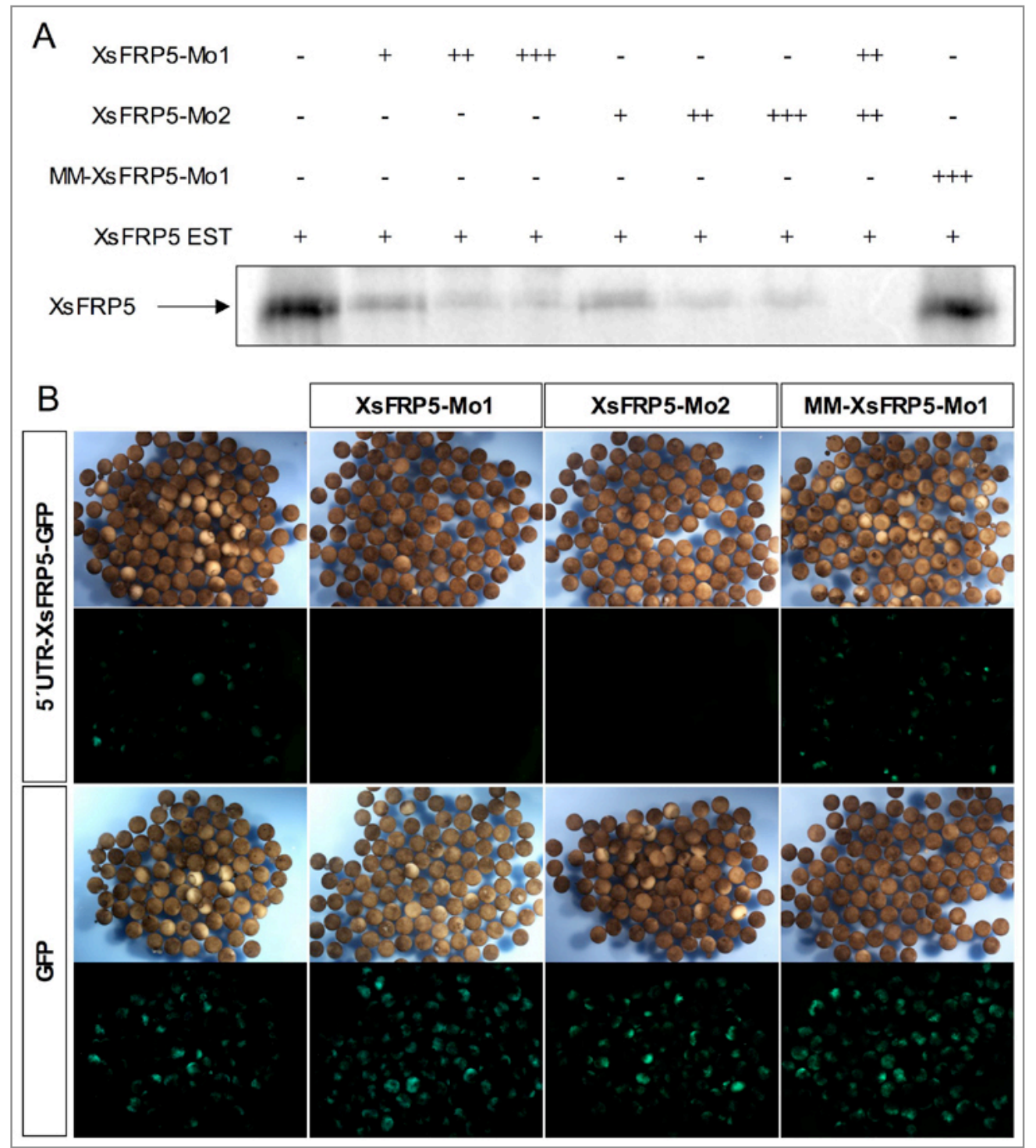

Abb. 4.7: Mehrere „antisense” Morpholino Oligonukleotide komplementär zu XsFRP5 können die Translation effizient unterdrücken. (A) Die in vitro Analyse der Morpholino Oligonukleotide in einem gekoppelten Transkriptions- und Translationsansatz zeigt, dass beide XsFRP5-Morpholinos die Translation effizient unterdrücken können, wobei die Kombination beider Morpholinos das beste Ergebnis erzielte. Der MM-XsFRP5-Mo1 konnte die Translation nicht signifikant inhibieren. (B) Sowohl 4ng XsFRP5-Mo1, als auch 4ng 
XsFRP5-Mo2, unterdrücken die Translation von GFP zu 100\%, während 4ng des MMXsFRP5-Mo1 keine Wirkung zeigen. Nach Injektion der GFP mRNA ohne den XsFRP5 5'UTR kommt es in keinem Fall zu einer Inhibition der Translation von GFP durch Morpholino Ko-Injektion.

Um den Einfluß von XsFRP5 auf die Entwicklung gastrointestinaler Organe zu untersuchen, wurden die Morpholino Oligonukleotide vegetal in frühe Teilungsstadien injiziert, wobei die Ko-Injektion von LacZ mRNA zur Kontrolle der Lokalisation der Morpholino Oligonukleotide diente. Die Injektion von XsFRP5-Mo1 wurde mehrfach mit unterschiedlichen Konzentrationen und in Kombination mit XsFRP5-Mo2 durchgeführt, in dieser Arbeit wird ein repräsentatives Experiment gezeigt (Abb. 4.8). Die erhaltenen Ergebnisse entsprachen in allen Fällen den in Abb. 4.8 gezeigten. Die Embryonen wurden im späten Schwanzknospen- bzw. im Kaulquappenstadium fixiert und mittels whole-mount in situ Hybridisierung auf die Expression verschiedener Markergene untersucht. Alle Organe, welche XsFRP5 exprimieren, oder proximal zu einem XsFRP5 exprimierenden Gewebe liegen, wurden untersucht, wobei die Analyse von Vorläuferzell- und Differenzierungsmarker des Herzens (anhand von Nkx2.5), der Leber und des Darmtraktes (Fibrinogen) keinen Effekt zeigte (Abb. 4.8 M-R). Bei Nkx2.5 handelt es sich um ein Mitglied der Nkx-Familie der Homöobox-Transktiptionsfaktoren, der spezifisch für das frühe Herzfeld ist (Tonissen et al., 1994). Es konnten im Stadium 37/38 keine Unterschiede in der Expression von Nkx2.5 in der Herzanlage zwischen Kontrollembryonen und mit XsFRP5-Morpholinos injizierten Embryonen festgestellt werden (Abb. 4.8 M-O). Fibrinogen, ein wichtiges Protein, das bei der Blutgerinnung und an der Entzündungsreaktion beteiligt ist und in Xenopus Embryonen im Stadium 40 in der Leber sowie dem Darmepithel exprimiert ist (Chen et al., 2003), wurde ebenfalls untersucht. Weder die Leber noch das Darmepithel scheinen nach Injektion von XsFRP5-Morpholinos in der Expression von Fibrinogen beeinträchtigt zu sein (Abb. 4.8 P-R).

Die Analyse des pankreatischen Vorläufermarkers Ptf1a/p48, einem bHLHTranskriptionsfaktor, ergab eine Reduktion der ventralen Pankreasanlage (Abb. 4.8 A-C). Dabei zeigte sich auch, dass andere Expressionsdomänen wie die Retina und das dorsale Pankreas nicht vom Funktionsverlust von XsFRP5 betroffen sind. Die dorsale Pankreasanlage scheint nach Injektion der XsFRP5-Morpholinos schwächer 
gefärbt als im Kontrollembryo, dieser Effekt lässt sich jedoch durch eine stärkere Makierung der dorsalen Anlage durch überliegendes Mesoderm begründen (Abb. 4.8 C). In den Ptf1a/p48-gefärbten Vibratomschnitten lässt sich erkennen, dass die dorsale Pankreasanlage (markiert mit blauen Pfeilspitzen) in den Morpholinoinjizierten Embryonen vergleichbar groß wie im Kontrollembryo ist (Abb. 4.8 A-C). Die ventralen Anlagen hingegen scheinen schmäler und verkürzt (rote Pfeilspitzen), ein Effekt der auch in den MM-XsFRP5-Mo1 injizierten Embryonen, wenngleich deutlich schwächer, zu beobachten ist. Dennoch ist anzumerken, dass alle Morpholino-injizierten Embryonen ventrale Pankreasanlagen aufwiesen, was auf einen Wachstumseffekt und nicht auf eine Wirkung von XsFRP5 auf die Spezifizierung dieser Organanlage hinweist. Die verringerte Größe der ventralen Pankreasanlage scheint auch mit einer leicht veringerten Größe des differenzierten Organs zu korrelieren, wie durch die Expression des exokrinen Markergens XPDIp gezeigt wird (Abb. 4.8 D-F). Allerdings ist der Effekt relativ schwach. Es lässt sich nicht eindeutig feststellen, ob der ventrale Anteil des Pankreas reduziert ist, oder womöglich das Duodenum einen größeren Teil des Pankreas verdeckt.

Um diese Frage zu beantworten, wurden Explantate des gastrointestinalen Trakts von Morpholino-injizierten und Kontrollembryonen auf die Expression von Sox2 untersucht (Abb. $4.8 \mathrm{G}-\mathrm{I}$ ). Sox2 ist ein ektodermal, aber auch ösophagial und im Magen exprimierter „SRY-related“ HMG-Box Transkriptionsfaktor (Chalmers et al., 2000; Mizuseki et al., 1998). Es zeigte sich nach Verlust von XsFRP5 eine posteriore Expansion der Sox2 Expression (markiert durch einen blauen Pfeil), welche möglicherweise den Effekt auf die XPDIp Expression erklärt. Sollte es sich um einen transienten Wachstumsdefekt handeln, könnte der ventrale Pankreas in späteren Stadien durch einen verbreiterten Magen stärker maskiert werden. Allerdings ist es in Kontrollembryonen das Duodenum, welches durch die Darmrotation über dem Pankreas zu liegen kommt. Um zu klären, ob der Verlust von XsFRP5 zur Expansion des Magens auf Kosten des Duodenums führt, wurden injizierte Embryonen auf die Expression von XIHbox8 untersucht (Abb. $4.8 \mathrm{~J}-\mathrm{L}$ ). XIHbox8, ein HomöodomänenTranskriptionsfaktor, wird in allen pankreatischen Vorläuferzellen sowie dem Duodenum exprimiert. Wie schon für die Ptf1a/p48 Expression konnte auch anhand dieses Markergens eine Reduktion der ventralen Pankreasanlage festgestellt werden (markiert mit einem roten Pfeil). Zusätzlich lässt sich ein starker Rückgang der 
duodenalen XIHbox8 Expression erkennen (markiert mit weißen Pfeilen), was auf eine Vergrößerung des Magens unter Verlust duodenaler Strukturen hinweist.

Generell war nach Analyse aller verwendeten Markergene erkennbar, dass auch der MM-XsFRP5-Mo1 die bereits für die Ko-Injektion der beiden XsFRP5-Morpholinos beschriebenen Phänotypen (siehe oben) hervorrief, wenngleich mit nicht signifikanter statistischen Häufigkeit (Daten nicht gezeigt). Lediglich die Reduktion der XIHbox8 Färbung im Duodenum war auch nach Injektion des "miss match“Morpholinos deutlich erkennbar (Abb. $4.8 \mathrm{~K}$ ). In den durchgeführten Spezifitätskontrollen zeigte der MM-XsFRP5-Mo1 in vivo und in vitro keine Inhibition der Translation von XsFRP5 (Abb. 4.7). Die beobachtete schwache Inhibition endogener XsFRP5 Expression könnte durch die hohe Konzentration von „miss match“-Morpholino Molekülen in Vergleich zur XsFRP5 mRNA bedingt sein. 


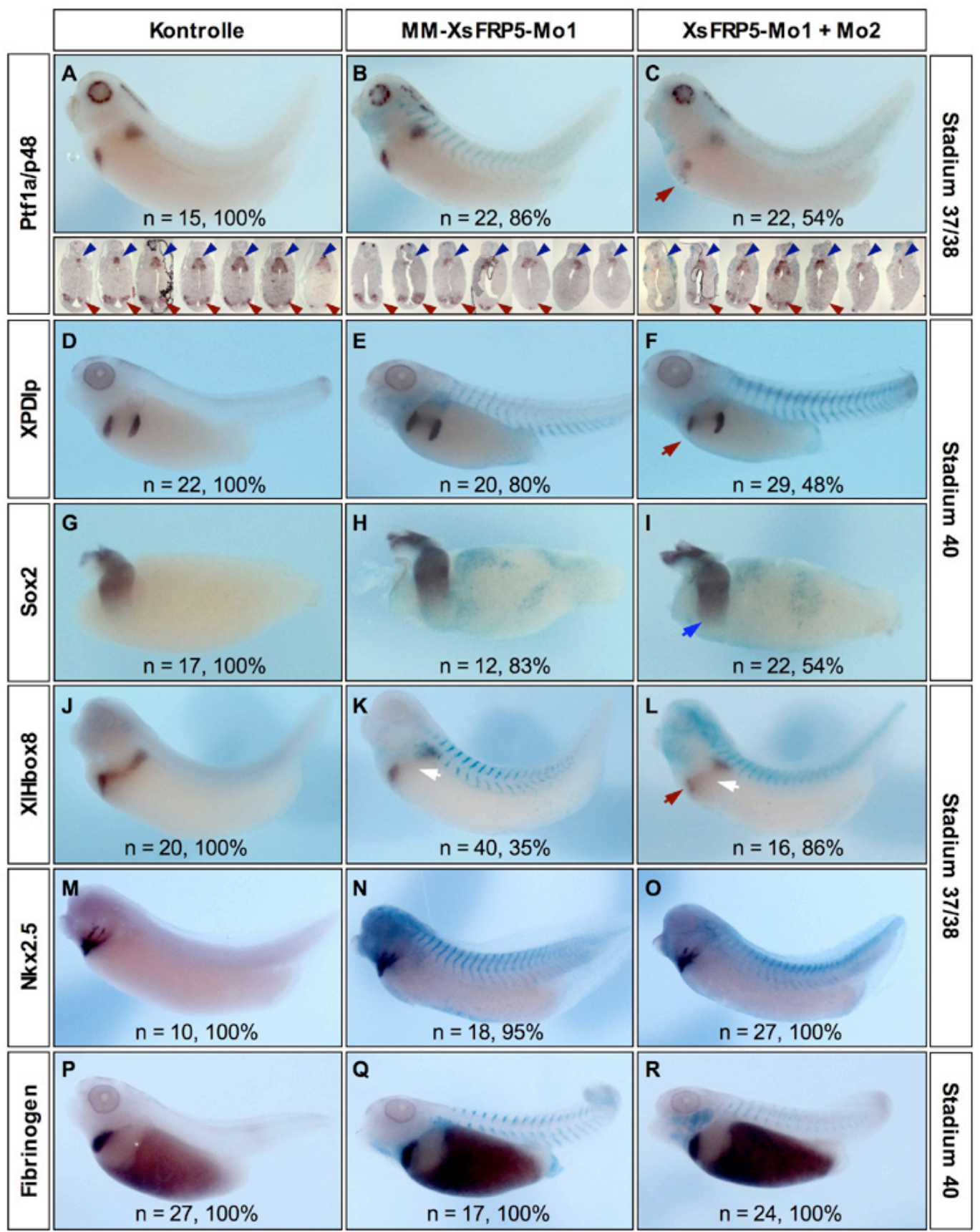

Abb. 4.8: Der Funktionsverlust von XsFRP5 im Entoderm führt zu einer Reduktion der ventralen Pankreasanlage sowie zu einer Vergrößerung des Magens unter Verlust duodenaler Stukturen. Kontrollembryonen, mit 4ng MM-XsFRP5-Mo1 injizierte Embryonen oder mit einer Kombination von 4ng XsFRP5-Mo1 und 2ng XsFRP5-Mo2 injizierte Embryonen wurden einer whole-mount in situ Hybridisierung gegen Ptf1a/p48 (A, B, C), XPDIp (D, E, F), Sox2 (G, H, I), XIHbox8 (J, K, L), Nkx2.5 (M, N, O) und Fibrinogen (P, Q, R) unterzogen. (A-C) Vibratom-Schnitte Ptf1a/p48-gefärbter Embryonen zeigen die dorsale und die beiden ventralen Pankreasanlagen. 150pg LacZ mRNA wurden als "lineage tracer" koinjiziert. Der rote Pfeil markiert das ventrale Pankreas, der blaue Pfeil die posteriore Expansion der Sox2 Expression und weiße Pfeile das Duodenum. Blaue Pfeilspitzen markieren die dorsale Pankreasanlage, rote Pfeilspitzen die beiden ventralen Anlagen. Laterale Ansicht mit anterior nach links. 
Die relativ geringe Anzahl an untersuchten Embryonen lag in der starken Toxizität der verwendeten Morpholino Oligonukleotide begründet. So wurde mit einer Injektion von insgesamt 6ng an XsFRP5-Morpholinos der Rahmen des Möglichen voll ausgeschöpft. Die geringe statistische Wahrscheinlichkeit der Phänotypen von ungefähr 50\% könnte durch die besseren Überlebenschancen von Embryonen, welche weniger Morpholino Moleküle im prospektiven Entoderm aufwiesen, erklärt werden, da die Injektion geringerer Dosen an XsFRP5-Morpholino Oligonukleotiden generell in sehr schwachen bis nicht detektierbaren Effekten resultierte (Daten nicht gezeigt).

Zusammenfassend kann festgehalten werden, dass nach Funktionsverlust von XsFRP5 eine möglicherweise transiente Reduktion der ventralen Pankreasanlage, sowie eine Expansion des Magens in den Bereich des Duodenums auftritt. Andere Organe, wie Herz und Leber sowie das Darmepithel, schienen nicht von einem „Knock-down“ von XsFRP5 betroffen zu sein.

\subsubsection{Die intrazelluläre Stimulation kanonischer Wnt Signaltransduktion bewirkt eine Reduktion der ventralen und einen Verlust der dorsalen Pankreasanlage}

Nachdem die Funktion der XsFRP5 vermittelten Inhibition der Wnt Signaltransduktion während der Entwicklung entodermaler Organe auf extrazellulärer Ebene untersucht wurde, sollte die Analyse auf die Transkriptionsfaktor-Ebene erweitert werden. Die Klonierung und ektopische Expression verschiedener Lef1- bzw. $\beta$-Catenin basierter Konstrukte an die Glucocorticoid-Rezeptor-Ligandenbindedomäne (GR-LBD, Abb. 4.9) ermöglichte die Entoderm-spezifische und zeitlich kontrollierte Stimulation kanonischer Wnt Signaltransduktion.

Bei Lef1-GR handelt es sich um ein Fusionskontrukt des murinen Lef1 C-terminal an die GR-LBD (Abb. 4.9). Lef1 gehört zu den HMG-Box Transkriptionsfaktoren und weist zusätzlich zur DNA-bindenden HMG-Domäne eine N-terminale $\beta$-CateninBindedomäne und eine Transaktivierungsdomäne auf. Nach Injektion von Lef1-GR 
mRNA in Xenopus Embryonen wird eine ektopische Aktivierung der kanonischen Wnt Signaltransduktion erwartet. Nach einer Deletion der $\beta$-Catenin-Bindedomäne bzw. der HMG-Domäne sollen die erhaltenen Konstrukte Lef $\Delta B D-G R$ und Lef $\Delta$ HMGGR nach ektopischer Expression dominant-negativ wirken. Um kanonische Wnt Signaltransduktion konstitutiv aktivieren zu können, wurde eine Variante des murinen $\beta$-Catenin C-terminal an die GR-LBD fusioniert. In $\beta$-CateninS33A wurde das Serin an Position 33 durch ein Alanin ersetzt, wodurch die GSK3 $\beta \beta$-Catenin nicht mehr phosphorylieren und dadurch der proteolytischen Degradation zuführen kann (Abb. 4.9). Zusätzliche Punktmutationen führten zu Aminosäureaustauschen an Position 37 (Serin zu Alanin) sowie an Position 41 (Tyrosin zu Alanin), wodurch neben der primären auch alle sekundären Phosphorylierungsstellen für GSK3 $\beta$ zerstört sind.

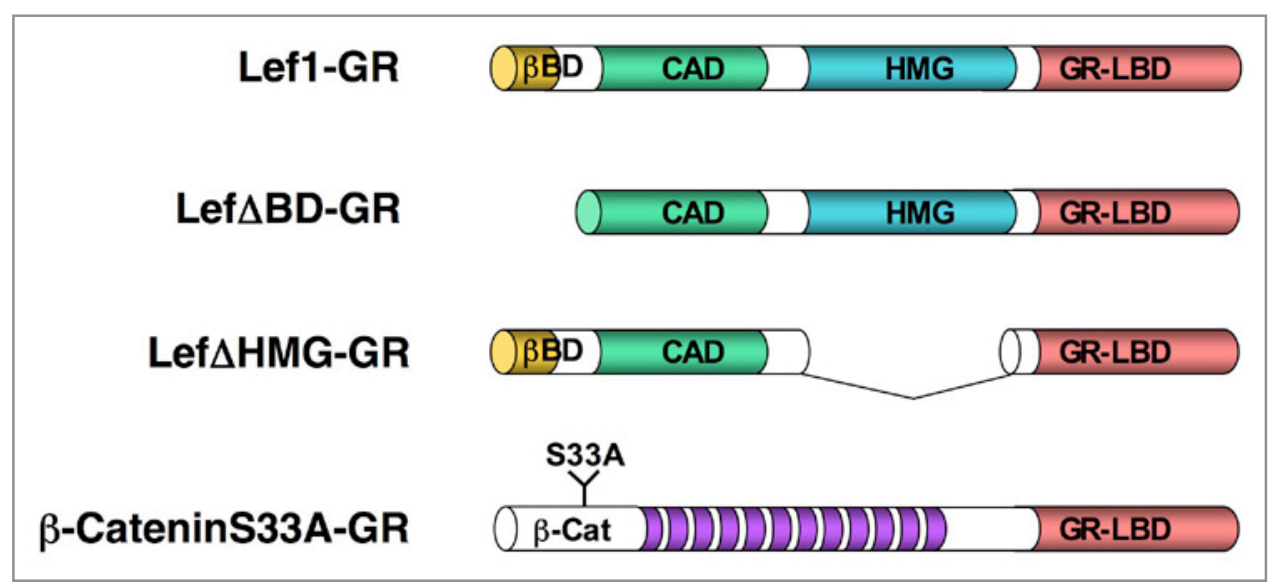

Abb. 4.9: Domänenstruktur verschiedener Lef1- bzw. $\beta$-Catenin basierter Hormoninduzierbarer Fusionskonstrukte. $\mathrm{BD}=\beta$-Catenin Bindedomäne, $\mathrm{CAD}=$ Transktivierungsdomäne, HMG = "High Mobility Group“ DNA-Bindedomäne, GR-LBD = Glucocorticoid Rezeptor Ligandenbindedomäne. S33A symbolisiert den Aminosäureaustausch von Serin33, Serin37 und Tyrosin41 zu Alanin. Die 12 Armadillo Repeat-Sequenzen in $\beta$-Catenin sind violett dargestellt.

Die Fusionskonstrukte wurden auf ihre Wirkung auf die dorso-ventrale Achsenspezifizierung untersucht, wobei die konstitutiv-aktiv wirkenden Konstrukte in eine ventrale Blastomere im 4-Zell-Stadium und die dominant-negativ wirkenden Konstrukte in beide dorsalen Blastomeren im 4-Zell-Stadium injiziert wurden (Abb. 4.10). Die Induktion der Konstrukte durch Dexamethason-Behandlung erfolgte im 16Zell-Stadium und wurde über Nacht bis zum Beginn der Gastrulation fortgesetzt. Die Embryonen wurden nach Injektion der konstitutiv-aktiven Konstrukte zwischen 
Stadium 30 und 35 auf die Ausprägung einer zweiten Körperachse oder nach Injektion der dominant-negativen Konstrukte auf eine Ventralisierung untersucht.

Es zeigte sich, dass besonders Lef1-GR eine gute Induzierbarkeit in Achsenduplikations-Experimenten, sowie wenig bis keine Hintergrundaktivität ohne Hormon-Induktion besitzt (Abb. 4.10 A). Lef1-GR induziert nach Behandlung mit Dexamethason beinahe 100\%-ige Achsenduplikation, während uninduziertes Lef1GR kaum einen Effekt auf die Achsendetermination zeigt. $\beta$-CateninS33A-GR ist nicht so effektiv in der Induktion zweiter Körperachsen wie Lef1-GR, zeigt jedoch auch ohne Hormon-Behandlung einen starken Effekt. Die Injektion niedrigerer Konzentrationen an $\beta$-CateninS33A-GR führte nicht mehr zu einer signifikanten Induktion zweiter Körperachsen. Die Injektion von $\beta$-CateninS333A diente als Kontrolle, um den Effekt von stabilisiertem $\beta$-Catenin auf die frühembryonale Musterbildung darzustellen (Abb. 4.10 B). Die beiden dominant-negativen Konstrukte sollten durch die Inhibition der kanonischen Wht Signaltransduktion auf der prospektiven dorsalen Seite zu einer Ventralisierung der Embryonen führen. Dieser Effekt konnte beobachtet werden, jedoch zeigen sowohl Lef $\triangle B D-G R$ (Abb. 4.10 C) wie auch Lef $\Delta$ HMG-GR (Abb. 4.10 D) auch ohne Induktion durch Dexamethason einen stark ventralisierenden Effekt. Die Injektion einer niedrigeren Konzentration an mRNA wirkte sich bei Lef $\triangle B D-G R$ nicht positiv auf die Hintergrundaktivität ohne Dexamethason-Behandlung aus (Abb. 4.10 C). Die Injektion einer niedrigeren Konzentration von Lef $\Delta \mathrm{HMG}-\mathrm{GR}$ reduzierte die Hintergrundaktivität des Fusionsproteins auf $10 \%$, jedoch konnte auch nach Dexamethason-Behandlung keine für weiterführende Experimente ausreichend starke Ventralisierung der Embryonen mehr hervorgerufen werden (Abb. 4.10 D). 


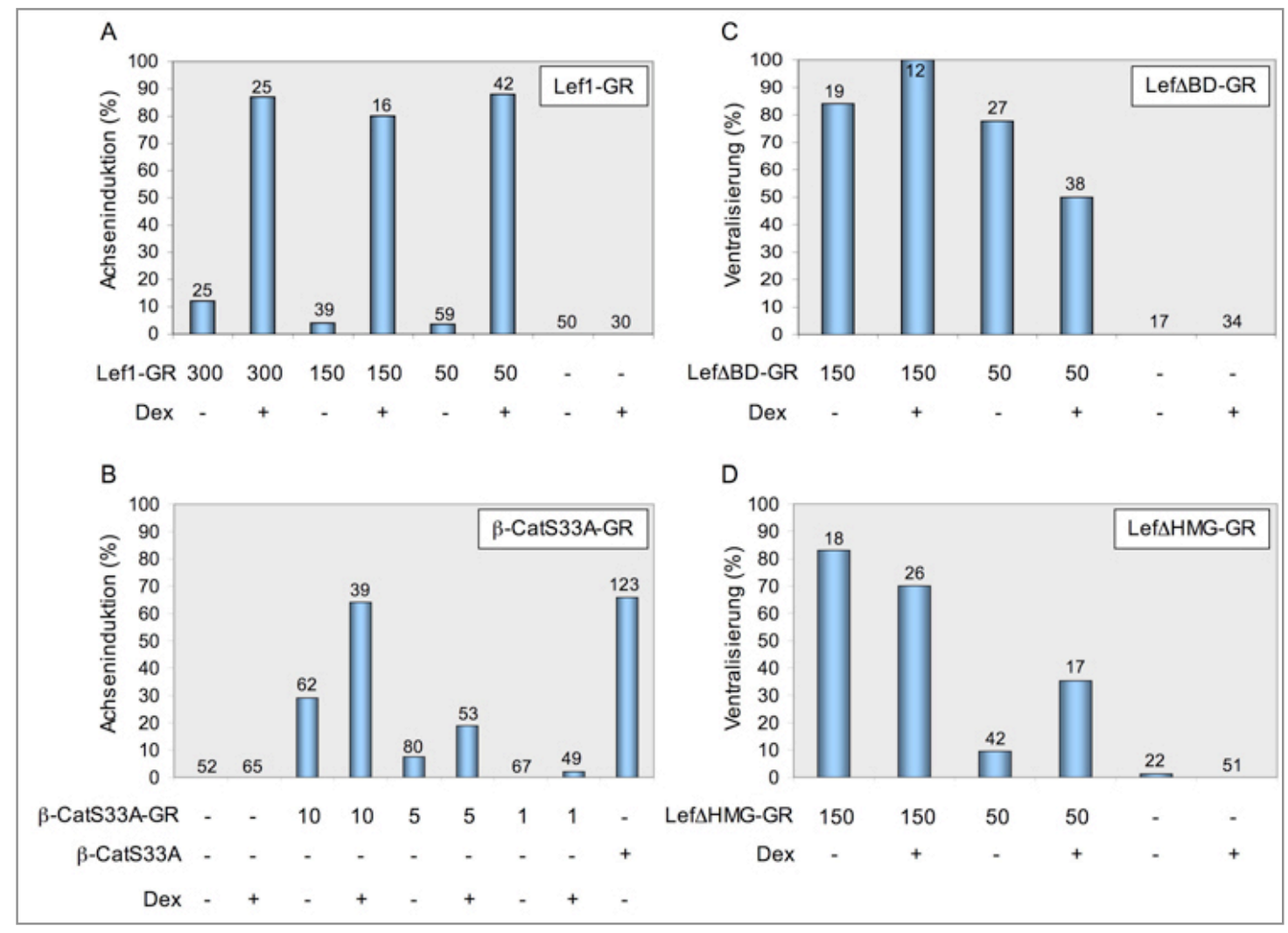

Abb. 4.10: Bei Injektion in frühe Teilungsstadien induzieren konstitutiv-aktiv wirkende Konstrukte nach Dexamethason-Behandlung dorsale Achsenduplikation, während dominant-negative Konstrukte zu einer Ventralisierung der Embryonen führen. Die konstitutiv-aktiv wirkenden, Hormon-induzierbaren Konstrukte wurden im 4-Zell-Stadium in eine von zwei ventralen Blastomeren in den angegebenen Konzentrationen (pg/Embryo) injiziert. Die dominant-negativ wirkenden Konstukte wurden in beide dorsalen Blastomeren im 4-Zell-Stadium injiziert. Die Dexamethason-Behandlung (Dex) wurde vom 16-Zell-Stadium bis zum Beginn der Gastrulation im Dunkeln durchgeführt. Da die Experimente nur 1x durchgeführt wurden, ist die jeweilige Zahl an Embryonen über den einzelnen Balken aufgeführt.

Für weiterführende Studien wurde anhand der in den AchsenduplikationsExperimenten erzielten Ergebnisse Lef1-GR ausgewählt. Die Auswirkungen der Lef1-GR-vermittelten, entoderm-spezifischen Stimulation der kanonischen Wnt Signaltransduktion zu unterschiedlichen Zeitpunkten der Embryonalentwicklung auf die Ausbildung verschiedener Organanlagen wurde in einer weiterführenden Studie bearbeitet (Melchert, Diplomarbeit 2007).

Im Wesentlichen wurde Lef1-GR mit LacZ mRNA als "lineage tracer“ in das prospektive Entoderm früher Embryonalstadien injiziert und Lef1-GR zu 
unterschiedlichen Zeitpunkten der Entwicklung durch Dexamethason-Behandlung aktiviert. Dazu wurden das Ende der Gastrulation (Stadium 13), ein spätes NeurulaStadium (Stadium 18) und ein Zeitpunkt während der Ausknospung unterschiedlicher Organanlagen (Stadium 25) zur ektopischen Aktivierung von Lef1-GR gewählt. Eine umfassende Analyse verschiedener entodermaler Markergene mittels whole-mount in situ Hybridisierung folgte (Melchert, Diplomarbeit 2007). Im Besonderen soll hier die Auswirkung einer stimulierten kanonischen Wnt Signaltransduktion auf das exokrine Markergen XPDIp hervorgehoben werden. Nach Induktion von Lef1-GR mit Dexamethason zu allen untersuchten Zeitpunkten kam es zu einem Verlust exokriner Zellen der dorsalen Pankreasanlage (Abb. 4.11 F-H). Das ventrale Pankreas war reduziert, wobei eine Korrelation zwischen der Reduktion der ventralen Anlage und dem Zeitpunkt der Dexamethason-Behandlung beobachtet werden konnte (Abb. 4.11 F-H). Je später die Dexamethason-Behandlung durchgeführt wurde, umso schwächer ausgeprägt war die Reduktion der ventralen Pankreasanlage.

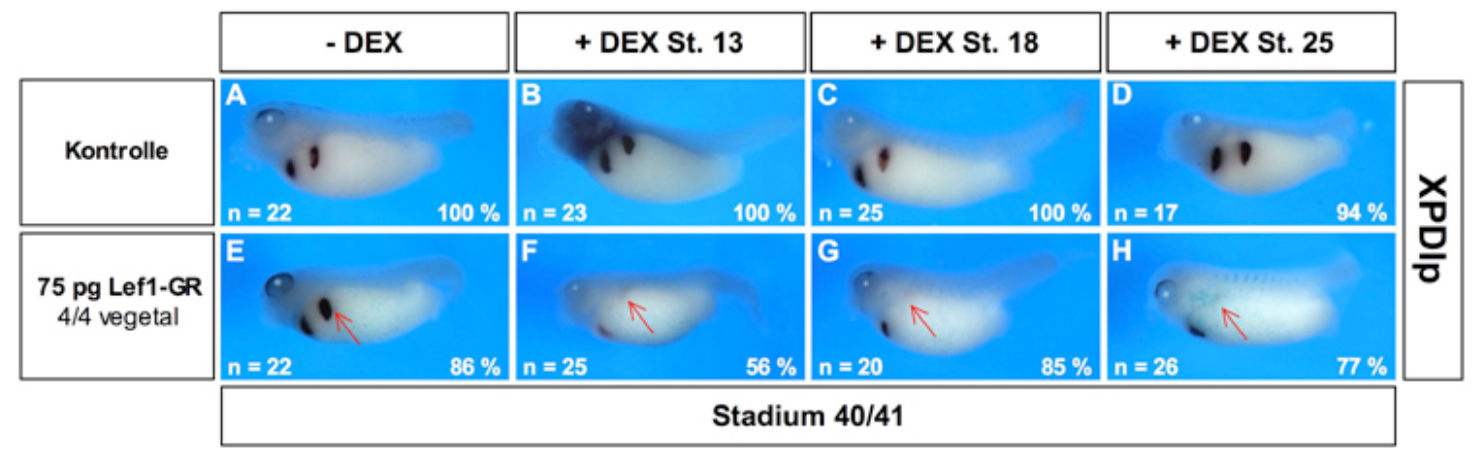

Abb. 4.11: Die Aktivierung von Lef1-GR zu unterschiedlichen Zeitpunkten der Entwicklung resultiert in einem Verlust der dorsalen und einer Reduktion der ventralen Pankreasanlage [entnommen aus (Melchert, Diplomarbeit 2007)]. Uninjizierte Kontrollembryonen (A-D) und mit Lef1-GR injizierte Embryonen (E-H) wurden mit Hilfe einer in situ Hybridisierung auf die Expression von XPDIp untersucht. Die Induktion von Lef1-GR durch Dexamethason-Behandlung erfolgte in Stadium $13(\mathrm{~B}, \mathrm{~F})$, Stadium $18(\mathrm{C}, \mathrm{G})$ und Stadium $25(\mathrm{D}, \mathrm{H})$. Die dorsale Pankreasanlage ist mit einem roten Pfeil markiert. Anterior nach links.

Sowohl der Funktionsverlust von XsFRP5 (Abb. 4.8) wie auch die Überaktivierung kanonischer Wnt Signaltransduktion [Abb. 4.11; (Melchert, Diplomarbeit 2007)] wirkten sich inhibierend auf die Pankreasentwicklung aus. Der Verlust von XsFRP5 beeinflusst jedoch nur das ventrale Pankreas negativ, was mit der endogenen Expression von XsFRP5 in der Leberanlage erklärt werden könnte. Demgegenüber 
ist XsFRP5 nicht im Bereich der dorsalen Pankreasanlage exprimiert (siehe Abb. 4.1). Die pan-entodermale Aktivierung kanonischer Signaltransduktion wirkt sich stärker inhibierend auf die Pankreasentwicklung aus, wobei der dorsale Teil besonders betroffen ist. Die stärkste Inhibition konnte bei Aktivierung von Lef1-GR nach dem Ende der Gastrulation im Stadium 13 erzielt werden (Abb. 4.11 B, F); zu diesem Zeitpunkt wird endogenes XsFRP5 nur schwach exprimiert. Zusätzlich kommt es wahrscheinlich nach „Knock-down“ von XsFRP5 zu einer De-Repression nicht-kanonischer Wnt Proteine, welche die hier durch die Aktivierung kanonischer Wnt Signaltransduktion beobachteten Effekte nicht induzieren können.

\subsubsection{Expressionsanalyse von XsFRP5 und verschiedenen Xwnt Proteinen}

Ein Vergleich der Expressionsdomänen von XsFRP5 und den in dieser Studie verwendeten Xwnt Proteinen sollte gemeinsam mit den funktionalen Daten ein oder mehrere Wnt Proteine als Kandidaten einer XsFRP5-vermittelten Inhibition der Wnt Signaltransduktion in der entodermalen Organogenese definieren. Untersucht wurde die Expression aller Xwnts, wobei besonders die Expression während der Organogenese in den Stadien 35 und 40 beleuchtet wurde. Da nach Funktionsverlust von XsFRP5 kein Defekt in der Spezifikation der Organanlagen festgestellt werden konnte, wurde auf einen möglicherweise transienten Wachstumsdefekt geschlossen (Punkt 4.1.3.1). Folglich sollte ein Xwnt Protein, um ein potentielles Ziel einer XsFRP5-vermittelten Inhibition zu sein, während der Ausknospung der pankreatischen Organanlage im oder um das Pankreasepithel exprimiert werden. Diese Ausknospung erfolgt in Froschembryonen ab Stadium 37 (Nieuwkoop und Faber, 1967). Selbige Schlussfolgerung kann auch für die gastroduodenale Vorläuferzellpopulation angewandt werden, da sich ab Stadium 37 entodermale Zellen der dorsalen Wand des Verdauungstrakts lösen, um die posteriore Wand des Magens zu bilden (Nieuwkoop und Faber, 1967). Auch an diesem Prozess könnten Wnt Proteine des umliegenden Ento- oder Mesoderms beteiligt sein, welche nach Funktionsverlust von XsFRP5 eine Expansion des Magens induzieren.

In Stadium 35 konnte die XsFRP5 Expression, wie bereits beschrieben, in der sich entwickelnden Leberanlage detektiert werden (Pilcher und Krieg, 2002; Abb. 4.1; 
Abb. 4.12 A). Xwnt2b konnte nur nach langer Färbedauer detektiert werden, wobei lediglich die Expression im Hinterhirn und in den Branchialbögen spezifisch zu sein scheint (Abb. 4.12 B). Xwnt3a Expression konnte entodermal nicht nachgewiesen werden, sondern nur in der Schwanzspitze sowie in Mittel- und Hinterhirn (Abb. 4.12 C). Xwnt4 zeigte ebenfalls keine entodermale Expression, sondern markierte neben verschiedenen Gehirnregionen und den Somiten den Hyoidbogen und die Branchialbögen, sowie den Pronephros (Abb. 4.12 D). Auch Xwnt5a scheint zu diesem Zeitpunkt nicht entodermal exprimiert zu sein. Es zeigte sich jedoch eine deutliche Färbung der Schwanzspitze und der Branchialbögen (Abb. 4.12 E). Xwnt8 Expression konnte in diesem Stadium anhand von in situ Hybridisierung nicht nachgewiesen werden (Abb. 4.12 F). Xwnt8b wird sehr schwach im Isthmus exprimiert (Abb. $4.12 \mathrm{G}$ ). Xwnt11 und Xwnt11R zeigen ein sehr ähnliches Expressionsmuster in den Somiten und den migrierenden Neuralleistenzellen, wobei zu beachten ist, dass Xwnt11R zusätzlich in der Herzanlage sowie in migratorischen mesenchymalen Zellen in der dorsalen Flosse exprimiert wird [(Abb. $4.12 \mathrm{H}, \mathrm{I}$; (Garriock et al., 2005; Ku und Melton, 1993)].

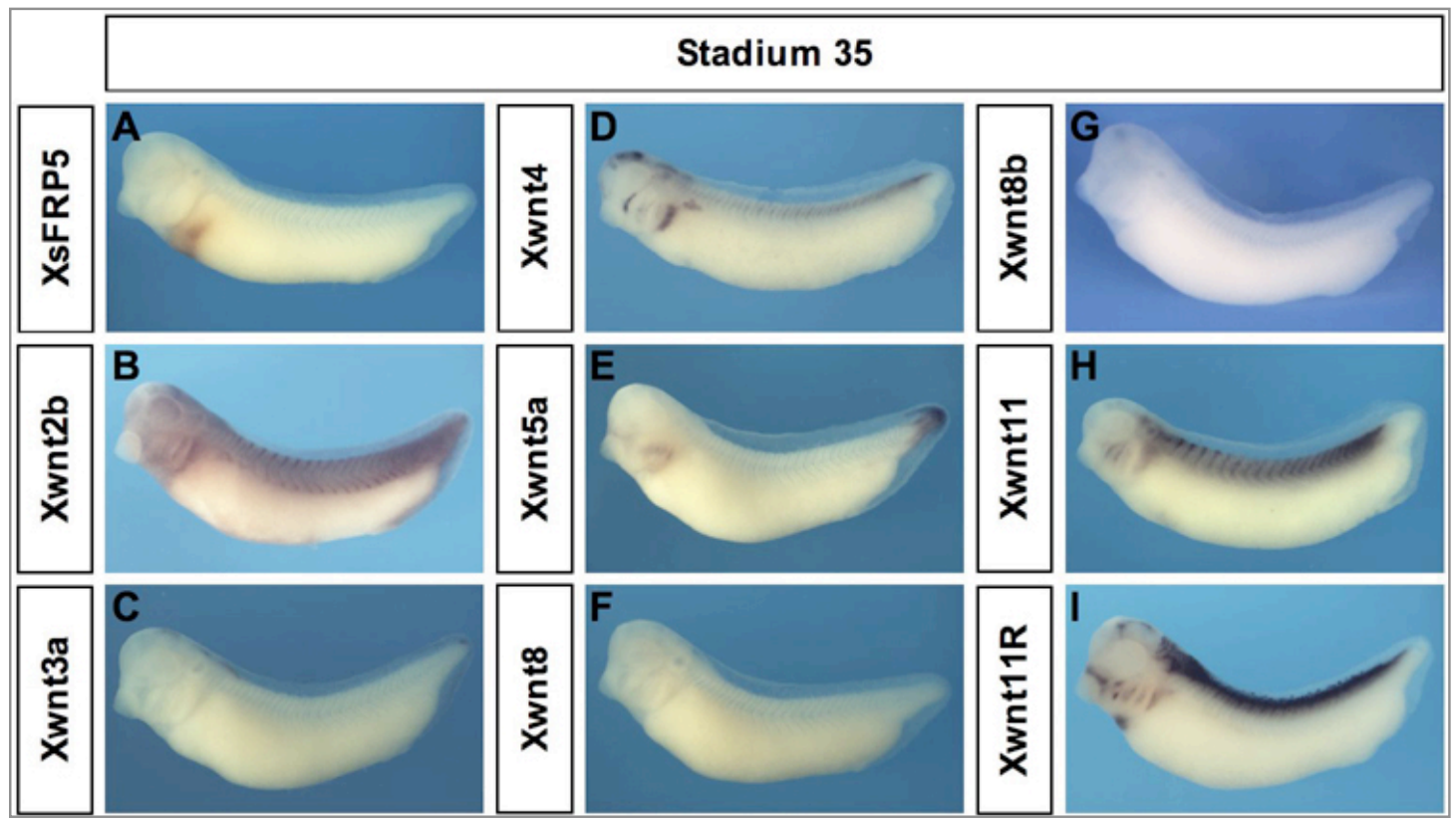

Abb. 4.12: Mehrere Xwnts zeigen komplementäre oder überlappende Expressionsmuster zu XsFRP5 im Stadium 35. Die whole-mount in situ Hybridisierung erfolgte unter Verwendung Digoxigenin-markierten „antisense”-Sonden gegen XsFRP5 (A), Xwnt2b (B), Xwnt3a (C), Xwnt4 (D), Xwnt5a (E), Xwnt8 (F), Xwnt8b (G), Xwnt11 (H) und $X w n t 11 R(I)$. Laterale Ansicht mit anterior nach links. 
Im Stadium 40 wurden zur detaillierteren Analyse der Expressionsmuster der Gastrointestinaltrakt und das Herz herauspräpariert und anschließend einer wholemount in situ Hybridisierung unterzogen. Dabei wurde XsFRP5 Expression wie bereits beschrieben im posterioren Magen und im Duodenum detektiert (Abb. 4.13 A, Pilcher und Krieg, 2002). Xwnt2b wird im gesamten anterioren Gastrointestinaltrakt exprimiert, wobei der Ösophagus die höchste Expression aufweist (Abb. 4.13 B). Xwnt3a wird zu diesem Zeitpunkt ausschließlich in der Lunge exprimiert (Abb. 4.13 C). Xwnt4 Transkripte konnten nur in der Spitze der Lungenanlage detektiert werden (Abb. 4.13 D). Xwnt5a konnte im Ösophagus, der Lungenspitze, dem anterioren Magen und dem posterioren Darm detektiert werden (Abb. 4.13 E). Im Stadium 40 konnte keine entodermale Xwnt8 oder Xwnt8b Expression festgestellt werden (Abb. 4.13 F, G). Xwnt11 zeigt eine sehr spezifische Expression im Septum transversum Mesenchym sowie in einigen Zellen des dorsalen Ösophagus (Abb. $4.13 \mathrm{H}$ ), während Xwnt11R hauptsächlich im Herzen detektiert werden konnte (Abb. $4.13 \mathrm{I}$ ).

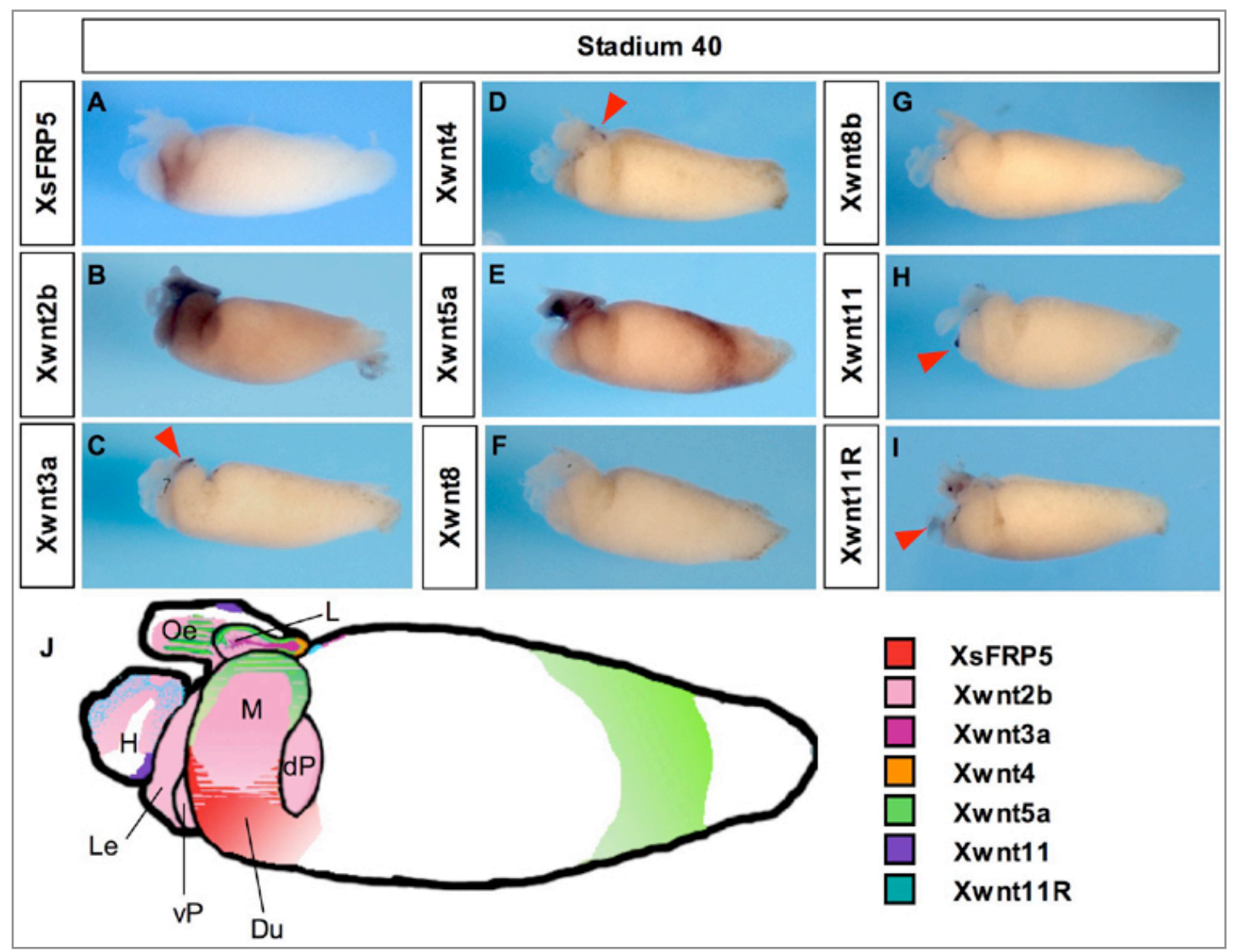

Abb. 4.13: Mehrere Xwnts zeigen komplementäre oder überlappende Expressionsmuster zu XsFRP5 in gastrointestinalen Explantaten des Stadiums 40. Der Gastrointestinaltrakt und das Herz wurden aus Kontrollembryonen im Stadium 40 explantiert 
und einer whole-mount in situ Hybridisierung unter Verwendung Digoxigenin-markierten „antisense" Sonden gegen XsFRP5 (A), Xwnt2b (B), Xwnt3a (C), Xwnt4 (D), Xwnt5a (E), Xwnt8 (F), Xwnt8b (G), Xwnt11 (H) und Xwnt11R (I) unterzogen. Rote Pfeilspitzen markieren spezifische Expressionsdomänen. (J) Graphische Darstellung aller detektierten Expressionsdomänen. Laterale Ansicht mit anterior nach links. Du $=$ Duodenum, $d P=$ dorsales Pankreas, $\mathrm{H}=\mathrm{Herz}, \mathrm{L}=$ Lunge, Le = Leber, $\mathrm{M}=$ Magen, $\mathrm{Oe}=$ Ösophagus, $v \mathrm{P}=$ ventrales Pankreas.

Um den Vergleich der einzelnen Expressionsdomänen zu erleichtern, wurden die verschiedenen Muster in einer graphischen Darstellung vereint (Abb. 4.13). Dabei zeigten sich Xwnt2b als überlappend mit und Xwnt5a als komplementär zu XsFRP5 exprimiert. Dieses Expressionsmuster unterstreicht die unter Punkt 4.1.2 erhaltenen Interaktionsdaten von XsFRP5 mit Xwnt2b bzw. Xwnt5a, was die Vermutung nahe legt, dass es sich bei Xwnt2b und Xwnt5a um die endogenen Interaktionspartner von XsFRP5 handeln könnte. Besonders Xwnt2b zeichnet sich durch eine sehr starke Immunopräzipitation aus (Tabelle 4.1). Um diese Hypothese zu überprüfen, könnten „antisense” Morpholino Oligonukleotide gegen Xwnt2b oder Xwnt5a zum Einsatz gebracht werden. Sollten Xwnt2b und Xwnt5a die gesuchten Kandidaten sein, wäre nach Injektion dieser Morpholinos ins prospektive Entoderm mit einem gegenteiligen Effekt auf die ventrale Pankreasanlage bzw. den Magen als nach Funktionsverlust von XsFRP5 beschrieben (Punkt 4.1.3.1) zu rechnen.

\subsection{4 Überexpression von XsFRP5 und VegT in animalen Kappenexplantaten induziert pankreatische Genexpression}

Im Blastulastadium bilden ektodermale Zellen das Dach des Blastocoels. Diese Zellen können isoliert und kultiviert werden, wobei sie ohne weiteren Stimulus zu atypischen Epidermiszellen differenzieren. Die Behandlung der Explantate mit Morphogenen, oder auch die Injektion verschiedener Keimblatt-spezifischer Determinanten oder Wachstumsfaktoren, erlaubt eine Differenzierung dieser pluripotenten Vorläuferzellpopulation in verschiedenste Zelltypen und Gewebe (Henry et al., 1996; Lamb et al., 1993). Diese Methode sollte für die weitere Analyse der Effekte einer XsFRP5 Überexpression genutzt werden.

Dazu wurde in den Kappenexplantaten durch die Expression von VegT, einem Transkriptionsfaktor, welcher in diesem System ausreichend für die Spezifizierung 
ento- und mesodermaler Zellen ist, eine gemischte Population solcher Zellen induziert. Die Auswirkung einer Ko-Expression von XsFRP5 auf pankreatische und hepatische Genexpression sollte nach Kultivierung der Explantate bis zur späten Organogenese-Phase mittels RT-PCR untersucht werden (Abb. 4.14).

Anhand verschiedener Kontrollen konnte die Qualität und Homogenität der untersuchten Proben festgestellt werden. Eine PCR mit Histon H4-spezifischen Oligonukleotiden zeigt in allen Proben eine gleichmäßig starke Bande, welche jedoch nicht ohne eine vorangegangene Reverse Transkription (RT) der mRNA in cDNA, auftritt. Folglich enthielten die RNA-Präparationen keine genomische DNA. Die effektive Induktion mesodermaler Zelltypen in den Explantaten durch VegT wurde anhand des mesodermalen Markergens Xtwist festgestellt. Kappenexplantate, welche mit VegT injiziert wurden, weisen die Expression duodenaler und hepatischer Markergene auf. Die Behandlung dieser VegT-injizierten Kappenexplantate mit Retinsäure (RA) führt zu einer robusten Induktion pankreatischer Markergene (Chen et al., 2004a). XIHbox8, eine Homöobox-Transkriptionsfaktor, wird in pankreatischen Vorläuferzellen und im Duodenum exprimiert. Da die mit VegT injizierten Explantate keine der anderen pankreatischen Marker wie Ptf1a/p48 bzw. XPDIp und Insulin exprimieren, scheint es sich bei den XIHbox8-exprimierenden Zellen um solche mit duodenaler Identität zu handeln. Weiters zeigte sich, dass die Expression von XsFRP5 durch VegT induziert werden konnte. XsFRP5 alleine zeigt keine Wirkung auf die hier analysierten Gene. Eine Ko-Expression von VegT und ansteigender Dosen an XsFRP5 führt zu einer robusten und Dosis-abhängigen Induktion pankreatischer Vorläufer- und Differenzierungsmarker. Eine Insulin Expression konnte durch XsFRP5 jedoch nicht induziert werden, im Gegensatz zur Behandlung VegT-injizierter Kappen mit $5 \mu \mathrm{M}$ Retinsäure (RA). Insulin-produzierende $\beta$-Zellen werden in Xenopus Embryonen nur in der dorsalen Pankreasanlage gebildet, was die Vermutung nahe legt, dass XsFRP5 die Bildung einer ausschließlich ventralen, pankreatischen Zellpopulation in VegT-injizierten Kappenexplanaten induziert. Die Expression des Homöobox Transkriptionsfaktors Hex, eines hepatischen Vorläufermarkers, kann durch XsFRP5 Ko-Injektion ebenfalls leicht erhöht werden. Transthyretin, ein Marker für differenzierte Leberzellen, zeigt jedoch keine Reaktion auf die XsFRP5 Expression. Die Expression des „SRY-related“ HMG-box Transkriptionsfaktors Sox2, eines Markergenes für Ösophagus und Magen, wird bei 
Koinjektion niedriger Dosen induziert, mit ansteigender XsFRP5 Dosis geht dieser Effekt jedoch wieder verloren. Die schwache Expression von Sox2 in Kontrollkappen könnte neurale Expression reflektieren, bei VegT-Injektion kann jedoch von einer Spezifizierung entodermaler Sox2-exprimierender Zellen ausgegangen werden. KoInjektion geringer Dosen von XsFRP5 verstärken die Sox2 Expression, bei Injektion höherer Dosen geht dieser Effekt wieder verloren.

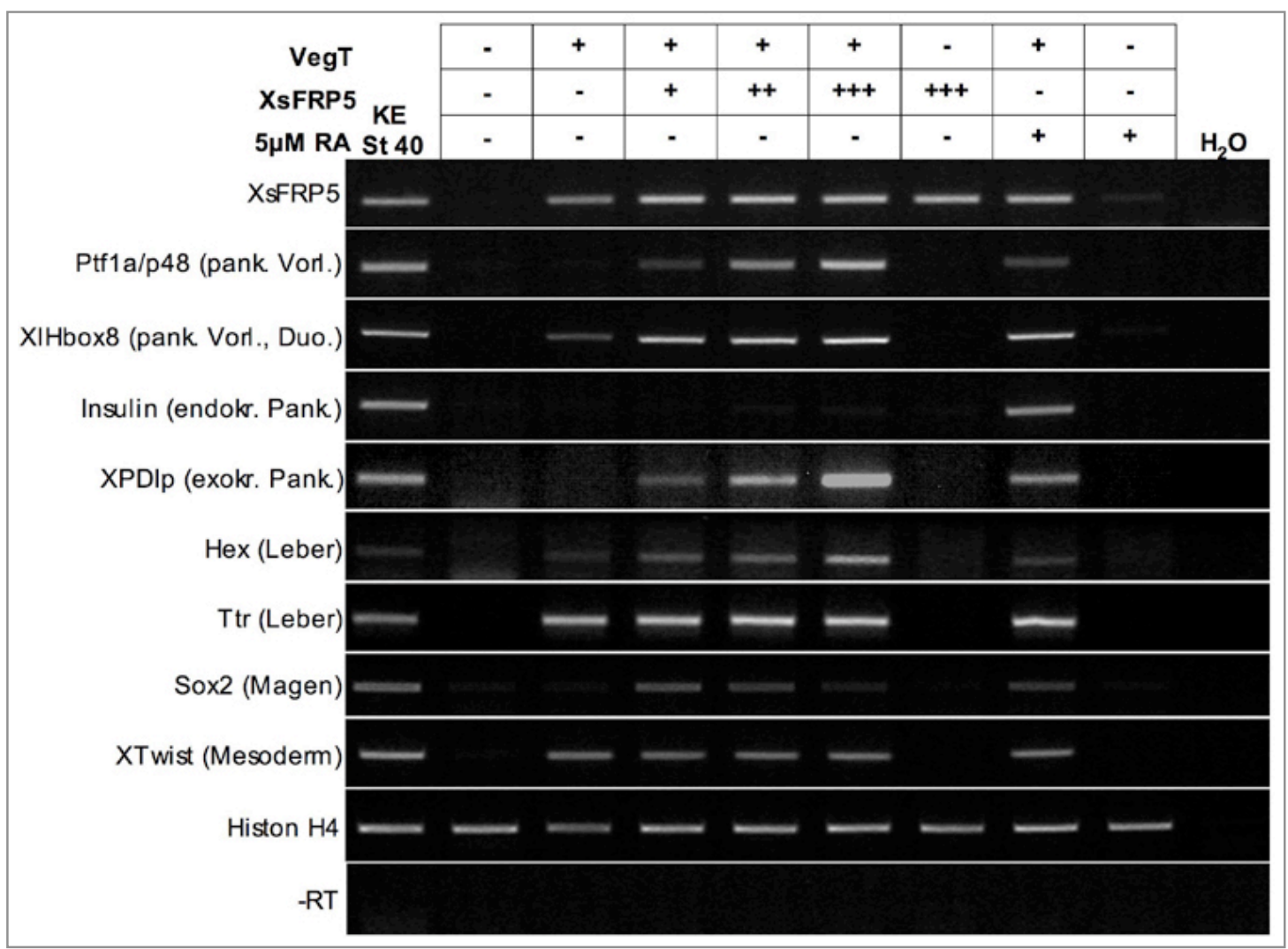

Abb. 4.14: Die Überexpression von XsFRP5 in VegT-injizierten animalen Kappenexplantaten induziert die robuste Expression pankreatischer Markergene. Es wurden 200pg VegT mRNA und 50, 100 und 200pg XsFRP5 mRNA animal in beide Blastomeren im Zweizell-Stadium injiziert. Animale Kappenexplantate wurden im Stadium 8/9 geschnitten, die Explantate in Stadium 9 mit RA behandelt und die Explantate bis Stadium 40 kultiviert. Die RT-PCR Analyse der pankreatischen Vorläufermarker Ptf1a/p48 und XIHbox8 sowie der exokrine Marker XPDIp zeigen eine deutliche Induktion nach Injektion von ansteigenden Dosen an XsFRP5 mRNA. Die XsFRP5 RT-PCR Analyse zeigt die endogene XsFRP5 Expression. KE = Kontrollembryonen im Stadium 40, RA = Retinsäure.

Die Analyse der Effekte einer ektopischen Expression von XsFRP5 gemeinsam mit VegT in animalen Kappenexplantaten zeigte eine starke Induktion ventralpankreatischer Markergenexpression, ein Effekt, der mit der spezifischen Reduktion der ventralen Pankreasanlage bei einem Funktionsverlust von XsFRP5 in ganzen Embryonen korreliert. Auch die, wenngleich schwache, Reduktion der Sox2 
Expression in Kappen komplementiert die nach einem Funktionsverlust von XsFRP5 auftretende Verbreiterung des Magens (wie unter Punkt 4.1.3.1 beschrieben).

\subsubsection{Die XsFRP5-vermittelte pankreatische Genexpression in VegT- injizierten Kappenexplantaten ist Retinsäure-abhängig}

Durch Vorarbeiten der eigenen Arbeitsgruppe konnte gezeigt werden, dass Retinsäure nicht nur essentiell für die Spezifizierung der dorsalen Pankreasanlage ist, sondern auch die Bildung exokriner Zellen in der ventralen Anlage verstärkt (Chen et al., 2004a). Wie bereits unter Punkt 4.1 .4 beschrieben legt die nach Überexpression von XsFRP5 in VegT-injizierten Kappenexplantaten aufgetretene XPDIp-Expression bei Fehlen von Insulin Expression die Induktion einer reinen ventral-pankreatischen Zellpopulation nahe. Ein möglicher Zusammenhang zwischen der Überexpression des Wnt Antagonisten XsFRP5 und der RetinsäureSignalwirkung bei der Induktion dieser ventralen Pankreaszellen sollte in VegTinjizierten Kappenexplantaten untersucht werden (Abb. 4.15).

Die Expression von VegT in Kappenexplantaten induziert die Expression ento- und mesodermaler Gene, als Kontrolle dieser Induktion diente, wie bereits beschrieben, das mesodermale Markergen Xtwist. VegT-Injektion alleine reichte nicht aus, um pankreatische Markergen-Expression zu induzieren. Durch Retinsäure-Behandlung kann die Expression des pankreatischen Vorläufermarkers Ptf1a/p48, des exokrinen Markers XPDIp, sowie des endokrinen Markers Insulin in VegT-injizierten Kappenexplantaten induziert werden (Chen et al., 2004a). Die Ko-Injektion von VegT und XsFRP5 führte, wie bereits in Abb. 4.14 gezeigt, zur robusten Expression von Ptf1a/p48 und XPDIp, während Insulin Expression nicht detektiert werden konnte. RALDH2, die Retinal-Dehydrogenase 2, ist das Schlüsselenzym in der RetinsäureBiosynthese. Die Überexpression von XsFRP5 in VegT-injizierten Kappenexplantaten führte jedoch nicht zu einem Anstieg der RALDH2 Expression, somit auch nicht zu verstärkter Retinsäure-Biosynthese. Die Behandlung der VegTund XsFRP5 ko-injizierten Kappenexplantate mit BMS453 führte zu einem starken Rückgang der Ptf1a/p48 und der XPDIp Expression (Abb. 4.15). Bei BMS453 handelt es sich um einen kompetitiven Inhibitor der Retinsäure, der mit Retinsäure um die Bindung an die Retinsäure-Rezeptoren $\alpha$ und $\gamma$ konkurriert (Schulze et al., 
2001). Da die Induktion pankreatischer Markergene durch BMS453-Behandlung inhibiert werden konnte, handelt es sich um einen vom Retinsäure-Signalweg abhängigen Effekt. RALDH2 konnte aber nicht als indirektes Zielgen von XsFRP5 identifiziert werden. Da die Aktivierung des Retinsäure-Signalweges durch XsFRP5 möglicherweise auf der Rezeptor-Ebene stattfindet, wurden die RetinsäureRezeptoren RAR 2.1 und RAR 2.1 auf ihre Expression in den animalen Kappen untersucht. Obwohl diese Rezeptoren die Kompetenz des dorsalen Entoderms, auf RA Signale zu reagieren, vermitteln (Pan et al., 2007), zeigte sich keine Änderung des Expressionsverhaltens in VegT- und XsFRP5-injizierten Kappenexplantaten (Daten nicht gezeigt). Möglicherweise trat durch die Ko-Injektion von VegT und XsFRP5 in animalen Kappenexplantaten eine transiente Induktion der Expression von RALDH2 oder der Retinsäure-Rezeptoren auf, die in Stadium 40 nicht mehr detektiert werden konnte. Oder aber XsFRP5 beeinflusst die Expression anderer, hier nicht untersuchter, Elemente des RA Signalweges.

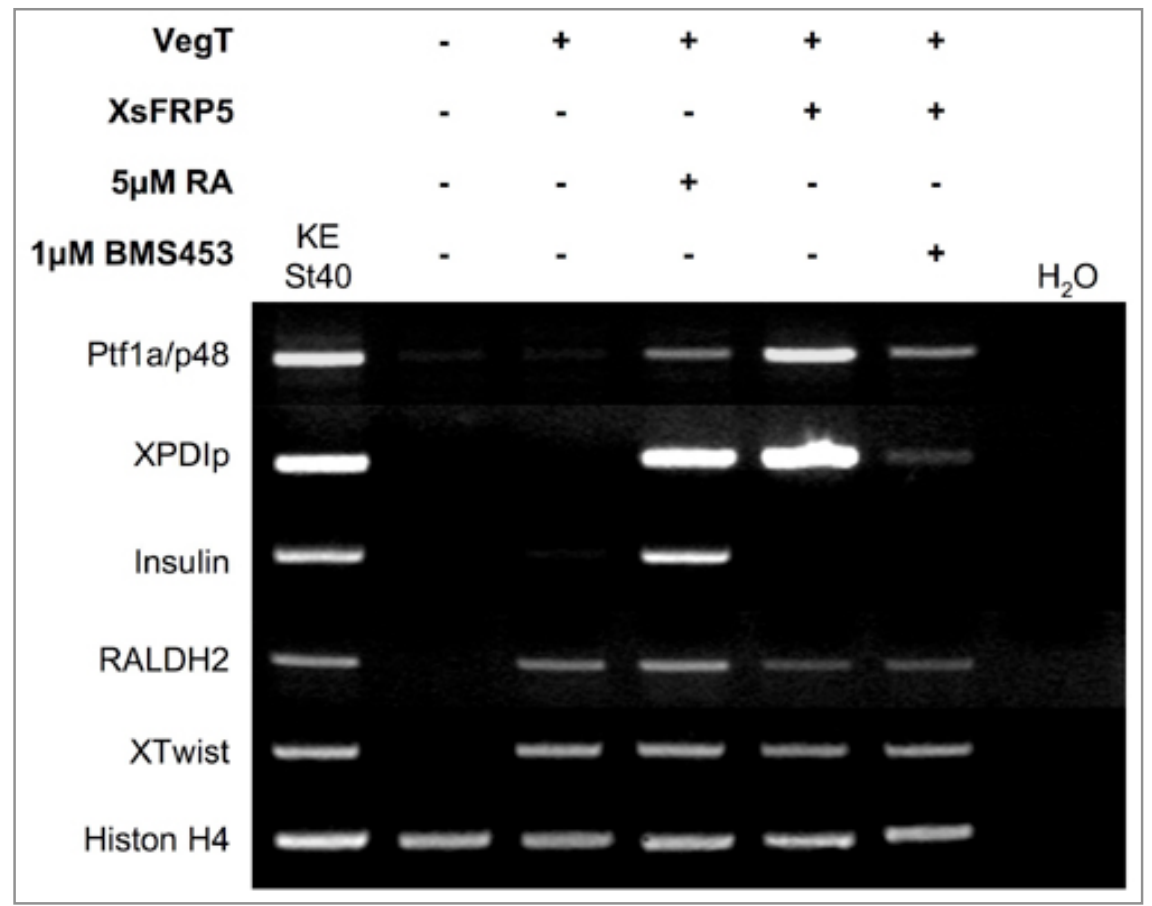

Abb. 4.15: Durch Behandlung der Kappenexplantate mit dem Retinsäure-Antagonisten BMS453 wird die XsFRP5-vermittelte Induktion pankreatischer Markergene unterdrückt. Es wurden je 200pg VegT und XsFRP5 mRNA animal im Zweizell-Stadium injiziert, die animalen Kappenexplantate im Stadium 8 präpariert und bis Stadium 40 kultiviert. Retinsäure (RA) und BMS453 Behandlung erfolgte für 1 Stunde in Stadium 9. KE = Kontrollembryo im Stadium 40. 
Durch die Behandlung mit BMS453 konnte gezeigt werden, dass die Induktion ventraler pankreatischer Markergene nach Ko-Injektion von VegT und XsFRP5 in animale Kappenexplantate vom Retinsäure-Signalweg abhängig ist.

\subsubsection{Die Überexpression von XsFRP2 und VegT führt nicht zur Induktion pankreatischer Markergenexpression in animalen Kappenexplantaten}

Um die Spezifität des Effekts nach Überexpression von XsFRP5 zu bestätigen, wurde XsFRP2, ein weiteres Mitglied der sFRP Familie, ebenfalls in VegT-injizierten Kappen ko-exprimiert. sFRP2 zählt auf Grund von Sequenzanalysen zur gleichen Untergruppe der sFRPs wie sFRP5 (Kawano und Kypta, 2003). Sowohl XsFRP2 als auch XsFRP5 sind Proteine von ungefähr 300 Aminosäuren (Abb. 4.16 A, B), wobei sich eine Identität von $67 \%$ in der N-terminalen Frizzled-homologen Domäne feststellen lässt. Diese N-terminale Domäne enthält 10 konservierte Cystein-Reste (Melkonyan et al., 1997) und ermöglicht die Interaktion der sFRPs mit Wnt Proteinen. Die C-terminale Netrin-ähnliche Domäne zeigt kaum Identität auf der Ebene der Aminosäuren. In der Maus bewirkt sFRP2 zusammen mit sFRP1 die Spezifizierung des Magenepithels (Kim et al., 2005a). Weiters konnte auch für sFRP2 eine Interaktion mit Wnt3a gezeigt werden (Deb et al., 2008; Galli et al., 2006).

\begin{tabular}{|c|c|c|c|c|}
\hline $\begin{array}{l}\text { XsFRP2 } \\
\text { XsFRP5 }\end{array}$ & $\begin{array}{l}1 \\
1\end{array}$ & \multicolumn{3}{|c|}{$\begin{array}{l}\text { MWHSGSRYVVVVLVVLLACDCMDSVRALFPFGQPEFSYKRSNCKPIPATLVL } \\
\text { MRFQWNILAWVNSVLLGLVLWSSAEEYDYYSWQSDNFQNGR_FYTKQSQCIDIPSDLHL }\end{array}$} \\
\hline XsFRP2 & 53 & \multirow{2}{*}{\multicolumn{3}{|c|}{$\begin{array}{l}\text { CHDIEYPNMRLPNLLGHESMKEVLQQASSWIPLVQKQCHQDTKKFLCSLFAPVCIDDLDE } \\
\text { CHNVGYKKMRLPNLLDHETMPEVKQQASSWVPLLAKRCHRDTQLFLCSLFAPIC___LER }\end{array}$}} \\
\hline XsFRP5 & 59 & & & \\
\hline XsFRP2 & 113 & \multirow{2}{*}{\multicolumn{3}{|c|}{$\begin{array}{l}\text { TIKPCRSLCEQVKDSCAPVMSAFGFPWPDMLECSRFPQDNDLCIPPATNEHQVPVTREAP } \\
\text { PIYPCRSLCEVVRDSCAPVMESYGFPWPEMLNCNKFPLDNDLCITVQFGSKQVTQPP_VT }\end{array}$}} \\
\hline XsFRP5 & 116 & & & \\
\hline XsFRP2 & 173 & \multirow{2}{*}{\multicolumn{3}{|c|}{$\begin{array}{l}\text { KVCDACKNSNEDDNDIVENLCKNDFALKIKVKEIAYINGDTKIIPETKGKTIYKLNGVTE } \\
\text { KICTQCEIEQKSETMRVQ_LCASDFVLRMRIKEVKIENGDRKLIAAQKKKKVLKAGKLKR }\end{array}$}} \\
\hline XsFRP5 & 175 & & & \\
\hline XsFRP2 & 233 & \multirow{2}{*}{\multicolumn{3}{|c|}{$\begin{array}{l}\text { RDLKKTVLWLKDGLQCTCDEMNDINAPYLVMGQKLGGELVITSVKRWQKGQQKFKRITRS } \\
\text { KEFRKLVLYIKNAASCPCPQLDNLSGSFLIMGRKVDNKLILTAIYKWDKKSKDMKYAVNF }\end{array}$}} \\
\hline XsFRP5 & 234 & & & \\
\hline XsFRP2 & 293 & \multirow{3}{*}{\multicolumn{3}{|c|}{$\begin{array}{l}\text { IRKLQC } \\
\text { MYSYPCSDTISHGTGSHLGSFR }\end{array}$}} \\
\hline XsFRP5 & 294 & & & \\
\hline & & & & \\
\hline & & XsFRP5 & XsFRP5-FRI & XsFRP5-NTR \\
\hline \multicolumn{2}{|c|}{ XsFRP2 } & $40,27 \%$ & - & - \\
\hline \multicolumn{2}{|c|}{ XsFRP2-FRI } & - & $66,67 \%$ & - \\
\hline \multicolumn{2}{|c|}{ XsFRP2-NTR } & - & - & $26,77 \%$ \\
\hline
\end{tabular}

Abb. 4.16: Ein Aminosäure-Sequenzvergleich zeigt ähnliche Wnt-bindende Domänen in XsFRP2 und XsFRP5. (A) Identische Aminosäuren in der XsFRP2 (NP_001080663) und XsFRP5 (NP_001083946) Sequenz wurden grau unterlegt. (B) Prozentualer Anteil an 
identischen Aminosäuren in den XsFRP2 und XsFRP5 Proteinen sowie in den einzelnen Proteindomänen.

XsFRP2 wird bereits während der Gastrulation vom Spemann Organisator sekretiert; Die Expression weitet sich im Stadium 20 auf die Augen, das Neuralrohr, die Somiten und eine anteriore, Gürtelförmige Expressionsdomäne aus (Pera und De Robertis, 2000). Eine weiterführende Untersuchung sollte die Expression von XsFRP2 im Vergleich mit den für XsFRP5 beschriebenen Expressionsdomänen im Schwanzknospenstadium aufklären (Abb. 4.17).

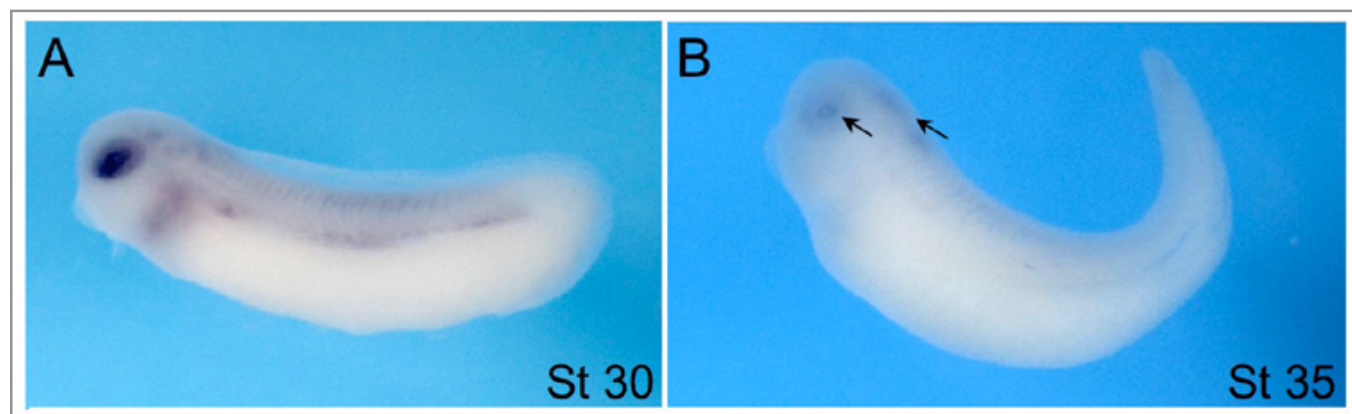

Abb. 4.17: XsFRP2 zeigt ein dynamisches, aber deutlich unterschiedliches Expressionsmuster zu XsFRP5. Laterale Ansicht mit anterior nach links auf Embryonen, die einer whole-mount in situ Hybridisierung gegen XsFRP2 unterzogen wurden. (A) In Stadium 30 wird XsFRP2 in den Augen, den Somiten, im Hinterhirn und dem anterioren Mesoderm exprimiert. (B) In Stadium 35 ist nur noch eine schwache XsFRP2 Expression in der Retina und neural festzustellen (markiert mit schwarzen Pfeilen).

Im frühen Schwanzknospenstadium wird XsFRP2 neural, in den Augen, den Somiten und dem anterioren Mesoderm exprimiert (Abb. 4.17 A). Die mesodermale XsFRP2 Expression scheint in diesem Stadium angrenzend an die XsFRP5 Expression in der Leberanlage zu sein. In Stadium 35 zeigt XsFRP2 eine schwache Expression in der Retina und im Hinterhirn (Abb. 4.17 B). In späteren Stadien konnte keine XsFRP2 Expression mehr detektiert werden (Daten nicht gezeigt). Somit konnte in keinem Entwicklungsstadium eine überlappende Expression von XsFRP5 und XsFRP2 festgestellt werden.

Da aber auch für XsFRP2 die Interaktion mit kanonischen Wnt Proteinen beschrieben ist, sollte der induktive Effekt auf pankreatische Markergene durch KoInjektion von XsFRP2 und VegT in animale Kappenexplantate untersucht werden (Abb. 4.18). Eine Ko-Injektion von VegT und XsFRP5 diente dabei als Kontrolle der bereits diskutierten Induktion pankreatischer Markergene. Wie bereits erwähnt, 
induziert die Expression von VegT Ento- und Mesoderm in animalen Kappenexplantaten, wie anhand des mesodermalen Markergens Xtwist gezeigt. Die Ko-Injektion von XsFRP5 zeigt wie oben eine Induktion von Ptf1a/p48, dem pankreatischen Vorläufermarker, sowie von XPDIP, einem exokrinen Differenzierungsmarker. Eine Ko-Injektion von VegT und XsFRP2 führt jedoch nicht zur Induktion dieser pankreatischen Genexpression.

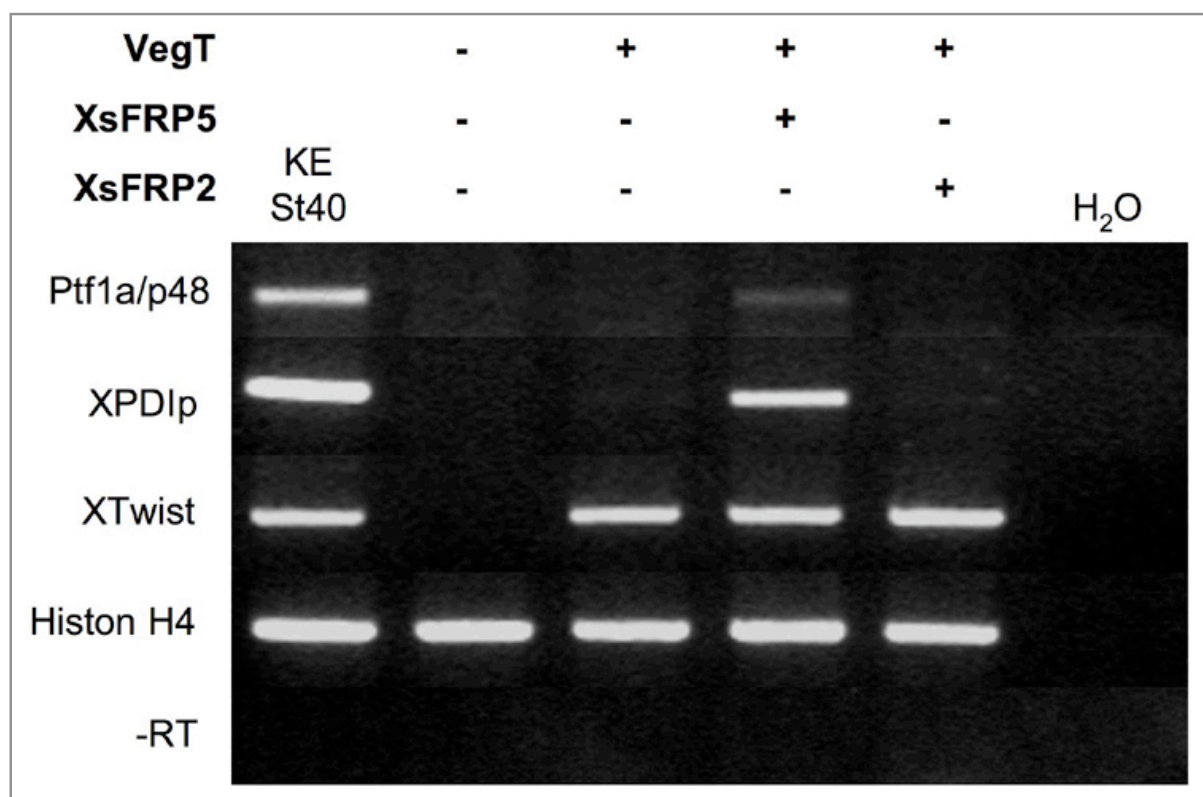

Abb. 4.18: XsFRP2 induziert keine pankreatische Markergenexpression in VegTinjizierten Kappenexplantaten. Es wurden je 200pg VegT, XsFRP2 und XsFRP5 injiziert, animale Kappenexplantate in Stadium 8 geschnitten und bis zum Stadium 40 kultiviert. XsFRP5 induziert die Expression von Ptf1a/p48 und XPDIp in VegT-injizierten Kappenexplantaten, XsFRP2-injizierte Kappen exprimieren wie VegT-injizierte Kappen keine pankreatischen Markergene. KE = Kontrollembryo im Stadium 40.

Aus diesem Ergebnis lässt sich schlussfolgern, dass es sich bei der Induktion pankreatischer Markergene in VegT-injizierten Kappenexplanaten um einen XsFRP5-spezifischen Effekt handelt, der durch Injektion eines strukturell ähnlichen Wnt Antagonisten nicht kopiert werden kann. 


\subsubsection{Analyse der Expression verschiedener Xwnts in VegT-injizierten Kappenexplantaten}

Ausgehend von der Beobachtung, dass XsFRP5 ein Wnt Antagonist ist, stell sich die Frage, welches Xwnt Protein in VegT-injizierten Kappen als Ziel von XsFRP5 dienen könnte, um die beschriebenen Effekte auf die pankreatischen Markergene auszulösen (Punkt 4.1.3.1). Um diese Frage zu beantworten, wurden Kontrollembryonen, unbehandelte animale Kappenexplante, sowie mit VegT mRNA injizierte Kappenexplante in verschiedenen Embryonalstadien gesammelt und auf die Expressionsmuster der in dieser Studie benutzen Xwnts untersucht (Abb. 4.19). Kontrollembryonen zeigen eine starke Expression aller untersuchten Xwnts von frühen Neurula-Stadien bis in späte Schwanzknospenstadien, wobei sich für Xwnt8 und Xwnt8b eine Reduktion in der Expressionsstärke im Stadium 37 zeigt. Im Gegensatz zu unbehandelten Explantaten zeigen die mit VegT-injizierten und somit ento- und mesodermalisierten Kappen nur eine schwache Expression von Xwnt2b und Xwnt3a, wobei sich in beiden Fällen ein Anstieg während der OrganogeneseStadien beobachten lässt. Alle anderen untersuchten Xwnts zeigen eine relativ gleich bleibende Expression in beinahe allen untersuchten Stadien, allerdings gilt es festzuhalten, dass insbesondere Xwnt8, Xwnt8b, Xwnt11 und Xwnt11R im Gegensatz zu den Kontrollkappen deutlich stärker exprimiert werden. Da XsFRP5 ab Stadium 15 mittels RT-PCR deutlich detektierbar ist, könnten alle ab diesem Zeitpunkt exprimierten Xwnt Proteine als potentielles Ziel in Frage kommen. 


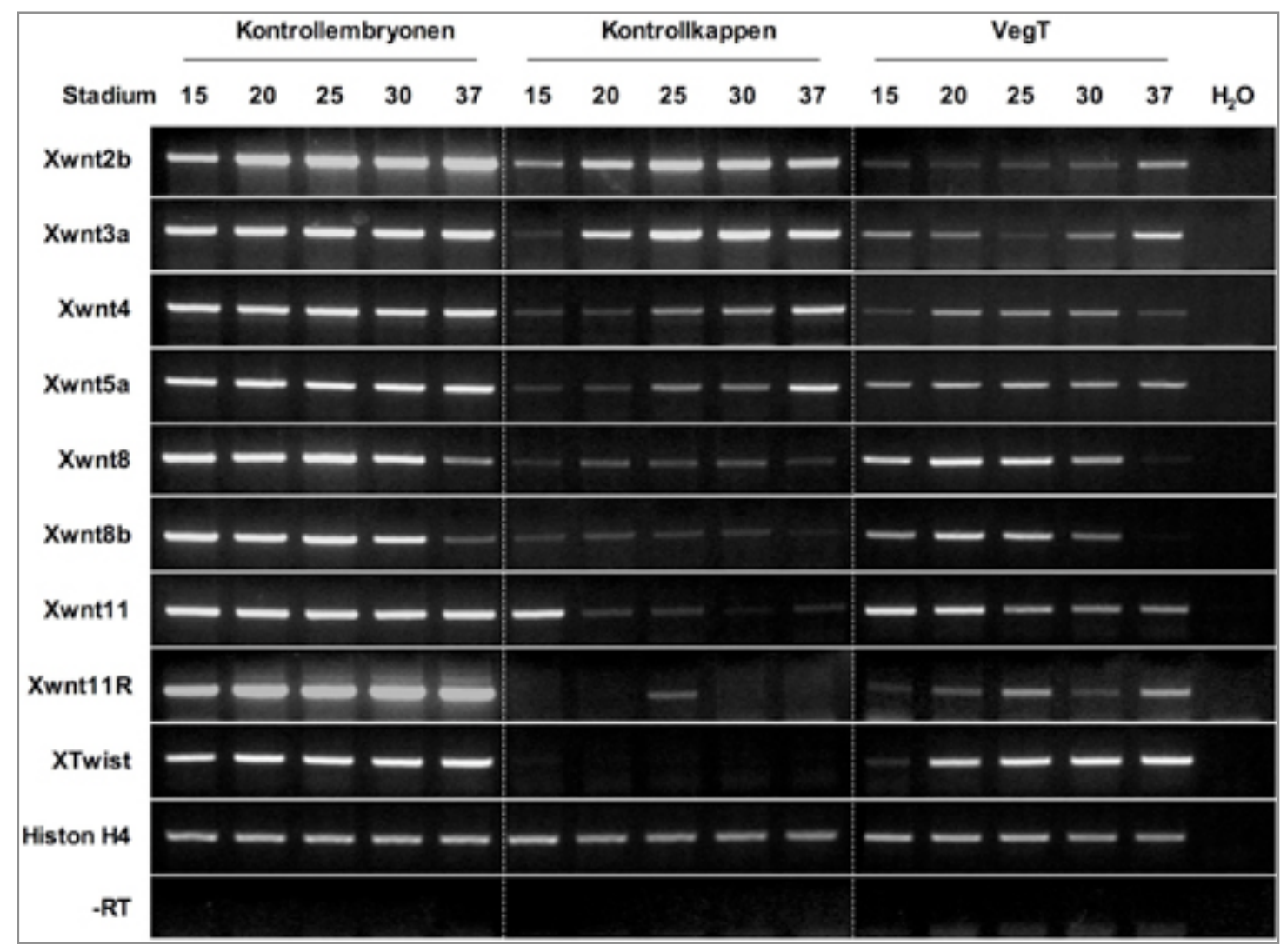

Abb. 4.19: Eine Vielzahl unterschiedlicher Xwnts wird in VegT-injizierten Kappenexplantaten verschiedener Entwicklungsstadien exprimiert. Embryonen wurden im Zweizell-Stadium animal mit 200pg VegT mRNA injiziert, animale Kappenexplantate im Stadium 8 aus Kontroll- und VegT-injizierten Embryonen präpariert und diese bis zu unterschiedlichen Entwicklungsstadien kultiviert. Kontrollembryonen, nicht-injizierte Kappenexplantate und VegT-injizierte Kappenexplantate wurden durch RT-PCR auf die Expression von Histon H4, XTwist sowie der für diese Studie relevanten Xwnts untersucht.

Es zeigte sich, dass alle untersuchten Xwnts in VegT-injizierten Kappenexplantaten exprimiert werden. Aus der temporären Analyse der unterschiedlichen Expressionsmuster konnten keine neuen Aufschlüsse über mögliche, präferierte Interaktionspartner von XsFRP5 gezogen werden. 


\subsection{Analyse des Synergieeffektes von $\Delta \mathrm{Np} 63 \alpha$ auf die Lef1- vermittelte Wnt Signaltransduktion}

Im Rahmen dieser Promotion ergab sich eine Kollaboration mit der Abteilung „Molekulare Onkologie“ (AG Dobbelstein). $\Delta$ Np63 $\alpha$, ein Transkriptionsfaktor, welcher in Mensch, Maus, Zebrafisch und Xenopus als überwiegend in mehrschichtigen Plattenepithelien exprimiert beschrieben wurde (Lee und Kimelman, 2002; Lu et al., 2001; Mills et al., 1999; van Bokhoven et al., 2001; Yang et al., 1999), sollte nach vorangegangenen Experimenten in Zellkultur (I. Drewelus, unveröffentlicht) auch in Xenopus Embryonen auf einen möglichen Synergie-Effekt mit der kanonischen Wnt Signaltransduktion untersucht werden.

Als experimentelles System wurde das Achsenduplikations-Experiment (wie bereits unter Punkt 4.1.2.1 beschrieben) gewählt, da die Ausprägung einer zweiten Körperachse auf der induktorischen Wirkung kanonischer Wnt Signale beruht (Sokol et al., 1991). Lef1-GR, welches nach Dexamethason-Induktion zur ektopischen Aktivierung des kanonischen Signalweges führt, wurde in einer suboptimalen Dosis injiziert und führte daher nur in einer geringen Zahl der Embryonen zur Achsenduplikation (Abb. 4.20). Eine Ko-Injektion von $\Delta N p 63 \alpha$ führt zu einer signifikanten Erhöhung der Achsenduplikation, jedoch wiederum nur nach Dexamethason-Induktion. Daraus lässt sich folgern, dass $\Delta N p 63 \alpha$ ohne aktives Lef1-GR nicht in der Lage ist, dorsale Achsenduplikation zu bewirken, was auch durch die ventrale Injektion von $\Delta \mathrm{Np} 63 \alpha$ alleine gezeigt werden konnte (Abb. 4.20). 


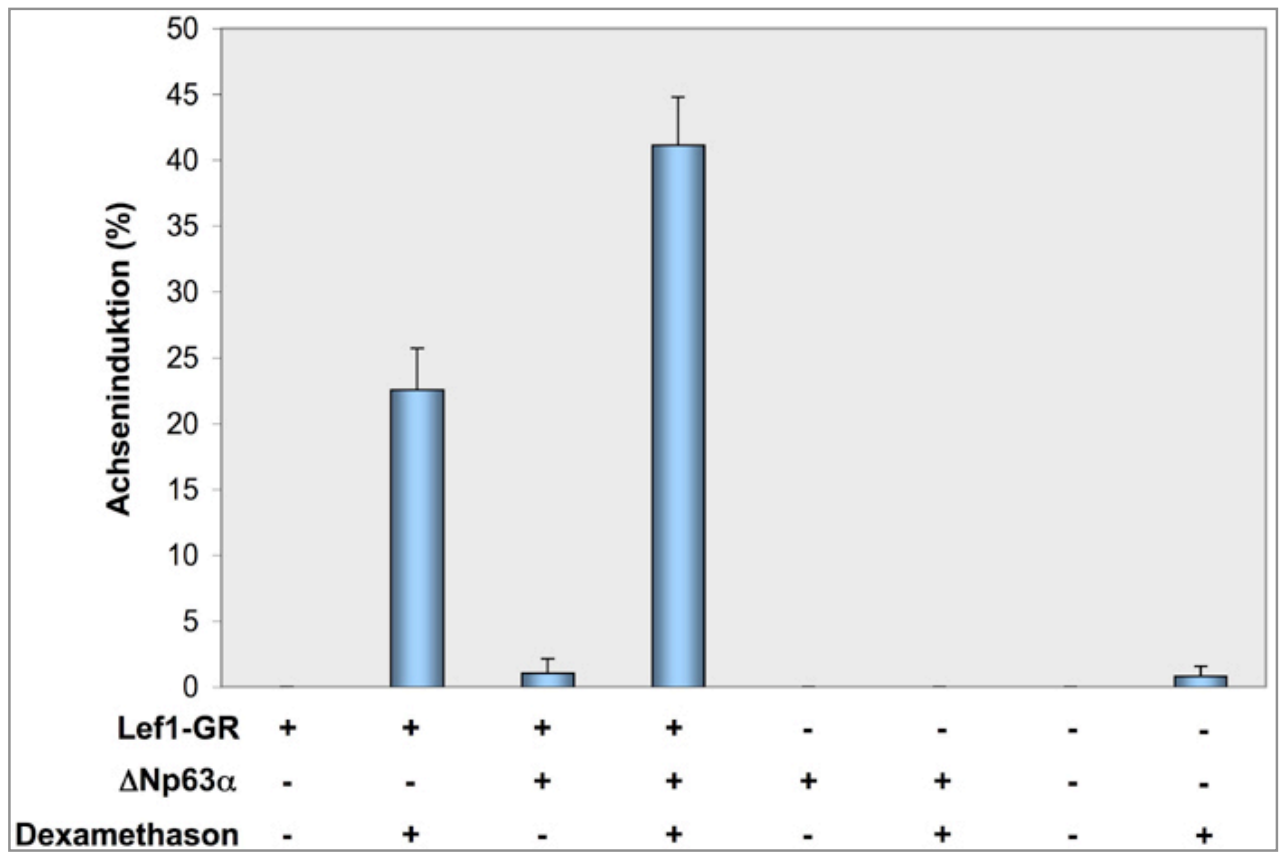

Abb. 4.20: $\Delta$ Np63 $\alpha$ wirkt synergistisch auf die Lef1-GR-vermittelte Achsenduplikation in Xenopus Embryonen. Je 3pg Lef1-GR und 50pg $\Delta N p 63 \alpha$ mRNA wurden in frühe Teilungsstadien injiziert. Die Induktion mit Dexamethason erfolgte im 16-Zell-Stadium. Es wurden drei unabhängige Experimente durchgeführt.

Somit konnten die in vitro gewonnen Daten über eine mögliche Synergie zwischen kanonischer Wnt Signaltransduktion und $\Delta \mathrm{Np} 63 \alpha$ in vivo bestätigt werden. 


\section{Diskussion}

Im Rahmen dieser Arbeit konnte gezeigt werden, dass XsFRP5 spezifisch an verschiedene Xwnt Proteine bindet und diese mit unterschiedlicher Effizienz in Achsenduplikations-Experimenten inhibiert. XsFRP5 zeigte eine Präferenz für einzelne Wnt Proteine, wobei eine Einteilung der Interaktionspartner nach den von innen aktivierten Signalwegen keine Spezifität von XsFRP5 für einen bestimmten Wnt Signalweg erkennen ließ. Die ektopische Expression von XsFRP5 in ganzen Embryonen resultierte in Defekten bei der Ausbildung der anterior-posterioren Körperachse, ein Phänotyp, welcher die Inhibition des Wnt/PCP Signalweges durch XsFRP5 reflektiert. Durch die Mikroinjektion von „antisense” Morpholino Oligonukleotiden in das prospektive Entoderm von Xenopus Embryonen konnte die Translation von XsFRP5 unterdrückt und die Auswirkungen des Funktionsverlustes auf die Ausbildung entodermaler Organe anhand der Expressionsanalyse von Markergenen untersucht werden. Der Funktionsverlust von XsFRP5 resultierte in einer Verkleinerung der ventralen Pankreasanlage, sowie einer Expansion des Magens. Die Entwicklung anderer Organanlagen war nach Verlust von XsFRP5 nicht verändert. Durch die ektopische Aktivierung des kanonischen Wnt Signalweges im Entoderm konnte eine deutliche Reduktion der dorsalen Pankreasanlage festgestellt werden (Melchert, Diplomarbeit 2007). Ektopische Expression von XsFRP5 in VegTinjizierten animalen Kappenexplantaten induziert eine robuste Expression pankreatischer Markergene, auch ohne Zugabe von Retinsäure. Eine vergleichende Expressionsanalyse der Xwnt Proteine in VegT-injizierten Kappenexplantaten und ganzen Embryonen identifizierte insbesondere Xwnt2b als mögliches Zielprotein für XsFRP5 in vivo. Weiterhin konnte ein synergistischer Effekt von $\Delta$ Np63 $\alpha$ auf die kanonischen Wnt Signaltransduktion in Achsenduplikations-Experimenten belegt werden. 


\subsection{Identifizierung von Wnt Bindungspartnern für XsFRP5}

In Abschnitt 4.1.2 konnte gezeigt werden, dass es sich bei Xenopus sFRP5 um einen Wnt Antagonisten handelt. Die ektopische Expression von XsFRP5 in frühen Teilungsstadien (Abb. 4.5) resultierte in einer dramatischen Verkürzung der anteriorposterioren Körperachse, ein Phänotyp der charakteristisch für Defekte im Wnt/PCP Signalweg ist. Es ist bekannt, welche Xenopus Wnt Proteine maßgeblich an der Steuerung der Bewegungen der konvergenten Extension beteiligt sind, nämlich Xwnt5a und Xwnt11 (De Calisto et al., 2005; Moon et al., 1993). Beide Xwnt Proteine wurden hier in der Ko-Immunopräzipitation, wenn auch nur schwach, als Interaktionspartner für XsFRP5 identifiziert (Abb. 4.4), jedoch wurde nur Xwnt5a in Achsenduplikations-Experimenten signifikant inhibiert (Abb. 4.3 F, G).

Beide Xwnts wurden lange Zeit ausschließlich der nicht-kanonischen Wnt Signaltransduktion zugerechnet, da sie nach Injektion in Xenopus Embryonen ohne Ko-Injektion von Frizzled Rezeptoren keine dorsale Achsenduplikation induzieren können [Abb. 4.3 F, G; (Du et al., 1995)] und nicht in der Lage sind, morphologische Veränderungen in Maus C57MG Mamma-Epithelialzellen hervorzurufen (Wong et al., 1994). Neuere Studien belegen jedoch, dass sowohl Xwnt5a als auch Xwnt11 unter bestimmten Bedingungen kanonische Wnt Signaltransduktion aktivieren können. So konnte gezeigt werden, dass Wnt5a im passenden Rezeptorkontext, in diesem Fall mit Frizzled4, in der Lage ist, kanonische Reportergen-Expression zu induzieren (Mikels und Nusse, 2006). Die Stabilisierung von $\beta$-Catenin auf der prospektiven dorsalen Seite von Xenopus Embryonen wird durch Xwnt11 vermittelt (Tao et al., 2005). Auch die im Rahmen dieser Arbeit durchgeführte Ko-Injektion dieser Wnt Proteine mit dem human Fz5 Rezeptor resultierte in der ektopischen Aktivierung der kanonischen Wnt Signaltransduktion (Abb. 4.3 E-H). Aus den Daten der Ko-Immunopräzipitation ist ersichtlich, dass XsFRP5 in der Lage ist, Xwnt11 zu binden. Die Funktion von Xwnt11 scheint dadurch aber kaum beeinträchtigt zu werden, da die Xwnt11-vermittelte Achsenduplikation durch XsFRP5 nicht signifikant inhibiert wurde. Entsprechend dieser Ergebnisse konnte nach vegetaler Injektion von XsFRP5 im Zweizell-Stadium keine Auswirkung auf die Ausbildung der dorsoventralen Achse beobachtet werden; im Stadium 25 weisen der XsFRP5-injizierte 
Embryo und der Kontrollembryo keine Unterschiede in den dorsalen Kopfstrukturen auf. Demnach scheint es nach Injektion von XsFRP5 mRNA nicht zu einer Inhibition endogener, Xwnt11-vermittelter kanonischer Wnt Signaltransduktion gekommen zu sein. Zusammenfassend weisen diese Befunde darauf hin, dass es sich bei dem endogenen Xwnt Protein, dessen Inhibition nach Überexpression von XsFRP5 zur Ausprägung des konvergenten Extensions-Phänotyps führt, um Xwnt5a handelt.

Wie bereits angedeutet, kann die strikte Einordnung der Wnt Proteine in kanonisch und nicht-kanonisch kaum noch aufrechterhalten werden. Vieles spricht für die Hypothese, dass der Rezeptorkontext an der Zelloberfläche, auch mit nicht-Frizzled Rezeptoren wie Ryk und Ror, sowie die Konzentration verschiedener Wnt Proteine ausschlaggebend für die Aktivierung der unterschiedlichen Wnt Signalwege sind (Keeble et al., 2006; Mikels und Nusse, 2006; Oishi et al., 2003; Schambony und Wedlich, 2007; Tao et al., 2005). Auch in dieser Studie zeigte sich, dass die Interaktion verschiedener Xwnt Proteine mit einem extrazellulären Antagonisten nicht eindeutig nach den durch diese Wnt Proteine aktivierten Signalwegen eingeteilt werden konnte. XsFRP5 stellte sich als ein spezifischer Antagonist unterschiedlicher Xwnt Proteine und nicht eines einzigen Wnt Signalweges dar.

Ausgehend von der Beobachtung, dass einige Xwnt Proteine zwar an XsFRP5 binden, jedoch durch diese Bindung nicht sehr stark in ihrer Funktion beeinträchtigt scheinen (Punkt 4.1.2), stellt sich die Frage, ob XsFRP5 auch als Agonist der Wnt Signalwege fungieren kann. Für sFRP1 konnte gezeigt werden, dass eine geringe Konzentration Wnt Signaltransduktion aktivieren kann, während hohe Konzentrationen an sFRP1 inhibierend wirken (Uren et al., 2000). Da die Experimente mit $\mathrm{Wg}$, dem Drosophila Wnt Homologen durchgeführt wurden, lässt sich allerdings kein genauer Rückschluss auf die Interaktion von sFRP1 mit Vertebraten Wnt Proteinen ziehen. Da in den Achsenduplikations-Experimenten keines der untersuchten Xwnt Proteine nach Ko-Injektion von niedrigen Dosen an XsFRP5 einen Synergieeffekt auf die Achseninduktion erkennen ließ, scheint XsFRP5 keine agonistische Wirkung auf die Wht Signaltransduktion auszuüben (Abb. 4.3). 
Es besteht jedoch die Möglichkeit, dass die Bindung von Xwnt Proteinen an XsFRP5 zur Wirksamkeit und Stabilität der Xwnts im extrazellulären Raum beiträgt. Die extrazelluläre Matrix (EZM) besteht aus einem dichten Netzwerk von Proteinen, wie Kollagen, Fibronektin oder Laminin, und den Glukosaminoglykanen (GAGs). Diese Polysaccharidketten liegen normalerweise an Proteine gebunden als sogenannte Proteoglykane vor; sie verleihen der EZM eine Gel-artige Konsistenz und erlauben die schnelle Diffusion von Metaboliten oder Hormonen. Die EZM dient nicht nur dem Schutz des Gewebes vor physikalischem Stress, sondern spielt eine wesentliche Rolle bei essentiellen Prozessen wie Form und Proliferation der einzelnen Zellen, Zell-Zell-Kommunikation oder Zellmigration. Die Bindung von Morphogenen an Heparansulfat-Proteoglykane (HSPGs) kann zu unterschiedlichen Effekten führen: Morphogene können in ihrer Reichweite inhibiert, sterisch in ihrer Funktion behindert, vor proteolytischer Degradation geschützt oder in ihrer lokalen Konzentration erhöht werden.

Bereits in mehreren Studien wurde eine Bindung von Wnt Proteinen an Heparansulfat-Proteoglykane beschrieben, wodurch die Wnt Proteine in der extrazellulären Matrix (EZM) stabilisiert werden (Lin, 2004). Syndecan-4, ein transmembranes Heparansulfat-Proteoglykan, wurde in Xenopus als Ko-Rezeptor für die Wnt-vermittelte Reglation der konvergenten Extensions-Bewegungen identifiziert (Munoz et al., 2006). Für sFRP1 konnte eine Komplexbildung mit Wg und Heparansulfat-Proteoglykanen nachgewiesen werden (Uren et al., 2000). Möglicherweise können auch andere sFRPs an Wnt Proteine und an die Glukosaminoglykan-Seitenketten (GAG) von Heparansulfat-Proteoglykanen binden. Bei einer niedrigen Konzentration von Wnt Proteinen in der EZM könnten sFRPs diese wenigen Liganden durch Bindung sequestrieren und dadurch die Bildung einiger weniger Wnt-Rezeptor-Komplexe unterbinden. Dagegen würde eine hohe, regionale Konzentration an Wnt Proteinen nicht vollständig sequestriert werden können und somit die Bildung von Wnt/Rezeptorkomplexen begünstigt werden, die Wnt Signaltransduktion würde aktiviert. In diesem Szenario könnten HeparansulfatProteoglykane dazu dienen, gegenläufige Gradienten von Wnt Proteinen und sekretierten Antagonisten durch die Bindung von Wnt/Antagonisten-Komplexen an GAGs weiter abzustufen und so eine feinere Regulation der Wnt Signaltransduktion zu ermöglichen. 


\subsection{Funktionale Charakterisierung von XsFRP5 in der entodermalen Organogenese}

Ausgehend von der Beobachtung, dass XsFRP5 ein ausgeprägt dynamisches Expressionsmuster mit spezifischer Expression in der Leberanlage aufweist, lag die Vermutung einer Funktion von XsFRP5 in der Leberentwicklung nahe. Die in dieser Studie vorgelegten Ergebnisse nach einem Funktionsverlust von XsFRP5 zeigten keine Auswirkung auf die Leberentwicklung, wie anhand des Differenzierungsmarkers Fibrinogen deutlich wurde (Abb. 4.8 P-R). Mit diesen Daten einhergehend konnte kürzlich gezeigt werden, dass auch in XsFRP5 „Knock-out“ Mäusen keine Veränderung in der Expression von Hex, einem hepatischen Vorläufermarker, festzustellen war (Leaf et al., 2006). Diese Ergebnisse legten die Vermutung nahe, dass SFRP5 möglicherweise redundant $\mathrm{zu}$ anderen Wnt Antagonisten exprimiert wird. Jedoch konnten auch in sFRP5 ${ }^{-/ /} / \mathrm{Dkk} 1^{-/-}$Doppel„Knock-out“ Mäusen keine Auswirkungen auf die Leberentwicklung nachgewiesen werden (Leaf et al., 2006).

Die Leberanlage entspringt der gleichen Vorläuferzellpopulation wie das ventrale Pankreas, welches sich posterior an die Leberanlage angrenzend bildet. Es zeigte sich, dass das ventrale Pankreas nach einem Funktionsverlust von XsFRP5 stark verkleinert vorlag, wohingegen das dorsale Pankreas nicht betroffen war (Abb. 4.8 AC). Das spricht für die Spezifität der erzielten Phänotypen, da sie, obwohl insgesamt eher moderat, nur Gewebe betreffen, welche der endogenen Sekretion von XsFRP5 ausgesetzt sind. Diese Aussage trifft auch auf das Magenepithel zu, welches ebenfalls durch einen „Knock-down“ von XsFRP5 beeinflusst werden konnte. Im Gegensatz zur beobachteten Reduktion der ventralen Pankreasanlage, konnte die Expansion des im Magenepithel exprimierten Transkriptionsfaktors Sox2 in anteriore Teile des Duodenums beobachtet werden (Abb. $4.8 \mathrm{G}-\mathrm{I}$ ). In einer Studie an neuralen Vorläuferzellen der Retina konnte Sox2 interessanterweise als Zielgen der kanonischen Wnt Signaltransduktion identifiziert werden (Van Raay et al., 2005). Wnt2b wurde in der Hühnerretina als essentiell für den Erhalt der undifferenzierten Vorläuferzellpopulation beschrieben (Kubo et al., 2003). In Analogie zu diesen Ergebnissen könnte es im Magen nach Funktionsverlust von XsFRP5 zu einer 
verstärkten Wirkung von Xwnt2b gekommen sein, was wiederum die Expansion der Sox2 Expression zur Folge haben könnte.

Auf Grund der Tatsache, dass beide zur Anwendung gekommenen Morpholino Oligonukleotide gegen XsFRP5 sich sowohl in vitro als auch in vivo als sehr effizient in der Unterdrückung der Translation erwiesen haben, die nach Injektion in Embryonen erzielten Defekte jedoch vergleichsweise mild ausfielen, drängt sich die Frage nach der Existenz und Ko-Expression funktionell redundanter Wnt Antagonisten auf. Vergleichende Expressionsanalysen in anderen Systemen, wie der murinen Retina oder dem adulten humanen Darmepithel, sowie der Neuralplatte in Huhn, zeigten, dass sekretierte Wnt Antagonisten oft komplementär und überlappend zueinander exprimiert werden, wodurch ein komplexes Muster an inhibitorisch wirkenden Signalen entsteht (Byun et al., 2005; Chapman et al., 2004; Chen et al., 2004b). Folglich besteht die Möglichkeit, dass andere sekretierte Wnt Antagonisten im Entoderm von Xenopus laevis exprimiert werden, die in der verfügbaren Literatur nicht beschrieben und im Rahmen dieser Studie nicht untersucht worden sind.

Setzt man die anhand der Xwnt Expressionsanalysen durch whole-mount in situ Hybridisierung erhaltenen Daten (Punkt 4.1.3.3) und die nach Funktionsverlust von XsFRP5 erhaltenen Defekte (Punkt 4.1.3.1) in Relation, so identifiziert man zwei Xwnt Proteine, Xwnt2b und Xwnt5a, die auf Grund ihrer räumlichen und zeitlichen Expression die aufgetretenen Pankreas- und Magenphänotypen bewirkt haben könnten. Auch die biochemischen Analysen unterstreichen diese Annahme, da besonders Xwnt2b, aber auch Xwnt5a, nicht nur mit XsFRP5 ko-präzipitiert (Abb. 4.4), sondern auch in den Achsenduplikations-Experimenten (Abb. 4.3 A, F) effizient inhibiert wurde.

Xwnt2b wird in Stadium 35 und 40 im anterioren Entoderm überlappend mit XsFRP5 exprimiert (Abb. $4.12 \mathrm{~B}$; Abb. $4.13 \mathrm{~B}$ ). Es konnte bereits in Maus und Xenopus gezeigt werden, dass eine Aktivierung des kanonischen Wnt Signalweges während früher Phasen der Pankreasentwicklung zu pankreatischer Hypoplasie führt, wohingegen in der späteren Phase der Ausknospung der Organanlage kanonische Wnt Signaltransduktion für die Proliferation der Zellen essentiell ist (Heiser et al., 
2006; McLin et al., 2007; Melchert, 2007). Es wäre möglich, dass es nach Mikroinjektion von Morpholino Oligonukleotiden durch den Anstieg an kanonischen Wnt Signalen zur Spezifizierung einer geringeren Anzahl an pankreatischen Vorläuferzellen in der ventralen Pankreasanlage gekommen ist, wie anhand der Vorläuferzellmarker Ptf1a/p48 und XIHbox8 erkennbar (Abb. 4.8 A-C; Abb. 5.1 A, B). Die Expression des exokrinen Markerss XPDIp lässt den Schluss zu, dass es sich um einen transienten Effekt handeln könnte, der durch die verstärkte Proliferation der einzelnen Vorläuferzellen ausgeglichen wird (Abb. 4.8 D-F). Welches Wnt Protein die Aktivierung der kanonischen Signaltransduktion bewirken könnte, lässt sich anhand des in Stadium 35 erstellten Expressionsmusters nicht klären. Zu diesem Zeitpunkt konnte für kein Xwnt eine Expression in der hepato-pankreatischen Region detektiert werden.

Im Stadium 40 könnte der Funktionsverlust von XsFRP5 durch eine De-Repression von Xwnt2b eine Aktivierung kanonischer Wnt Signaltransduktion im anterioren Entoderm nach sich gezogen haben. Wie bereits erwähnt, könnte diese DeRepression von Xwnt2b zu einer verstärkten Expression von Sox2 im Magenepithel geführt haben (Abb. 5.1 C, D). Xwnt5a wird im Stadium $40 \mathrm{im}$ posterioren Magen bogenförmig exprimiert. Die Enden des Bogens schließen mit den Enden der gegenläufigen XsFRP5-Expression ab (Abb. 4.13 E). Auch in diesem Fall könnte es nach Funktionsverlust von XsFRP5 zu einer Verstärkung der Xwnt5a-vermittelten Wnt Signaltransduktion gekommen sein, wodurch die Grenze zwischen Magen und Duodenum verschoben wurde. 


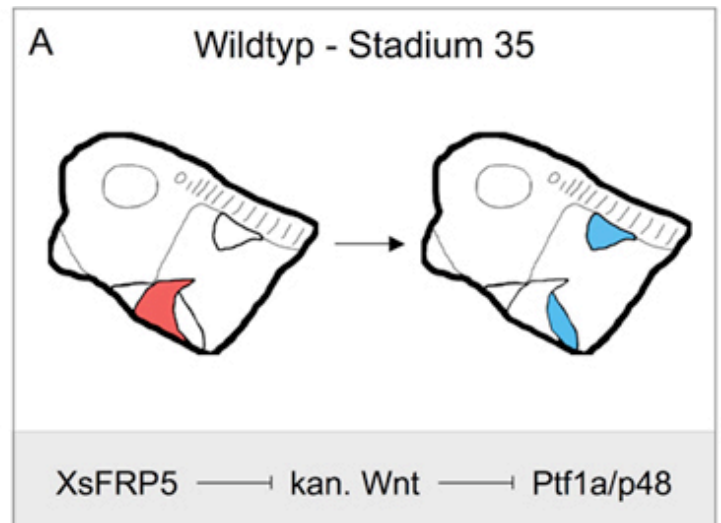

B „Knock-down” - Stadium 35

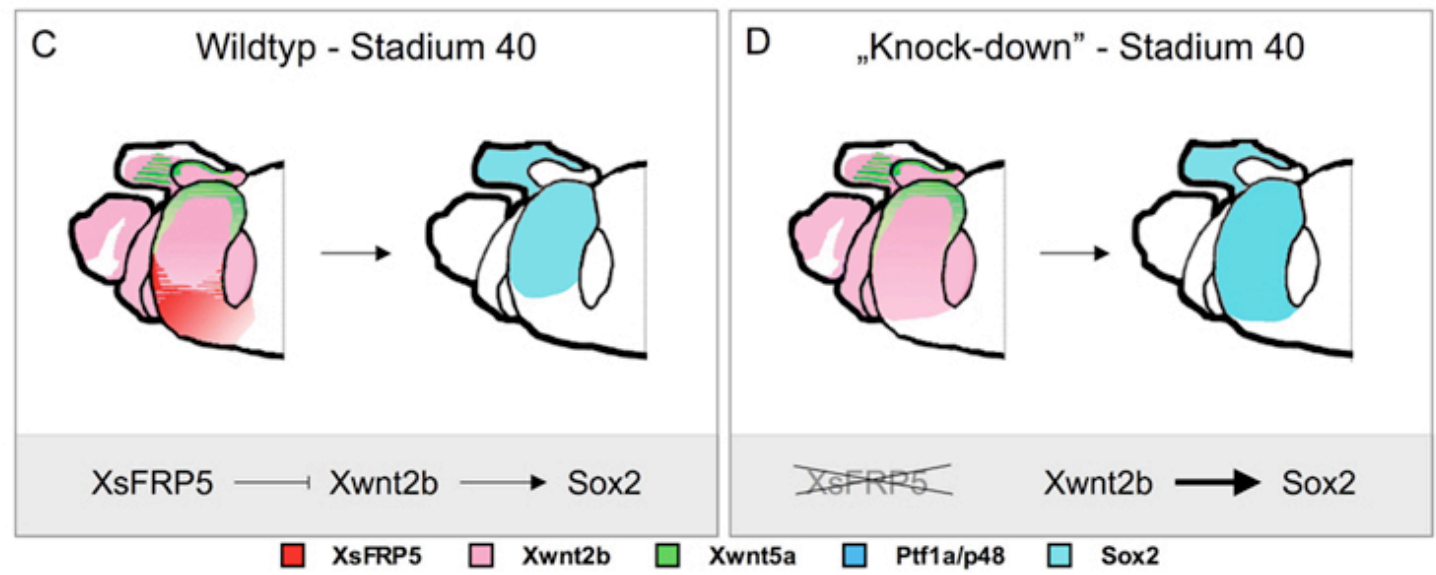

Abb. 5.1: Schematische Darstellung einer möglichen Korrelation zwischen den Wnt Expressionsmustern und den nach XsFRP5-,,Knock-down“ erzielten Effekten auf verschiedene Markergene. (A) Anteriore Strukturen eines Xenopus Embryos im Stadium 35 mit anterior nach links. Die XsFRP5 Expression in der Leberanlage ist rot hervorgehoben. Anterior zur Leber wurde das Herz, posterior das ventrale Pankreas dargestellt. Das dorsale Pankreas befindet sich im dorsalen Entoderm. Die Ptf1a/p48 Expression in ventraler und dorsaler Pankreasanlage ist blau dargestellt. (B) Nach einem „Knock-down“ von XsFRP5 ist die Größe der Leber unverändert, während das ventrale Pankreas verkleinert vorliegt. Die Ptf1a/p48 Expression in ventraler und dorsaler Pankreasanlage ist blau dargestellt. Xwnt Proteine, welche diesen Effekt bewirken könnten, konnten im Rahmen dieser Studie nicht identifiziert werden. (C) Der anteriore Gastrointestinaltrakt eines Xenopus Embryos im Stadium 40 mit anterior nach links. Die Expressionsdomänen von Xwnt2b, Xwnt5a, XsFRP5 und Sox2 sind farblich gekennzeichnet. Sox2 wird im Kontrollembryo vom Ösophagus bis in den posterioren Magen exprimiert. (D) Der Funktionsverlust von XsFRP5 bewirkt eine Expansion der Sox2 Expression, womöglich durch eine Expansion der Xwnt2b Expression.

Die Überexpression von VegT und XsFRP5 in animalen Kappenexplantaten führte auch ohne Retinsäure-Behandlung zu einer robusten und dosis-abhängigen Induktion pankreatischer Markergene wie Ptf1a/p48 und XPDIp (Abb. 4.14). Vor kurzem konnte gezeigt werden, dass in Xenopus Embryonen ektopische kanonische Wnt Signaltransduktion ab der Gastrulation bis zur späten Neurulation die Spezifizierung anteriorer, entodermaler Organe wie Leber und Pankreas unterbindet 
(McLin et al., 2007). Eine temporäre Expressionsanalyse zeigte bereits während der Gastrulation eine schwache und während der Neurulation (Stadium15) eine robuste Expression von XsFRP5 (Abb. 4.2 A). Möglicherweise inhibiert XsFRP5 in diesen frühen Stadien vorhandene kanonische Wnt Signale und fördert dadurch die Bildung ventral-pankreatischer Vorläuferzellen. Da in allen mit XsFRP5-Morpholino injizierten Embryonen die ventrale Pankreasanlage anhand der Ptf1a/p48-Färbung nachgewiesen werden konnte, scheint der Funktionsverlust von XsFRP5 nicht ausreichend, um die Spezifizierung pankreatischer Vorläuferzellen komplett zu unterbinden. In animalen Kappenexplantaten hingegen kommt es nach Mikroinjektion zu einer deutlich früheren, ektopischen Expression von XsFRP5 und somit bereits während Entwicklungsstadien, welche in Kontrollembryonen der Gastrulation entsprechen, zu einer Inhibition möglicher kanonischer Wnt Signaltransduktion. Dadurch könnte die Induktion pankreatischer Genexpression in VegT-injizierten Kappenexplantaten ermöglicht worden sein. Auffällig dabei ist, dass durch die Ko-Injektion von VegT und XsFRP5 zwar XPDIp, aber keine InsulinExpression in animalen Kappenexplantaten induziert werden konnte (Abb. 4.14, Abb. 4.15). Im Vergleich dazu kann die robuste Expression von Insulin in VegTinjizierten Kappenexplantaten durch die Behandlung mit Retinsäure (RA) induziert werden. RA wurde in der Literatur als essentiell für die dorsale Pankreasentwicklung beschrieben und fördert die Differenzierung endokriner Zellen, nicht aber die exokriner Zellen (Chen et al., 2004a). Aus dieser Beobachtung lässt sich der Schluss ziehen, dass die Ko-Injektion von VegT und XsFRP5 zur Spezifizierung einer ausschließlich ventral-pankreatischen Zellpopulation in den animalen Kappenexplantaten führte.

Ein strukturell sehr ähnlicher Wnt Antagonist, XsFRP2, wurde ebenfalls mit VegT in animalen Kappenexplantaten überexprimiert und auf die Fähigkeit hin, pankreatische Genexpression zu induzieren, untersucht (Abb. 4.18). Dabei zeigte sich, dass die XsFRP5-vermittelte Induktion pankreatischer Markergene von XsFRP2 nicht kopiert werden konnte. Dieses Ergebnis spricht dafür, dass der in VegT-injizierten Kappenexplantaten beobachtete Effekt auf pankreatische Markergene spezifisch für XsFRP5 ist. 
Abschließend kann festgehalten werden, dass sowohl der Funktionsverlust als auch die ektopische Expression von XsFRP5 in VegT-injizierten Kappenexplantaten Einfluss auf ventrale Pankreaszellen sowie Sox2-exprimierende Zellen ausüben, Zellpopulationen, die auch in vivo der Expression von XsFRP5 ausgesetzt sind. Die Modulation der XsFRP5 Expression im Entoderm wirkte sich nur auf Organanlagen, die sich aus einer gemeinsamen Vorläuferzellpopulation mit einer angrenzenden Organanlage entwickeln, aus. Es wurde bereits für andere sFRPs die Vermutung geäußert, dass Wnt Gradienten durch die Expression sekretierter Antagonisten so moduliert würden, dass innerhalb einer Zellpopulation die Abgrenzung einzelner Organanlagen ermöglicht werden könnte (Kawano und Kypta, 2003). Ausgehend von dieser Vermutung wäre es denkbar, dass XsFRP5 die Abgrenzung von Leber und ventralem Pankreas bzw. von Magen und Duodenum reguliert.

\subsection{Verknüpfung von Wnt Signalen mit anderen Signalwegen}

Die gelungene Reprogrammierung adulter Zellen in solche Zellen, die embryonalen Stammzellen (ES) ähnlich sind, sorgte für viel Aufsehen (Takahashi et al., 2007; Wernig et al., 2007). Murine und humane Fibroblasten wurden durch eine Kombination von nur vier Transkriptionsfaktoren dazu gebracht, ihr Genom zu reprogrammieren und einen pluripotenten, embryonalen Charakter anzunehmen. Eine große Hürde für die Nutzung dieser ES-Zell-ähnlichen Zellen in der regenerativen Medizin ist der Einsatz retroviraler Vektoren, welche unspezifisch ins Genom dieser Zellen integrieren und so möglicherweise tumorigen wirken. Diese Experimente zeigen jedoch, dass die Kenntnis der richtigen Stimuli sogar die in vitro de-Differenzierung terminal differenzierter, adulter Zellen ermöglichen kann. Wären in weiterer Folge die genauen molekularen Vorgänge bekannt, welche zur Differenzierung unterschiedlicher Zelltypen führen, so ließen sich aus ES-ähnlichen Zellen durch die Behandlung mit bestimmten Morphogenen in vitro Insulinproduzierende $\beta$-Zellen, Neurone oder Kardiomyocyten generieren.

Die gezielte Erforschung des Zusammenspiels einzelner Signalwege während der Embryonalentwicklung liefert wertvolle Hinweise für ein besseres Verständnis, welche Signale für die Differenzierung bestimmter Zellpopulationen essentiell sind. 
Im Rahmen dieser Arbeit konnte eine funktionale Verknüpfung des Wnt und des RA Signalweges bei der Pankreasentwicklung festgestellt werden. Die Induktion pankreatischer Genexpression in VegT- und XsFRP5-injizierten Kappenexplantaten konnte durch die Behandlung mit dem Retinsäure-Antagonisten BMS453 inhibiert werden (Abb. 4.15); das heißt, dass die beobachtete Induktion pankreatischer Markergene auch in dieser Situation von Retinsäure Signalen abhängig zu sein scheint. Um RALDH2 als mögliches Wnt Zielgen identifizieren zu können, hätte eine Analyse der RALDH2 Expression in Kappenexplantaten des Gastrulastadiums Aufschluss geben können. Im Stadium 40, wie in Abb. 4.14 untersucht, konnte keine Auswirkung auf die RALDH2 Expression in den verschiedenen Explantaten festgestellt werden. Das gleiche gilt für die Expression von RAR 2.1 , welcher als notwendig für die Pankreasentwicklung in Xenopus beschrieben wurde (Pan et al., 2007), hier hätte ebenfalls die Expression zu einem früheren Zeitpunkt untersucht werden müssen. Möglicherweise gibt es keinen direkten Zusammenhang zwischen den Wnt und RA Signalwegen, denkbar wäre auch ein „relay“ Mechanismus über die Interaktion mit einem dritten Signalweg. Es konnte gezeigt werden, dass durch die Injektion von Noggin, einem BMP Antagonisten, in animalen Kappenexplantaten eine robuste Aktivierung von RALDH2 erzielt werden kann (Pan et al., 2007). Somit scheint RALDH2 ein negatives BMP Zielgen zu sein.

Es könnte in den VegT und XsFRP5-injizierten Kappenexplantaten durch die Inhibition von Wnt Signalen zu einer Fehlregulation des BMP Signalwegs gekommen sein, welche in weiterer Folge zu einer Induktion der RALDH2 Expression und somit zu einer Aktivierung der RA Signaltransduktion geführt haben könnte. Im Stadium 40 konnte keine Aktivierung von RALDH2 oder verschiedener Retinsäurerezeptoren detektiert werden (Abb. 4.15, Daten nicht gezeigt). Möglicherweise könnte eine Untersuchung von VegT und XsFRP5 injizierten Kappenexplantaten zu einem früheren Entwicklungszeitpunkt Aufschluss über eine Aktivierung des RetinsäureSignalweges geben.

Im Rahmen dieser Arbeit konnte nicht nur ein möglicher Zusammenhang zwischen den Wnt und RA Signalwegen gefunden, sondern auch das Zusammenspiel kanonischer Wnt Signaltransduktion mit $\Delta \mathrm{Np63 \alpha}$ beleuchtet werden. In Achsenduplikations-Experimenten konnte die Aktivität des Transkriptionsfaktors Lef1 
durch die Ko-Injektion von $\Delta$ Np63 $\alpha$ um $100 \%$ gesteigert werden (Abb. 4.20). $\Delta$ Np63 $\alpha$ wurde als essentiell für die Aufrechterhaltung des undifferenzierten Status der Stammzellen in der Basalmembran mehrschichtiger Plattenepithelien beschrieben werden und scheint das Überleben und die hohe Zellteilungsrate von Stammzellen durch die negative Regulation von IGFBP-3 (,Insulin-like Growth Factor Binding Protein-3“), einem anti-proliferativen p53-Zielgen, zu ermöglichen (Barbieri et al., 2005). Es konnte weiterhin gezeigt werden, dass in Epithelzellen der Schilddrüse der Verlust von $\Delta \mathrm{Np} 63 \alpha$ zur Apoptose führt (Senoo et al., 2007). Diese Studie impliziert $\Delta \mathrm{Np63 \alpha}$ als Schlüsselfaktor für den Erhalt der Proliferationskapazität embryonaler und adulter Stammzellen. Auch die kanonische Wnt Signaltransduktion wurde als essentiell für adulte Stammzellen beschrieben, als Beispiel seien die KryptenStammzellen des Dünndarms, die Stammzellpopulationen des Magens, der Haarfollikel und der Brustdrüsen angeführt, welche sich alle durch die Expression des Wnt Zielgens Lgr5 auszeichnen (Barker et al., 2007). Eine mögliche Synergie des kanonischen Signalweges mit dem Transkriptionsfaktor $\Delta N p 63 \alpha$ könnte den undifferenzierten Zustand und das hohe Proliferationspotential der Stammzellen sichern. 


\section{Zusammenfassung}

Bei XsFRP5 handelt es sich um einen Wnt Antagonisten der „secreted Frizzledrelated Proteins" (sFRPs). Es konnte gezeigt werden, dass XsFRP5 sowohl kanonische als auch nicht-kanonische Wnt Liganden binden und inhibieren kann. Andere Xwnt Proteine werden von XsFRP5 zwar effizient gebunden, jedoch kaum in ihrer Funktion beeinträchtigt.

Der „Knock-down“ von XsFRP5 resultierte in einer Reduktion der ventralen Pankreasanlage. Die ektopische, pan-entodermale, intrazelluläre Aktivierung kanonischer Signaltransduktion wirkt sich ebenfalls negativ auf die Pankreasentwicklung aus [siehe auch (Melchert, Diplomarbeit 2007)]. Es konnte nicht geklärt werden, welches Xwnt Protein diese Funktion in vivo vermittelt. Die Überexpression von VegT und XsFRP5 in animalen Kappenexplantaten induziert die robuste Induktion pankreatischer Markergene, wobei dieser Effekt nicht nur durch eine Inhibition der Wnt Signaltransduktion, sondern auch über eine hiervon abhängige Fehlregulation der Retinsäure-Signalwirkung bedingt ist. Der Vergleich mit dem strukturell verwandten Wnt Antagonisten XsFRP2 ergab, dass es sich bei der Induktion pankreatischer Markergene um einen XsFRP5-spezifischen Effekt handelt.

Es scheint wahrscheinlich, dass XsFRP5 die Auftrennung der hepato-pankreatischen Vorläuferzellpopulation in Leber und ventrales Pankreas beeinflusst. Gleiches gilt für die Grenze zwischen Magen und Duodenum, die sich nach Verlust von XsFRP5 zu verschieben scheint. Die im Rahmen dieser Arbeit durchgeführten Interaktionsstudien gemeinsam mit der Analyse der Expressionsmuster definierten Xwnt2b und Xwnt5a als wahrscheinliche in vivo Zielproteine von XsFRP5.

Damianitsch, K. und Pieler, T. (manuscript in preparation). XsFRP5 is a multivalent Wnt inhibitor involved in pancreas and stomach development in Xenopus laevis.

Drewelus, I., Möritz, C., Damianitsch, K., Dickmanns, A., Dickmanns, A., Hippel, K., Pieler, T. und Dobbelstein, M. (manuscript in preparation). $\Delta$ Np63 $\alpha$ and TCF/Lef family members co-operate for canonical Wnt signaling. 


\section{Literaturverzeichnis}

Aberle, H., Bauer, A., Stappert, J., Kispert, A. und Kemler, R. (1997). betacatenin is a target for the ubiquitin-proteasome pathway. Embo $\mathrm{J} \mathrm{16,} \mathrm{3797-804.}$

Afelik, S., Chen, Y. und Pieler, T. (2004). Pancreatic protein disulfide isomerase (XPDIp) is an early marker for the exocrine lineage of the developing pancreas in Xenopus laevis embryos. Gene Expr Patterns 4, 71-6.

Afelik, S., Chen, Y. und Pieler, T. (2006). Combined ectopic expression of Pdx1 and Ptf1a/p48 results in the stable conversion of posterior endoderm into endocrine and exocrine pancreatic tissue. Genes Dev 20, 1441-6.

Altschul, S. F., Gish, W., Miller, W., Myers, E. W. und Lipman, D. J. (1990). Basic local alignment search tool. J Mol Biol 215, 403-10.

Aravind, L. und Koonin, E. V. (1998). A colipase fold in the carboxy-terminal domain of the Wnt antagonists--the Dickkopfs. Curr Biol 8, R477-8.

Bafico, A., Gazit, A., Pramila, T., Finch, P. W., Yaniv, A. und Aaronson, S. A. (1999). Interaction of frizzled related protein (FRP) with Wnt ligands and the frizzled receptor suggests alternative mechanisms for FRP inhibition of Wnt signaling. J Biol Chem 274, 16180-7.

Bakkers, J., Hild, M., Kramer, C., Furutani-Seiki, M. und Hammerschmidt, M. (2002). Zebrafish DeltaNp63 is a direct target of Bmp signaling and encodes a transcriptional repressor blocking neural specification in the ventral ectoderm. Dev Cell 2, 617-27.

Bamberger, C. und Schmale, H. (2001). Identification and tissue distribution of novel KET/p63 splice variants. FEBS Lett 501, 121-6.

Banyai, L. und Patthy, L. (1999). The NTR module: domains of netrins, secreted frizzled related proteins, and type I procollagen C-proteinase enhancer protein are homologous with tissue inhibitors of metalloproteases. Protein Sci 8, 1636-42.

Barbieri, C. E., Perez, C. A., Johnson, K. N., Ely, K. A., Billheimer, D. und Pietenpol, J. A. (2005). IGFBP-3 is a direct target of transcriptional regulation by DeltaNp63alpha in squamous epithelium. Cancer Res 65, 2314-20.

Barbieri, C. E. und Pietenpol, J. A. (2006). p63 and epithelial biology. Exp Cell Res 312, 695-706.

Barker, N., van Es, J. H., Kuipers, J., Kujala, P., van den Born, M., Cozijnsen, M., Haegebarth, A., Korving, J., Begthel, H., Peters, P. J. et al. (2007). Identification of stem cells in small intestine and colon by marker gene Lgr5. Nature 449, $1003-7$. 
Behrens, J., von Kries, J. P., Kuhl, M., Bruhn, L., Wedlich, D., Grosschedl, R. und Birchmeier, W. (1996). Functional interaction of beta-catenin with the transcription factor LEF-1. Nature 382, 638-42.

Bienz, M. und Clevers, H. (2003). Armadillo/beta-catenin signals in the nucleus-proof beyond a reasonable doubt? Nat Cell Biol 5, 179-82.

Bier, E., Vaessin, H., Shepherd, S., Lee, K., McCall, K., Barbel, S., Ackerman, L., Carretto, R., Uemura, T., Grell, E. et al. (1989). Searching for pattern and mutation in the Drosophila genome with a P-lacZ vector. Genes Dev 3, 1273-87.

Bilic, J., Huang, Y. L., Davidson, G., Zimmermann, T., Cruciat, C. M., Bienz, M. und Niehrs, C. (2007). Wnt induces LRP6 signalosomes and promotes dishevelleddependent LRP6 phosphorylation. Science 316, 1619-22.

Blyszczuk, P., Asbrand, C., Rozzo, A., Kania, G., St-Onge, L., Rupnik, M. und Wobus, A. M. (2004). Embryonic stem cells differentiate into insulin-producing cells without selection of nestin-expressing cells. Int J Dev Biol 48, 1095-104.

Bort, R., Martinez-Barbera, J. P., Beddington, R. S. und Zaret, K. S. (2004). Hex homeobox gene-dependent tissue positioning is required for organogenesis of the ventral pancreas. Development 131, 797-806.

Byun, T., Karimi, M., Marsh, J. L., Milovanovic, T., Lin, F. und Holcombe, R. F. (2005). Expression of secreted Wnt antagonists in gastrointestinal tissues: potential role in stem cell homeostasis. J Clin Pathol 58, 515-9.

Cavallo, R. A., Cox, R. T., Moline, M. M., Roose, J., Polevoy, G. A., Clevers, H., Peifer, M. und Bejsovec, A. (1998). Drosophila Tcf and Groucho interact to repress Wingless signalling activity. Nature 395, 604-8.

Chalmers, A. D. und Slack, J. M. (1998). Development of the gut in Xenopus laevis. Dev Dyn 212, 509-21.

Chalmers, A. D., Slack, J. M. und Beck, C. W. (2000). Regional gene expression in the epithelia of the Xenopus tadpole gut. Mech Dev 96, 125-8.

Chang, J. T., Esumi, N., Moore, K., Li, Y., Zhang, S., Chew, C., Goodman, B., Rattner, A., Moody, S., Stetten, G. et al. (1999). Cloning and characterization of a secreted frizzled-related protein that is expressed by the retinal pigment epithelium. Hum Mol Genet 8, 575-83.

Chapman, S. C., Brown, R., Lees, L., Schoenwolf, G. C. und Lumsden, A. (2004). Expression analysis of chick Wnt and frizzled genes and selected inhibitors in early chick patterning. Dev Dyn 229, 668-76.

Chen, C., Zhang, Y., Sheng, X., Huang, C. und Zang, Y. Q. (2008). Differentiation of embryonic stem cells towards pancreatic progenitor cells and their transplantation into streptozotocin-induced diabetic mice. Cell Biol Int. 
Chen, G., Fernandez, J., Mische, S. und Courey, A. J. (1999). A functional interaction between the histone deacetylase Rpd3 and the corepressor groucho in Drosophila development. Genes Dev 13, 2218-30.

Chen, Y., Jurgens, K., Hollemann, T., Claussen, M., Ramadori, G. und Pieler, T. (2003). Cell-autonomous and signal-dependent expression of liver and intestine marker genes in pluripotent precursor cells from Xenopus embryos. Mech Dev 120, 277-88.

Chen, Y., Pan, F. C., Brandes, N., Afelik, S., Solter, M. und Pieler, T. (2004a). Retinoic acid signaling is essential for pancreas development and promotes endocrine at the expense of exocrine cell differentiation in Xenopus. Dev Biol 271, 144-60.

Chen, Y., Stump, R. J., Lovicu, F. J. und McAvoy, J. W. (2004b). Expression of Frizzleds and secreted frizzled-related proteins (Sfrps) during mammalian lens development. Int J Dev Biol 48, 867-77.

Christian, J. L., McMahon, J. A., McMahon, A. P. und Moon, R. T. (1991). Xwnt-8, a Xenopus Wnt-1/int-1-related gene responsive to mesoderm-inducing growth factors, may play a role in ventral mesodermal patterning during embryogenesis. Development 111, 1045-55.

Crompton, M. R., Bartlett, T. J., MacGregor, A. D., Manfioletti, G., Buratti, E., Giancotti, V. und Goodwin, G. H. (1992). Identification of a novel vertebrate homeobox gene expressed in haematopoietic cells. Nucleic Acids Res 20, 5661-7.

Cui, Y., Brown, J. D., Moon, R. T. und Christian, J. L. (1995). Xwnt-8b: a maternally expressed Xenopus Wnt gene with a potential role in establishing the dorsoventral axis. Development 121, 2177-86.

Davidson, G., Wu, W., Shen, J., Bilic, J., Fenger, U., Stannek, P., Glinka, A. und Niehrs, C. (2005). Casein kinase 1 gamma couples Wnt receptor activation to cytoplasmic signal transduction. Nature 438, 867-72.

De Calisto, J., Araya, C., Marchant, L., Riaz, C. F. und Mayor, R. (2005). Essential role of non-canonical Wnt signalling in neural crest migration. Development 132, 2587-97.

Deb, A., Davis, B. H., Guo, J., Ni, A., Huang, J., Zhang, Z., Mu, H. und Dzau, V. J. (2008). SFRP2 regulates cardiomyogenic differentiation by inhibiting a positive transcriptional autofeedback loop of Wnt3a. Stem Cells 26, 35-44.

Dellavalle, R. P., Egbert, T. B., Marchbank, A., Su, L. J., Lee, L. A. und Walsh, P. (2001). CUSP/p63 expression in rat and human tissues. J Dermatol Sci 27, 82-7.

Dessimoz, J., Bonnard, C., Huelsken, J. und Grapin-Botton, A. (2005). Pancreas-specific deletion of beta-catenin reveals Wnt-dependent and Wntindependent functions during development. Curr Biol 15, 1677-83. 
Deutsch, G., Jung, J., Zheng, M., Lora, J. und Zaret, K. S. (2001). A bipotential precursor population for pancreas and liver within the embryonic endoderm. Development 128, 871-81.

Di Como, C. J., Urist, M. J., Babayan, I., Drobnjak, M., Hedvat, C. V., TeruyaFeldstein, J., Pohar, K., Hoos, A. und Cordon-Cardo, C. (2002). p63 expression profiles in human normal and tumor tissues. Clin Cancer Res 8, 494-501.

Dominguez, I. und Green, J. B. (2000). Dorsal downregulation of GSK3beta by a non-Wnt-like mechanism is an early molecular consequence of cortical rotation in early Xenopus embryos. Development 127, 861-8.

Dor, Y., Brown, J., Martinez, O. I. und Melton, D. A. (2004). Adult pancreatic betacells are formed by self-duplication rather than stem-cell differentiation. Nature $\mathbf{4 2 9}$, 41-6.

Du, S. J., Purcell, S. M., Christian, J. L., McGrew, L. L. und Moon, R. T. (1995). Identification of distinct classes and functional domains of Wnts through expression of wild-type and chimeric proteins in Xenopus embryos. Mol Cell Biol 15, 2625-34.

Finley, K. R., Tennessen, J. und Shawlot, W. (2003). The mouse secreted frizzledrelated protein 5 gene is expressed in the anterior visceral endoderm and foregut endoderm during early post-implantation development. Gene Expr Patterns 3, 681-4.

Fuerer, C., Nusse, R. und Ten Berge, D. (2008). Wnt signalling in development and disease. Max Delbruck Center for Molecular Medicine meeting on Wnt Signaling in Development and Disease. EMBO Rep 9, 134-8.

Galli, L. M., Barnes, T., Cheng, T., Acosta, L., Anglade, A., Willert, K., Nusse, R. und Burrus, L. W. (2006). Differential inhibition of Wnt-3a by Sfrp-1, Sfrp-2, and Sfrp-3. Dev Dyn 235, spc1.

Garriock, R. J., D'Agostino, S. L., Pilcher, K. C. und Krieg, P. A. (2005). Wnt11$R$, a protein closely related to mammalian Wnt11, is required for heart morphogenesis in Xenopus. Dev Biol 279, 179-92.

Glinka, A., Wu, W., Delius, H., Monaghan, A. P., Blumenstock, C. und Niehrs, C. (1998). Dickkopf-1 is a member of a new family of secreted proteins and functions in head induction. Nature 391, 357-62.

Glinka, A., Wu, W., Onichtchouk, D., Blumenstock, C. und Niehrs, C. (1997). Head induction by simultaneous repression of Bmp and Wnt signalling in Xenopus. Nature 389, 517-9.

Gregorieff, A., Grosschedl, R. und Clevers, H. (2004). Hindgut defects and transformation of the gastro-intestinal tract in Tcf4(-/-)/Tcf1(-/-) embryos. Embo $\mathrm{J} 23$, 1825-33.

Harland, R. M. (1991). In situ hybridization: an improved whole-mount method for Xenopus embryos. Methods Cell Biol 36, 685-95. 
Harlow, E. und Lane, D. (1988). Antibodies - A Laboratory Manual. Cold Spring Harbor Laboratory Press, New York.

He, X., Saint-Jeannet, J. P., Wang, Y., Nathans, J., Dawid, I. und Varmus, H. (1997). A member of the Frizzled protein family mediating axis induction by Wnt-5A. Science 275, 1652-4.

Hebrok, M., Kim, S. K. und Melton, D. A. (1998). Notochord repression of endodermal Sonic hedgehog permits pancreas development. Genes Dev 12, 170513.

Heiser, P. W., Lau, J., Taketo, M. M., Herrera, P. L. und Hebrok, M. (2006). Stabilization of beta-catenin impacts pancreas growth. Development 133, 2023-32.

Henry, G. L., Brivanlou, I. H., Kessler, D. S., Hemmati-Brivanlou, A. und Melton, D. A. (1996). TGF-beta signals and a pattern in Xenopus laevis endodermal development. Development 122, 1007-15.

Hollemann, T., Panitz, F. und Pieler, T. (1999). In situ Hybridization Techniques with Xenopus Embryos. In "A Comparative Methods Approach to the Study of Oocytes and Embryos": Oxford University Press Inc., Oxford.

Hollemann, T. und Pieler, T. (2000). Xnkx-2.1: a homeobox gene expressed during early forebrain, lung and thyroid development in Xenopus laevis. Dev Genes Evol 210, 579-81.

Hsieh, J. C., Kodjabachian, L., Rebbert, M. L., Rattner, A., Smallwood, P. M., Samos, C. H., Nusse, R., Dawid, I. B. und Nathans, J. (1999). A new secreted protein that binds to Wnt proteins and inhibits their activities. Nature 398, 431-6.

Jiang, R., Lan, Y., Chapman, H. D., Shawber, C., Norton, C. R., Serreze, D. V., Weinmaster, G. und Gridley, T. (1998). Defects in limb, craniofacial, and thymic development in Jagged2 mutant mice. Genes Dev 12, 1046-57.

Joseph, E. M. und Melton, D. A. (1998). Mutant Vg1 ligands disrupt endoderm and mesoderm formation in Xenopus embryos. Development 125, 2677-85.

Jung, J., Zheng, M., Goldfarb, M. und Zaret, K. S. (1999). Initiation of mammalian liver development from endoderm by fibroblast growth factors. Science 284, 19982003.

Kawano, Y. und Kypta, R. (2003). Secreted antagonists of the Wnt signalling pathway. J Cell Sci 116, 2627-34.

Keeble, T. R., Halford, M. M., Seaman, C., Kee, N., Macheda, M., Anderson, R. B., Stacker, S. A. und Cooper, H. M. (2006). The Wnt receptor Ryk is required for Wnt5a-mediated axon guidance on the contralateral side of the corpus callosum. $J$ Neurosci 26, 5840-8.

Kelly, O. G. und Melton, D. A. (2000). Development of the pancreas in Xenopus laevis. Dev Dyn 218, 615-27. 
Kim, B. M., Buchner, G., Miletich, I., Sharpe, P. T. und Shivdasani, R. A. (2005a). The stomach mesenchymal transcription factor Barx1 specifies gastric epithelial identity through inhibition of transient Wnt signaling. Dev Cell 8, 611-22.

Kim, H. J., Schleiffarth, J. R., Jessurun, J., Sumanas, S., Petryk, A., Lin, S. und Ekker, S. C. (2005b). Wnt5 signaling in vertebrate pancreas development. BMC Biol 3, 23.

Ku, M. und Melton, D. A. (1993). Xwnt-11: a maternally expressed Xenopus wnt gene. Development 119, 1161-73.

Kubo, F., Takeichi, M. und Nakagawa, S. (2003). Wnt2b controls retinal cell differentiation at the ciliary marginal zone. Development 130, 587-98.

Kühl, M., Geis, K., Sheldahl, L. C., Pukrop, T., Moon, R. T. und Wedlich, D. (2001). Antagonistic regulation of convergent extension movements in Xenopus by Wnt/beta-catenin and Wnt/Ca2+ signaling. Mech Dev 106, 61-76.

Kühl, M., Sheldahl, L. C., Malbon, C. C. und Moon, R. T. (2000). $\mathrm{Ca}(2+) /$ calmodulin-dependent protein kinase II is stimulated by Wnt and Frizzled homologs and promotes ventral cell fates in Xenopus. J Biol Chem 275, 12701-11.

Lamb, T. M., Knecht, A. K., Smith, W. C., Stachel, S. E., Economides, A. N., Stahl, N., Yancopolous, G. D. und Harland, R. M. (1993). Neural induction by the secreted polypeptide noggin. Science 262, 713-8.

Lammert, E., Cleaver, O. und Melton, D. (2001). Induction of pancreatic differentiation by signals from blood vessels. Science 294, 564-7.

Landesman, Y. und Sokol, S. Y. (1997). Xwnt-2b is a novel axis-inducing Xenopus Wnt, which is expressed in embryonic brain. Mech Dev 63, 199-209.

Larabell, C. A., Torres, M., Rowning, B. A., Yost, C., Miller, J. R., Wu, M., Kimelman, D. und Moon, R. T. (1997). Establishment of the dorso-ventral axis in Xenopus embryos is presaged by early asymmetries in beta-catenin that are modulated by the Wnt signaling pathway. J Cell Biol 136, 1123-36.

Leaf, I., Tennessen, J., Mukhopadhyay, M., Westphal, H. und Shawlot, W. (2006). Sfrp5 is not essential for axis formation in the mouse. Genesis 44, 573-578.

Lee, E., Salic, A., Kruger, R., Heinrich, R. und Kirschner, M. W. (2003). The roles of APC and Axin derived from experimental and theoretical analysis of the Wnt pathway. PLoS Biol 1, E10.

Lee, H. und Kimelman, D. (2002). A dominant-negative form of p63 is required for epidermal proliferation in zebrafish. Dev Cell 2, 607-16.

Lee, H. X., Ambrosio, A. L., Reversade, B. und De Robertis, E. M. (2006). Embryonic dorsal-ventral signaling: secreted frizzled-related proteins as inhibitors of tolloid proteinases. Cell 124, 147-59. 
Leyns, L., Bouwmeester, T., Kim, S. H., Piccolo, S. und De Robertis, E. M. (1997). Frzb-1 is a secreted antagonist of Wnt signaling expressed in the Spemann organizer. Cell 88, 747-56.

Lin, X. (2004). Functions of heparan sulfate proteoglycans in cell signaling during development. Development 131, 6009-21.

Logan, C. Y. und Nusse, R. (2004). The Wnt signaling pathway in development and disease. Annu Rev Cell Dev Biol 20, 781-810.

Lu, P., Barad, M. und Vize, P. D. (2001). Xenopus p63 expression in early ectoderm and neurectoderm. Mech Dev 102, 275-8.

Lu, X., Borchers, A. G., Jolicoeur, C., Rayburn, H., Baker, J. C. und TessierLavigne, M. (2004). PTK7/CCK-4 is a novel regulator of planar cell polarity in vertebrates. Nature 430, 93-8.

Ma, L. und Wang, H. Y. (2007). Mitogen-activated protein kinase p38 regulates the Wnt/cyclic GMP/Ca2+ non-canonical pathway. J Biol Chem 282, 28980-90.

Mao, B., Wu, W., Davidson, G., Marhold, J., Li, M., Mechler, B. M., Delius, H., Hoppe, D., Stannek, P., Walter, C. et al. (2002). Kremen proteins are Dickkopf receptors that regulate Wnt/beta-catenin signalling. Nature 417, 664-7.

Mao, B., Wu, W., Li, Y., Hoppe, D., Stannek, P., Glinka, A. und Niehrs, C. (2001). LDL-receptor-related protein 6 is a receptor for Dickkopf proteins. Nature 411, 321-5.

Maurus, D., Heligon, C., Burger-Schwarzler, A., Brandli, A. W. und Kuhl, M. (2005). Noncanonical Wnt-4 signaling and EAF2 are required for eye development in Xenopus laevis. Embo J 24, 1181-91.

McLin, V. A., Rankin, S. A. und Zorn, A. M. (2007). Repression of Wnt/beta-catenin signaling in the anterior endoderm is essential for liver and pancreas development. Development 134, 2207-17.

Melchert, J. (2007). Die Rolle der kanonischen Wnt Signaltransduktion bei der Differenzierung des Gastrointestinaltrakts in Xenopus laevis. Diplomarbeit, Universität Göttingen, Göttingen.

Melkonyan, H. S., Chang, W. C., Shapiro, J. P., Mahadevappa, M., Fitzpatrick, P. A., Kiefer, M. C., Tomei, L. D. und Umansky, S. R. (1997). SARPs: a family of secreted apoptosis-related proteins. Proc Natl Acad Sci U S A 94, 13636-41.

Mikels, A. J. und Nusse, R. (2006). Purified Wnt5a protein activates or inhibits betacatenin-TCF signaling depending on receptor context. PLoS Biol 4, e115.

Miller, J. R., Rowning, B. A., Larabell, C. A., Yang-Snyder, J. A., Bates, R. L. und Moon, R. T. (1999). Establishment of the dorsal-ventral axis in Xenopus embryos coincides with the dorsal enrichment of dishevelled that is dependent on cortical rotation. J Cell Biol 146, 427-37. 
Mills, A. A., Zheng, B., Wang, X. J., Vogel, H., Roop, D. R. und Bradley, A. (1999). p63 is a p53 homologue required for limb and epidermal morphogenesis. Nature 398, 708-13.

Mizuseki, K., Kishi, M., Matsui, M., Nakanishi, S. und Sasai, Y. (1998). Xenopus Zic-related-1 and Sox-2, two factors induced by chordin, have distinct activities in the initiation of neural induction. Development 125, 579-87.

Moon, R. T., Campbell, R. M., Christian, J. L., McGrew, L. L., Shih, J. und Fraser, S. (1993). Xwnt-5A: a maternal Wnt that affects morphogenetic movements after overexpression in embryos of Xenopus laevis. Development 119, 97-111.

Morkel, M., Huelsken, J., Wakamiya, M., Ding, J., van de Wetering, M., Clevers, H., Taketo, M. M., Behringer, R. R., Shen, M. M. und Birchmeier, W. (2003). Betacatenin regulates Cripto- and Wnt3-dependent gene expression programs in mouse axis and mesoderm formation. Development 130, 6283-94.

Munoz, R., Moreno, M., Oliva, C., Orbenes, C. und Larrain, J. (2006). Syndecan-4 regulates non-canonical Wnt signalling and is essential for convergent and extension movements in Xenopus embryos. Nat Cell Biol 8, 492-500.

Murtaugh, L. C., Law, A. C., Dor, Y. und Melton, D. A. (2005). Beta-catenin is essential for pancreatic acinar but not islet development. Development 132, 4663-74.

Nasevicius, A., Hyatt, T., Kim, H., Guttman, J., Walsh, E., Sumanas, S., Wang, Y. und Ekker, S. C. (1998). Evidence for a frizzled-mediated wnt pathway required for zebrafish dorsal mesoderm formation. Development 125, 4283-92.

Newman, C. S., Chia, F. und Krieg, P. A. (1997). The XHex homeobox gene is expressed during development of the vascular endothelium: overexpression leads to an increase in vascular endothelial cell number. Mech Dev 66, 83-93.

Nieuwkoop, P. D. und Faber, J. (1967). Normal Table of Xenopus laevis. North Holland Publishing, Amsterdam.

Nusse, R. und Varmus, H. E. (1982). Many tumors induced by the mouse mammary tumor virus contain a provirus integrated in the same region of the host genome. Cell 31, 99-109.

Nüsslein-Volhard, C. und Wieschaus, E. (1980). Mutations affecting segment number and polarity in Drosophila. Nature 287, 795-801.

Ober, E. A., Verkade, H., Field, H. A. und Stainier, D. Y. (2006). Mesodermal Wnt2b signalling positively regulates liver specification. Nature 442, 688-91.

Ohkawara, B., Yamamoto, T. S., Tada, M. und Ueno, N. (2003). Role of glypican 4 in the regulation of convergent extension movements during gastrulation in Xenopus laevis. Development 130, 2129-38.

Oishi, I., Suzuki, H., Onishi, N., Takada, R., Kani, S., Ohkawara, B., Koshida, I., Suzuki, K., Yamada, G., Schwabe, G. C. et al. (2003). The receptor tyrosine kinase 
Ror2 is involved in non-canonical Wnt5a/JNK signalling pathway. Genes Cells 8, 645-54.

Okubo, T. und Hogan, B. L. (2004). Hyperactive Wnt signaling changes the developmental potential of embryonic lung endoderm. J Biol 3, 11.

Pan, F. C., Chen, Y., Bayha, E. und Pieler, T. (2007). Retinoic acid-mediated patterning of the pre-pancreatic endoderm in Xenopus operates via direct and indirect mechanisms. Mech Dev 124, 518-31.

Patthy, L. (2000). The WIF module. Trends Biochem Sci 25, 12-3.

Pera, E. M. und De Robertis, E. M. (2000). A direct screen for secreted proteins in Xenopus embryos identifies distinct activities for the Wnt antagonists Crescent and Frzb-1. Mech Dev 96, 183-95.

Piccolo, S., Agius, E., Leyns, L., Bhattacharyya, S., Grunz, H., Bouwmeester, T. und De Robertis, E. M. (1999). The head inducer Cerberus is a multifunctional antagonist of Nodal, BMP and Wnt signals. Nature 397, 707-10.

Pieler, T. und Chen, Y. (2006). Forgotten and novel aspects in pancreas development. Biol Cell 98, 79-88.

Pilcher, K. E. und Krieg, P. A. (2002). Expression of the Wnt inhibitor, sFRP5, in the gut endoderm of Xenopus. Gene Expr Patterns 2, 369-72.

Pinto, D. und Clevers, H. (2005). Wnt control of stem cells and differentiation in the intestinal epithelium. Exp Cell Res 306, 357-63.

Price, M. A. (2006). CKI, there's more than one: casein kinase I family members in Wnt and Hedgehog signaling. Genes Dev 20, 399-410.

Rossi, J. M., Dunn, N. R., Hogan, B. L. und Zaret, K. S. (2001). Distinct mesodermal signals, including BMPs from the septum transversum mesenchyme, are required in combination for hepatogenesis from the endoderm. Genes Dev 15, 1998-2009.

Rowning, B. A., Wells, J., Wu, M., Gerhart, J. C., Moon, R. T. und Larabell, C. A. (1997). Microtubule-mediated transport of organelles and localization of beta-catenin to the future dorsal side of Xenopus eggs. Proc Natl Acad Sci U S A 94, 1224-9.

Rupp, R. A., Snider, L. und Weintraub, H. (1994). Xenopus embryos regulate the nuclear localization of XMyoD. Genes Dev 8, 1311-23.

Sambrook, J. und Russel, D. W. (2001). Molecular Cloning: A Laboratory Manual. Cold Spring Harbor Laboratory Press, New York.

Saneyoshi, T., Kume, S., Amasaki, Y. und Mikoshiba, K. (2002). The Wnt/calcium pathway activates NF-AT and promotes ventral cell fate in Xenopus embryos. Nature 417, 295-9. 
Sasaki, Y., Ishida, S., Morimoto, I., Yamashita, T., Kojima, T., Kihara, C., Tanaka, T., Imai, K., Nakamura, Y. und Tokino, T. (2002). The p53 family member genes are involved in the Notch signal pathway. J Biol Chem 277, 719-24.

Schambony, A. und Wedlich, D. (2007). Wnt-5A/Ror2 regulate expression of XPAPC through an alternative noncanonical signaling pathway. Dev Cell 12, 779-92.

Schulze, G. E., Clay, R. J., Mezza, L. E., Bregman, C. L., Buroker, R. A. und Frantz, J. D. (2001). BMS-189453, a novel retinoid receptor antagonist, is a potent testicular toxin. Toxicol Sci 59, 297-308.

Schwarz-Romond, T., Fiedler, M., Shibata, N., Butler, P. J., Kikuchi, A., Higuchi, Y. und Bienz, M. (2007). The DIX domain of Dishevelled confers Wnt signaling by dynamic polymerization. Nat Struct Mol Biol 14, 484-92.

Seifert, J. R. und Mlodzik, M. (2007). Frizzled/PCP signalling: a conserved mechanism regulating cell polarity and directed motility. Nat Rev Genet 8, 126-38.

Semenov, M. V., Habas, R., Macdonald, B. T. und He, X. (2007). SnapShot: Noncanonical Wnt Signaling Pathways. Cell 131, 1378.

Semenov, M. V., Tamai, K., Brott, B. K., Kuhl, M., Sokol, S. und He, X. (2001). Head inducer Dickkopf-1 is a ligand for Wnt coreceptor LRP6. Curr Biol 11, 951-61.

Senoo, M., Pinto, F., Crum, C. P. und McKeon, F. (2007). p63 Is essential for the proliferative potential of stem cells in stratified epithelia. Cell 129, 523-36.

Sheldahl, L. C., Slusarski, D. C., Pandur, P., Miller, J. R., Kuhl, M. und Moon, R. T. (2003). Dishevelled activates Ca2+ flux, PKC, and CamKII in vertebrate embryos. J Cell Biol 161, 769-77.

Sive, H. J., Grainger, R. M. und Harland, R. M. (2000). Early Development of Xenopus laevis - A Laboratory Manual. Cold Spring Harbor, New York: Cold Spring Harbor Laboratory Press.

Sokol, S., Christian, J. L., Moon, R. T. und Melton, D. A. (1991). Injected Wnt RNA induces a complete body axis in Xenopus embryos. Cell 67, 741-52.

Spemann, H. (1938). Embryonic Development and Induction. Yale University Press, New Haven.

Stoick-Cooper, C. L., Moon, R. T. und Weidinger, G. (2007). Advances in signaling in vertebrate regeneration as a prelude to regenerative medicine. Genes Dev 21, 1292-315.

Suksaweang, S., Lin, C. M., Jiang, T. X., Hughes, M. W., Widelitz, R. B. und Chuong, C. M. (2004). Morphogenesis of chicken liver: identification of localized growth zones and the role of beta-catenin/Wnt in size regulation. Dev Biol 266, 10922. 
Tada, M. und Smith, J. C. (2000). Xwnt11 is a target of Xenopus Brachyury: regulation of gastrulation movements via Dishevelled, but not through the canonical Wnt pathway. Development 127, 2227-38.

Tahinci, E., Thorne, C. A., Franklin, J. L., Salic, A., Christian, K. M., Lee, L. A., Coffey, R. J. und Lee, E. (2007). Lrp6 is required for convergent extension during Xenopus gastrulation. Development 134, 4095-106.

Takahashi, K., Tanabe, K., Ohnuki, M., Narita, M., Ichisaka, T., Tomoda, K. und Yamanaka, S. (2007). Induction of pluripotent stem cells from adult human fibroblasts by defined factors. Cell 131, 861-72.

Tao, Q., Yokota, C., Puck, H., Kofron, M., Birsoy, B., Yan, D., Asashima, M., Wylie, C. C., Lin, X. und Heasman, J. (2005). Maternal wnt11 activates the canonical wnt signaling pathway required for axis formation in Xenopus embryos. Cell 120, 857-71.

Taub, R. (2004). Liver regeneration: from myth to mechanism. Nat Rev Mol Cell Biol 5, 836-47.

The Wnt Homepage, N. http://www.stanford.edu/ rnusse/wntwindow.html.

Thomas, P. Q., Brown, A. und Beddington, R. S. (1998). Hex: a homeobox gene revealing peri-implantation asymmetry in the mouse embryo and an early transient marker of endothelial cell precursors. Development 125, 85-94.

Thorpe, C. J. und Moon, R. T. (2004). nemo-like kinase is an essential co-activator of Wnt signaling during early zebrafish development. Development 131, 2899-909.

Tonissen, K. F., Drysdale, T. A., Lints, T. J., Harvey, R. P. und Krieg, P. A. (1994). XNkx-2.5, a Xenopus gene related to Nkx-2.5 and tinman: evidence for a conserved role in cardiac development. Dev Biol 162, 325-8.

Topczewski, J., Sepich, D. S., Myers, D. C., Walker, C., Amores, A., Lele, Z., Hammerschmidt, M., Postlethwait, J. und Solnica-Krezel, L. (2001). The zebrafish glypican knypek controls cell polarity during gastrulation movements of convergent extension. Dev Cell 1, 251-64.

Unterseher, F., Hefele, J. A., Giehl, K., De Robertis, E. M., Wedlich, D. und Schambony, A. (2004). Paraxial protocadherin coordinates cell polarity during convergent extension via Rho A and JNK. Embo J 23, 3259-69.

Uren, A., Reichsman, F., Anest, V., Taylor, W. G., Muraiso, K., Bottaro, D. P., Cumberledge, S. und Rubin, J. S. (2000). Secreted frizzled-related protein-1 binds directly to Wingless and is a biphasic modulator of Wnt signaling. J Biol Chem 275, 4374-82.

van Bokhoven, H., Hamel, B. C., Bamshad, M., Sangiorgi, E., Gurrieri, F., Duijf, P. H., Vanmolkot, K. R., van Beusekom, E., van Beersum, S. E., Celli, J. et al. (2001). p63 Gene mutations in eec syndrome, limb-mammary syndrome, and 
isolated split hand-split foot malformation suggest a genotype-phenotype correlation. Am J Hum Genet 69, 481-92.

Van Raay, T. J., Moore, K. B., Iordanova, I., Steele, M., Jamrich, M., Harris, W. A. und Vetter, M. L. (2005). Frizzled 5 signaling governs the neural potential of progenitors in the developing Xenopus retina. Neuron 46, 23-36.

Wernig, M., Meissner, A., Foreman, R., Brambrink, T., Ku, M., Hochedlinger, K., Bernstein, B. E. und Jaenisch, R. (2007). In vitro reprogramming of fibroblasts into a pluripotent ES-cell-like state. Nature 448, 318-24.

Wikramanayake, A. H., Hong, M., Lee, P. N., Pang, K., Byrum, C. A., Bince, J. M., Xu, R. und Martindale, M. Q. (2003). An ancient role for nuclear beta-catenin in the evolution of axial polarity and germ layer segregation. Nature 426, 446-50.

Willert, K., Brown, J. D., Danenberg, E., Duncan, A. W., Weissman, I. L., Reya, T., Yates, J. R., 3rd und Nusse, R. (2003). Wnt proteins are lipid-modified and can act as stem cell growth factors. Nature $423,448-52$.

Wolda, S. L., Moody, C. J. und Moon, R. T. (1993). Overlapping expression of Xwnt-3A and Xwnt-1 in neural tissue of Xenopus laevis embryos. Dev Biol 155, 4657.

Wong, G. T., Gavin, B. J. und McMahon, A. P. (1994). Differential transformation of mammary epithelial cells by Wnt genes. Mol Cell Biol 14, 6278-86.

Wright, C. V., Schnegelsberg, P. und De Robertis, E. M. (1989). XIHbox 8: a novel Xenopus homeo protein restricted to a narrow band of endoderm. Development 105, 787-94.

Xu, Q., D'Amore, P. A. und Sokol, S. Y. (1998). Functional and biochemical interactions of Wnts with FrzA, a secreted Wnt antagonist. Development 125, 476776.

Xu, X., D'Hoker, J., Stange, G., Bonne, S., De Leu, N., Xiao, X., Van de Casteele, M., Mellitzer, G., Ling, Z., Pipeleers, D. et al. (2008). Beta cells can be generated from endogenous progenitors in injured adult mouse pancreas. Cell 132, 197-207.

Yamada, M., Ohnishi, J., Ohkawara, B., lemura, S., Satoh, K., Hyodo-Miura, J., Kawachi, K., Natsume, T. und Shibuya, H. (2006). NARF, an nemo-like kinase (NLK)-associated ring finger protein regulates the ubiquitylation and degradation of $T$ cell factor/lymphoid enhancer factor (TCF/LEF). J Biol Chem 281, 20749-60.

Yamanaka, H., Moriguchi, T., Masuyama, N., Kusakabe, M., Hanafusa, H., Takada, R., Takada, S. und Nishida, E. (2002). JNK functions in the non-canonical Wht pathway to regulate convergent extension movements in vertebrates. EMBO Rep 3, 69-75.

Yang, A., Schweitzer, R., Sun, D., Kaghad, M., Walker, N., Bronson, R. T., Tabin, C., Sharpe, A., Caput, D., Crum, C. et al. (1999). p63 is essential for regenerative proliferation in limb, craniofacial and epithelial development. Nature 398, 714-8. 
Yi, R., Poy, M. N., Stoffel, M. und Fuchs, E. (2008). A skin microRNA promotes differentiation by repressing 'stemness'. Nature.

Yoshida, Y., Kim, S., Chiba, K., Kawai, S., Tachikawa, H. und Takahashi, N. (2004). Calcineurin inhibitors block dorsal-side signaling that affect late-stage development of the heart, kidney, liver, gut and somitic tissue during Xenopus embryogenesis. Dev Growth Differ 46, 139-52.

Yu, J., Vodyanik, M. A., Smuga-Otto, K., Antosiewicz-Bourget, J., Frane, J. L., Tian, S., Nie, J., Jonsdottir, G. A., Ruotti, V., Stewart, R. et al. (2007). Induced pluripotent stem cell lines derived from human somatic cells. Science 318, 1917-20.

Zeng, X., Huang, H., Tamai, K., Zhang, X., Harada, Y., Yokota, C., Almeida, K., Wang, J., Doble, B., Woodgett, J. et al. (2008). Initiation of Wnt signaling: control of Wnt coreceptor Lrp6 phosphorylation/activation via frizzled, dishevelled and axin functions. Development 135, 367-75.

Zhang, J., Houston, D. W., King, M. L., Payne, C., Wylie, C. und Heasman, J. (1998). The role of maternal VegT in establishing the primary germ layers in Xenopus embryos. Cell 94, 515-24.

Zorn, A. M. und Mason, J. (2001). Gene expression in the embryonic Xenopus liver. Mech Dev 103, 153-7. 


\section{Danksagung}

Mein herzlicher Dank geht an Prof. Tomas Pieler, für die Unterstützung und das entgegengebrachte Vertrauen.

Für die freundliche Übernahme des Korreferats bedanke ich mich bei Prof. Ernst Wimmer.

Besonderer Dank gilt Dr. Annette Borchers, für viele inspirierende und angenehme Gespräche, und ebenso Katja Ditter, Juliane Melchert und Barbara Rust, die nicht nur Kolleginnen waren, sondern Freunde geworden sind.

Allen weiteren Mitgliedern der Abteilung Entwicklungsbiochemie danke ich für die angenehme Arbeitsatmosphäre.

Ganz besonders danke ich meiner Familie, die mich während meines Studiums auf vielfältige Weise unterstützt hat. 


\section{Lebenslauf}

Name: Damianitsch

Vorname: Katharina

Geburtstag: $\quad 09.10 .1979$

Geburtsort: Wien, Österreich

Staatsbürgerschaft: Österreich

Familienstand: ledig

Adresse: $\quad 37073$ Göttingen

\section{Ausbildung}

1986-1990

Franz-Schubert-Grundschule in Wien, Österreich

1990-1998

Wasagymnasium BGIX in Wien, Österreich

1998

Reifeprüfung am 17. Juni 1998

1998

Beginn des Studiums der Biologie an der Universität Wien

2000

Vordiplom am 02. Oktober 2000

2000-2003

Hauptstudium an der Universität Wien

2001

Sommersemester 2001: ERASMUS-Aufenthalt an der Universität Göttingen

Anfertigung der Diplomarbeit am Albrecht-von-Haller-Institut für

2003 Pflanzenwissenschaften der Universität Göttingen (Abt. Allgemeine und Entwicklungsphysiologie der Pflanzen)

2003 Diplom am 26. Oktober 2003

Promotionsarbeit am Institut für Biochemie und Molekulare seit Feb. 2004 Zellbiologie der Universität Göttingen (Abt. Entwicklungsbiochemie)

Göttingen, den 17.03.2008 